\title{
Zur Darstellung künstlerischer Existenz in Thomas Manns frühen Erzählungen Der kleine Herr Friedemann, Schwere Stunde und Das Wunderkind.
}

Eine vergleichende Untersuchung.

Als Dissertation vorgelegt von

Sunthorn Srichai, M.A. (Thailand).

Göttingen, Februar 2009.

Erstgutachter: Prof. Dr. Dr. h.c. Heinrich Detering.

Zweitgutachter: Prof. Dr. Gerhard Lauer. 
Für

meine Mutter

und meine Freunde 


\section{Inhaltsverzeichnis}

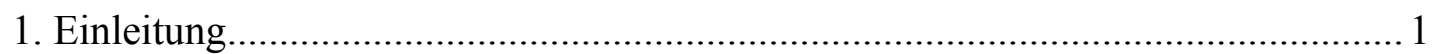

2. Thomas Manns Beschäftigung mit der Romantik ....................................................

3. Die Musik Richard Wagners in Thomas Manns Frühwerk.........................................9

4. Nietzsches Kritik an Wagner in Bezug auf die Romantik........................................15

5. Schopenhauer, Nietzsche, Wagner: Das Streben nach philosophisch-ästhetischer Form

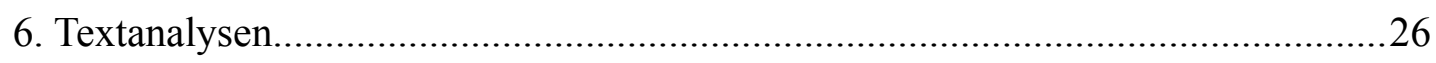

6.1 Zur Künstlerproblematik in Der kleine Herr Friedemann.................................26

6.1.1 Das Stigma der Behinderung und die Künstlernatur...............................26

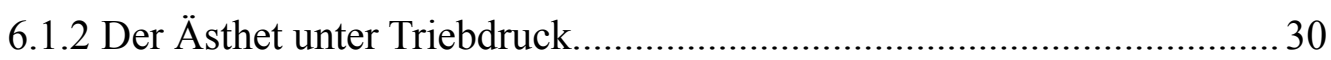

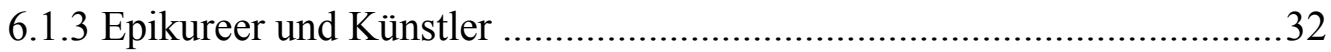

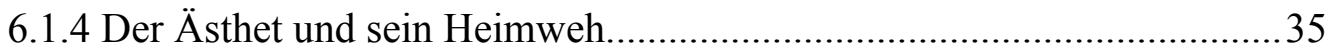

6.1.5 Musik als sinnliches Anregungsmittel....................................................... 40

6.1.6 Der Tod als ein letzter Zufluchtsort? Der Ästhet in der Gewalt der Be-

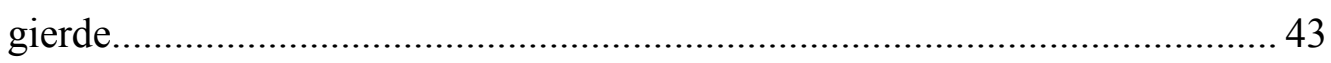

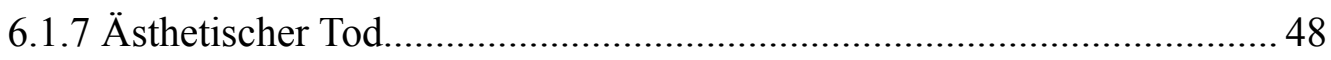

6.2 Zur Künstlerproblematik in Schwere Stunde................................................ 52

6.2.1 Zum werkgeschichtlichen Hintergrund: Schillers Gegenwart...................52

6.2.2 Schiller und Thomas Mann im Licht der Antike......................................55

6.2.3 Genie und Menschlichkeit in Schwere Stunde........................................59

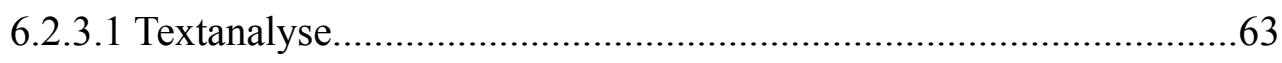

6.2.3.2 „Talent“ als Grundbedürfnis nach schöpferischer Form....................71

6.2.3.3 Goethe und Schiller - „naiver“" und „sentimentalischer“ Dichter...76

6.3 Zur Künstlerproblematik in Das Wunderkind.................................................. 78

6.3.1 Der ,übergeniale' Zustand des Künstlers in Das Wunderkind...................78

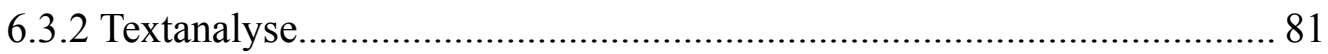

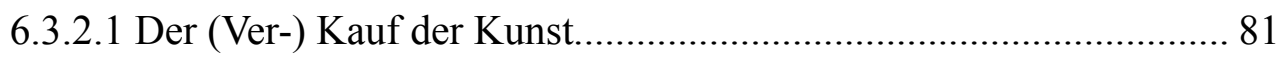

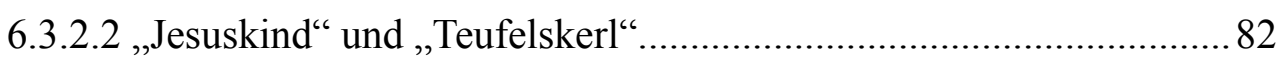

6.3.2.3 Genie vs. Artist: Das „Kindergemüt“ als anzustrebende Erschei-

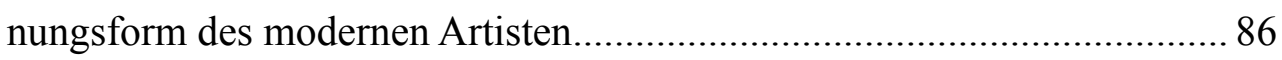

6.3.2.4 Der Künstler und sein Mäzen.......................................................... 96 


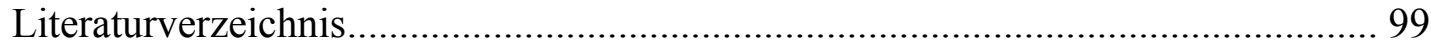

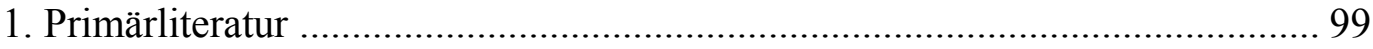

1.1 Schriften von Thomas Mann........................................................................ 99

1.2 Schriften anderer Autoren................................................................. 100

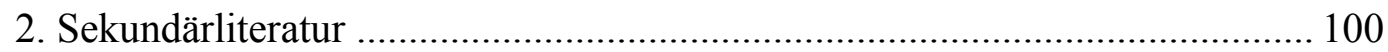




\section{Einleitung}

Die vorliegende Studie steht im Zusammenhang mit der ersten thailändischen Übersetzung der Erzählungen Thomas Manns. Sie fragt nach Modellen des Künstlertums in drei frühen Erzählungen und fasst dazu die poetischen und philosophischen Rezeptionen und Konzeptionen zusammen, die Einfluss auf die Ausgestaltung von Thomas Manns Figuren im Frühwerk ausüben. Im Mittelpunkt stehen - da die bedeutende Künstlererzählung Tonio Kröger bereits Gegenstand meiner in Thailand vorgelegten Magisterarbeit gewesen ist - Auseinandersetzung mit und Analyse von dreien seiner Hauptfiguren, ihres Charakters und ihrer spezifischen künstlerischen Existenzformen in den Erzählungen Das Wunderkind, Der kleine Herr Friedemann und Schwere Stunde. Andere Figuren, ob Künstler oder nicht, werden ebenfalls vergleichsweise einbezogen, soweit sie die Thematik betreffen und analytisch relevant sind.

Es ist angebracht, dabei auf die zeitgenössische deutsche Literatur sowie die künstlerischen und philosophischen Gedanken der deutschen dichterischen und philosophischen Tradition einzugehen, insbesondere auf Novalis, Tieck, Schlegel, Nietzsche und nicht zuletzt auf Wagner. Denn sie erlangten wesentliche Bedeutung für Thomas Manns Kunstverständnis und seine künstlerische Praxis, und sie wurden für seine Erzählungen auch intertextuell einflussreich. Besondere Aufmerksamkeit muss Wagners musikalischem Kunstkonzept gelten, von dem Thomas Mann offenkundig lebenslang geprägt war. Vor allen Dingen ist die weitgehende Übernahme von Nietzsches Kritik an Wagner für Thomas Manns musikkritische und literarische Praxis von großer Bedeutung. Gerade wenn Richard Wagner als bloß dilettantischmoderner Artist wahrgenommen oder denunziert wird (so wie Nietzsche ihn zu zeigen versuchte), ist es angebracht zu fragen, ob Thomas Mann ein echter Wagnerianer mit Gewissenbissen war oder ob er Wagner - Nietzsche folgend - als eigentlich artistischen Verleugner seiner musikalischen Gabe wahrnahm, der den Bedürfnissen des seine Musikstücke genießenden Publikums folgt. Zu diesem Zweck werden traditionelle und moderne Konzeptionen der künstlerischen sowie ästhetischen Existenz dargelegt und analytisch an ausgewählten Texten Thomas Manns entwickelt.

Dabei werden die Protagonisten der drei ausgewählten frühen Erzählungen in ihrer künstlerischen, ästhetischen Existenz in Auseinandersetzung mit der traditio- 
nellen Genieästhetik und ihrer Transformation in der Weimarer Klassik gedeutet. Ziel der vorliegenden Studie ist es, anhand der Ästhetik und der literarischen Praxis in Thomas Manns Frühwerk, insbesondere der von ihm ästhetisch präsentierten Figuren Gemeinsamkeiten und Unterschiede zwischen diesen Traditionen und den von ihm entwickelten neuen Künstlermodellen zu vergleichen. Dabei wird die Kontrastierung des im konventionellen Sinne des Wortes „Genialen“ mit einem neuen Entwurf eines ,Übergenialen’ im Mittelpunkt der Überlegungen stehen. 


\section{Thomas Manns Beschäftigung mit der Romantik}

Im Zentrum der Mannschen Beschäftigung mit der Romantik stehen einerseits das dionysisch gefärbte Sehnsuchtspathos der Liebe, andererseits der apollinische Überwältigungsversuch des genialen Ichs in der Auseinandersetzung mit Wagners Musikfunktion; beides führt zur spezifischen Ausgestaltung der dekadenten Figuren in seinen frühen Prosatexten. Entsprechend Nietzsches Kritik an Wagners Tonkunst sind sie als Opfer der Kunst zu verstehen, ohne dass Thomas Mann selbst aus der Spannung zwischen der Kritik Nietzsches einerseits und der als Vorbild verstandenen Wagnerschen Kunst herauszufinden vermag, ohne dass es ihm also gelänge, einen Mittelweg zu entwerfen.

Die literarische Stilisierung in Thomas Manns früher Prosa kreist immer wieder um die Auseinandersetzung mit der Problematik des Künstlers - verstanden als die Existenzform des ästhetischen Menschen. Von der Forschung ausführlich untersucht worden sind hierin zwei romantische Spuren: die Thematik des „Doppelgängers“ und diejenige des „Seiltänzers“. Entsprechend den Dichotomien der Romantik wird der Mensch dabei gewissermaßen in zwei seelische Hälfte geteilt: Die erste besteht aus Vernunft und Verstand, die zweite aus Empfindung und Gefühl; in moderner Perspektive lassen sie sich in weiten Teilen mit Sigmund Freuds Begriffen des Bewusstseins und des Unbewussten zusammenbringen, die in ein- und demselben Ich existieren.

Bei dem Versuch, Formen menschlicher Existenz nach seelischen Kategorien zu unterscheiden, spielt für Thomas Mann offenbar Ricarda Huchs Gesamtdarstellung der Frühromantik eine wesentliche Rolle (die wiederum Züge von Nietzsches Philosophie erkennen lässt). Mit ihren Begriffen und Metaphern lässt sich darum andeuten, worin seine Probleme und Lösungsversuche bestehen. In Bezug auf die geheimnisvollen seelischen Seiten des Menschen kann man danach eine dreiteilige Typologie entwerfen: ,Durchschnittsmenschen', ,Dämmerungsmenschen' und ,Übergangsmenschen' (weiblicher oder männlicher Art); hinzu kommen ,mannweibliche', androgyne Menschen. ${ }^{1}$ Im Bestreben, einen harmonischen Menschen zu finden, richtet sich Thomas Manns Psychologisierung auf das Ziel des dritten Menschentyps: mannweibliche Zwitterwesen, die er in stetiger Auseinandersetzung mit

\footnotetext{
${ }^{1}$ Vgl. Huch, 1922, S. 98 f.
} 
der Romantik als seine ästhetischen Figuren entwirft und die deutlich romantischweibliche Charakterzüge tragen.

$\mathrm{Zu}$ analysieren ist der Entstehungsprozess des Bewussten und Unbewussten im menschlichen Wesen. Kann der Mittelzustand als Zwitterwesen zu verstehen und dieses als Genie im Mannschen Sinn herzuleiten sein? Wodurch unterscheidet sich denn der ,harmonische' und der , unharmonische' Mensch? Hieße es, das Bewusste übertrifft das Unbewusste, oder bedingen die beiden einander? Benötigt der Mensch seinen Geist zur Unterdrückung, ja zur Abschaffung seines wilden Instinkts, der ihn zum ,genialen' Menschen machen könnte? $\mathrm{Zu}$ fragen ist, ob das Ergebnis dann gleichsam ein reines Engelswesen wäre oder ein Mensch, der zur vollen Liebe fähig ist.

Wenn Thomas Mann das Bestreben eines Menschen nach sinnlicher Reinheit und stabiler Geistigkeit thematisiert, versucht er womöglich, seine Figuren im Sinne des „Doppelgänger“-Konzepts zu romantisieren. Angestrebt ist dabei eine seelische Harmonie seiner, ästhetischen' Figuren, die in dieser Darstellung romantische Züge aufweisen: Der „Doppelgänger“ richtet sich nach seinem Geist und nach seiner Natur; er schwankt zwischen reiner Geistigkeit und nackter Natürlichkeit in sich; deshalb erlangt er keine starke und dauerhafte Verbindung zur Liebe und schließlich zur Ehe. Nach Ricarda Huchs Auffassung muss der romantische Mensch seine innerliche Harmonie entwickeln, denn er besitzt, auch wenn er ein Mann ist, doch womöglich „das Weibliche“ in sich - das in dieser Sichtweise nicht viel anderes zu sein scheint als das Freudsche „Unbewusste“.

Infolgedessen muss jedes Wesen seine eine Seite durch die andere ausgleichen. Erst dann entsteht in seinem Inneren die angestrebte harmonische Ganzheit. In den mythologischen Bildern betrachtet, die von der Romantik über Nietzsche bis zu Ricarda Huch führen und die der junge Thomas Mann rezipiert, ergibt sich dieses ausgeglichene ästhetische Wesen eigentlich aus dem harmonischen Ausgleich zwischen „Mann und Weib, Tier und Engel“, die sich gegenseitig erdulden und somit in einer Art von „Kameradschaft“ leben können. In der germanischen Mythologie, so konnte Thomas Mann bei Huch lesen, erschienen die „Heidengötter nie ohne ein edles Tier". ${ }^{2}$

Wird der ,romantische Mensch' nur als, weibliches' Gefühlswesen aufgefasst, fehlt es ihm also an der anderen, der männlichen Hälfte, d.h., dem Bewussten, dann

\footnotetext{
${ }^{2}$ Huch 1922, S. 118
} 
stellt er, Huch zufolge, ,eine personifizierte unglückliche Ehe und Mißheirat“" dar. ${ }^{3}$ Die Ursache besteht in seinem Kampf um die andere Hälfte, den männlichen Geist, der allein seine Melancholie und Sentimentalität rechtfertigen kann. Fehlt ihm dieser, gerät er in Todesgefahr, wie z.B. der kleine Herr Friedemann - oder, unter den frühesten Verkörperungen romantischer Existenz, der jung gestorbene Dichter Wilhelm Heinrich Wackenroder. ${ }^{4}$

Deshalb muss sich ein Romantiker sein Leben erst erkämpfen, wie Tieck sich in Ricarda Huchs Augen durch seine Harzreise retten konnte: ${ }^{5}$ Wenn der Geist und die Intelligenz dem Willen zur Wollust erlegen sind, dann wird die Intelligenz benötigt, um diesem Willen zu widerstehen; diese inneren Konflikte lassen sich als Beziehung zwischen ,Mann’ und ,Frau' veranschaulichen. Denn die bloße „Buhlschaft“ wird durch den Geist als unrein und unwahr erkannt - in dessen Augen bedeutet sie „Verschwendung“ des Geistes und „Verderbtheit“" der Intelligenz überhaupt. ${ }^{6}$ Tonio Krögers Gegensatz zwischen Leben und Kunst, den Thomas Mann in seiner Novelle thematisiert, ist in Analogie zu diesem auf Versöhnung zielenden Kampf zu verstehen.

Im Gegensatz dazu wird der „Kleine Herr Friedemann“ zum Opfer der anderen, der tödlichen romantischen Möglichkeit: Wenn die Intelligenz der Sinnlichkeit unterliegt und sich nicht durchsetzen kann, strebt das Ich seine Auflösung in einen harmonischen Sehnsuchtsort hinein an, der in der Natur zu finden ist (oder mit Schopenhauer: im blinden Willen); dort erst lassen sich für ihn beide, Liebe und Tod, ,im allmächtigen Blick“ umfangen. ${ }^{7}$ Aus fehlender Befriedigung der Sinnlichkeit wächst die Qual, die von Huch poetisch umschriebene „Marterblume mit tiefem, blutendem Kelche“. ${ }^{\circ}$ Der kleine Friedemann empfindet den unendlichen Schmerz der unerfüllbaren Sinnlichkeit als „Seelenmarter“9 und zugleich das unerträgliche Verlangen nach dem höchsten Genuss der Liebe. Deren letzte Erfüllung könnte nur in der Umarmung des Göttlichen liegen, und so endet er seine unendliche Sehnsucht erst im Tod - so ließe sich der Novellenschluss im Blick auf Huchs Romantik-Bild deuten.

\footnotetext{
${ }^{3}$ Ebd.

${ }^{4}$ Vgl. ebd., S. 120.

${ }^{5}$ Vgl. ebd.

${ }^{6}$ Ebd.

${ }^{7}$ Ebd., S. 121.

${ }^{8} \mathrm{Ebd}$.

${ }^{9}$ Ebd., S. 124.
} 
$\mathrm{Ob}$ dagegen, wie oft vermutet worden ist, Gerda von Rinnlingen den kleinen Herrn Friedemann umgebracht habe, ist fraglich. Er endet, so lässt sich im Blick auf diese romantischen Muster vielleicht sagen, den Doppelgang seiner Existenz durch die Erkenntnis der Leere, die das Dasein auf der Erde ihm bietet, indem er durch seinen eigenen Willen zur Ruhe eingeht im Reich des Vaters, Gottes. ${ }^{10}$

Im romantischen Sinn hat die Liebe geheime Bedeutung für das menschliche Wesen: Der Mensch soll diese „reinste und inbrünstige Liebe“ in sich selbst fühlen und dafür gegebenenfalls auch sterben können. ${ }^{11}$ Auf diese Weise kann der romantische Mensch wissen, dass er kein Engel, sondern nur ein Mensch ist - in Huchs Worten:

daß wir von tausenden Phantomen erlöst werden, die uns als Engelsgestalten besuchen und doch Furien werden, wenn sie das glänzende Gewand fallen lassen. ${ }^{12}$

Somit sind die Romantiker bereit, sich der Kunst selbst aufzuopfern, um sich als Mensch beweisen zu können. Sie werden vom Tode nicht geängstigt, weil dieser vielleicht die letzte Lösung für sie wäre. Denn sie könnten sozusagen ihr durch ihre künstlerische Einbildungskraft in schöne oder nicht-schöne Erscheinungen und Gegenstände hineinversetztes Gefühl in ihrer eigenen Wesenstiefe nicht ertragen, wie Tieck sagte:

Denn schläft nicht die wildeste Verzweiflung, die gräßlichste Angst, der blutigste $\mathrm{Ha}$, Selbstmord und alle Greuel im Innern dieses Gefühls $[\ldots] ?^{13}$

Also besitzen die Romantiker eine gefährliche Furie, die wiederum enge Beziehungen zu ihrer Kunst aufweist: Sie ist das (für die Romantiker) Ästhetischste und Gefährlichste; denn wenn das Ich sie genießt, befindet es sich in Todesgefahr; sie ist die Göttin, die dem Künstler Rache schwören könnte, wie sie es mit dem Kleinen Herrn Friedemann oder dem großen Künstler Aschenbach tut. ${ }^{14}$

Ein Romantiker müsste Vernunft und Verstand besitzen, um seinen Zugang zum Unbewussten steuern zu können, gleichsam eine Tür oder, mit Ricarda Huchs Meta-

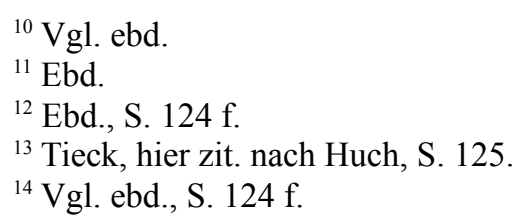


pher, eine „Klappe“ zwischen dem Bewussten und Unbewussten. ${ }^{15}$ Verliert ein Romantiker die Kontrolle über diesen Zugang, kann er ihn nicht mehr steuern, dann entsteht eine tödliche Gefahr: Das Ich wird ausgezehrt in Ausschweifungen; es wird im Inneren verwüstet, es stürzt in Wollust und geht unter in Liebe und Wein: im Dionysischen. Denn es müsste, um nicht unterzugehen, die andere Hälfte seines eigenen Ichs stillen, das Bewusstsein; erst dann könnte es die eigentlichen Wonnen der Liebe genießen, nach denen sich etwa Tonio Kröger bei Ingeborg vergebens sehnt.

Kalt und geistig wiederum wird das Dasein ohne das Unbewusste, die Sinnlichkeit, denn es wäre das Dasein eines Engels ohne Liebe zu den Menschen. Damit ist der romantische Ästhet sozusagen ein „Seiltänzer“, schwankend und balancierend zwischen Gefühl und Verstand. Hat er sich selbst geistig nicht im Griff, stürzt geht er auf der einen oder auf der anderen Seite des Seils in den Abgrund. Will er nicht im Reich „Dionysos des Lösenden“ enden, ${ }^{16}$ dann muss er versuchen, das Tor zwischen dem Bewussten und Unbewussten zu kontrollieren. Andernfalls könnte er seinen Leib, seine Phantasien und Vorstellungen, in der Kunst nicht meistern. Denn das Ziel der Romantiker bleibt doch eigentlich dies:

Die Eine, Eine glänzende Sonne, das Ich, das nicht mehr zerspaltete, die Einheit des eigenen Wesens, das ist im Grunde das Ziel aller Sehnsucht. ${ }^{17}$

Als solch einen - in Bezug auf seinen nicht verlässlich zu steuernden Zugang zur sinnlich-dionysischen Welt -, als einen schwachen ,Romantiker' schildert der frühe Thomas Mann sich selbst, so formt er seine fiktionalen Künstlergestalten. Ziel seiner und ihrer Sehnsucht ist es aber, weder ein engelreines Geschöpf zu werden noch Trieb und Rausch zu erliegen, sondern jene „Tür“ mit dem eigenen Willen steuern zu können. Novalis sagte einmal, der „Zukunftsmensch“ werde wach und schläfrig zugleich sein; er trägt also, mit Nietzsche zu sprechen, apollinisches und dionysisches Durchsetzungsvermögen zugleich in sich. Dies wäre dann vielleicht der eigentliche Charakter desjenigen selbstbewussten Sehers, des beide Seiten integrierenden ,Androgynen', der seine Phantasien nicht ausdenken muss und damit zu

\footnotetext{
${ }^{15}$ Ebd., S. 98.

${ }^{16}$ Ebd.

${ }^{17}$ Huch, 1922, S. 126.
} 
mehr als zu jener „Simili-Offenbarung“ gelangen kann, ${ }^{18}$ die er als Schauspieler dem Publikum bloß vortäuschen konnte.

Damit sind wir bei Nietzsches Kritik der Wagnerschen Romantik angekommen.

${ }^{18}$ Ebd., S. 105. 


\section{Die Musik Richard Wagners in Thomas Manns Frühwerk}

Thomas Manns Verhältnis zu Richard Wagner und seiner Kunstpraxis lässt sich als ambivalent beschreiben. Seine früheren poetisch-literarischen Erlebnisse von Wagners Erzeugung eines künstlerisch-schönen Scheins und die Versuche einer ltierarischen Imitation seiner künstlerischen Techniken werden von der gegenwärtigen Forschung als eine Art „Liebe mit Gewissensbissen“ verstanden. ${ }^{19}$ Der junge Thomas Mann hat die Persönlichkeit Wagners und seine Kunstübung hoch geschätzt, und deren Wirkung war für ihn der Inbegriff des gelungenen Scheins, der perfekten Illusionswirkung einer raffinierten Kunstproduktion. Wagners Opern und deren musikalische Wirkung haben sicherlich nicht nur den jungen Thomas Mann, sondern auch sein ganzes Publikum berauscht und in Erregung versetzt. Wertend geäußert hat sich Thomas Mann dazu schon früh bei verschiedenen Gelegenheiten. Die Wirkung von Wagners musikalisch-schauspielerischer Kunst sei von „narkotischer und aufpeitschender Art“" ${ }^{\circ 2}$ sie fasziniert und erregt, erweckt Sehnsüchte und inspiriert ihn gerade dadurch zur Konzeption und Ausgestaltung seiner dekadenten Romanfiguren. Thomas Mann wird von Wagners musikalischer Technik angeregt, das Musikalische ins Literarische umzusetzen. Er synthetisiert nämlich das durch Wagner erfahrene überwältigende Kunsterlebnis und dessen in Nietzsches Kritik vollzogene rationale Analyse und Dekonstruktion. Auf der Grundlage dieses ambivalenten Wagner-Erlebnisses hat sich ein zugleich literarisches und musikalisches Modell für seine Romane und Erzählungen entwickelt - ein Modell auch für die Konzeption seiner frühen Künster-Gestalten.

In den Betrachtungen eines Unpolitischen äußert sich Thomas Mann ausführlich über seine jüngeren, seit der Jahrhundertwende gemachten Erfahrungen mit Wagners Musik. Dabei ist in seinen Formulierungen deutlich eine literarische Umsetzung der von Nietzsche formulierten Wagner-Kritik zu erkennen:

Was ich vom Haushalt der Mittel, von der Wirkung überhaupt- im Gegensatz zum Effekt, dieser „Wirkung ohne Ursache“, vom epischen Geist, vom Anfangen und Enden, vom Stil als einer geheimnisvollen Anpassung des

\footnotetext{
${ }^{19}$ Kurzke 1997, S. 114.

${ }^{20}$ Ebd.
} 
Persönlichen an das Sachliche, von der Symbolbildung, von der organischen Geschlossenheit der Einzel-, und Lebenseinheit des Gesamtwerkes, - was ich von alldem weiß und zu üben und auszubilden in meinem Grenzen versucht habe, ich verdanke es der Hingabe an diese Kunst. ${ }^{21}$

In dieser Passage wird besonders gut sichtbar, dass Thomas Mann sich als ein echter Wagnerianer verstanden und sich dem Erlebnis und dem Verstehen von Wagners Kunsttechnik hingebungsvoll gewidmet hat.

Wagners überwältigende, betäubende musikalische Kunst und die ihr zugrunde liegende raffinierte Technik versucht Thomas Mann schon früh in seine literarische Praxis umzusetzen. Das gilt namentlich für die Leitmotivtechnik, die in späteren Kapiteln detaillierter analysiert wird. Diese Technik lässt sich ganz offensichtlich schon in seinem ersten Roman Buddenbrooks (1901) und, in kleinerem Maßstab, in frühen Erzählungen wie z.B. in Tonio Kröger (1903) erkennen. Hermann Kurzke fasst Thomas Manns Rezeption Wagners in Inhaltliches und Formales zusammen:

Das inhaltliche Wagner-Erlebnis ist immer aus den gleichen Ingredienzien gebraut: Unbürgerliche Pflichtsvergessenheit, Erotik, Rausch, Sakralität (religiöser Zweck), Todesfaszination und schopenhauerische Metaphysik (Entindividuation, Verlust von Raum und Zeit, Verlorengehen in der Welt als Wille). ${ }^{22}$

Das Inhaltliche betrifft seine literarischen Übungen im Umfeld (und in kritischer Auseinandersetzung mit) der Décadence. Auch Thomas Manns Charakterisierungen seiner dekadenten Figuren - von Hanno Buddenbrook bis eben zu Tonio Kröger liegt Nietzsches Kritik an Wagners musikalischen Kunstwerken zugrunde, die im Sinne der Morbidität als eines elementaren und typischen Grundzugs zum Stereotyp in Thomas Manns frühen Prosatexten wird.

Die für diese Texte inhaltlich zentrale literarische Verarbeitung von existenziellen Lebensdimensionen des modernen Menschen, in denen der eigentliche Ursprung seine Kunstpraxis liegt und die gerade die Bedeutsamkeit dieser Werke ausmacht, gilt zumeist der Frage nach dem wahren Wesen des Ich und seinen psychologischen Problemen. Sein Grundthema ist das Leben, die Existenz des modernen Menschen

\footnotetext{
${ }^{21}$ GW XII, S. 79 f.

${ }^{22}$ Kurzke 1997, S. 111.
} 
überhaupt. Die Protagonisten seines Frühwerks weisen eine Reihe von wiederkehrenden stereotypen Merkmalen auf, die sie als morbide ,Randfiguren’ charakterisieren: als Außenseiter nicht so sehr im Sinne sozialer Deklassierung, sondern eher innerhalb gesellschaftlich angesehener Kreise, in denen sie aber zumeist im Vergleich mit anderen Angehörigen ihres Standes, ihrer Klasse oder ihres gesellschaftlichen Niveaus als andersartig erscheinen: als charakterschwach, als lebensuntüchtig, als physisch oder seelisch krank.

Diese soziale und psychologische Durchdringung geheimer, verborgener menschlicher Lebensdimensionen seiner Figuren ist für Thomas Manns Frühwerk charakteristisch. In ihm wird der zentrale Konflikt seiner Novellenfiguren als eine spezifische Künstlerproblematik literarisch formuliert und gestaltet. Den Höhepunkt dieses schöpferischen Entwurfs bildet die Erzählung Der Tod in Venedig, ihren wesentlichen Wendepunkt hin zu einer positiveren Gestaltung markieren die Bekenntnisse des Hochstaplers Felix Krull: eine Wende vom Außenseitertum zum „schöpferischen Narzissmus“. ${ }^{23}$

Thomas Mann arbeitet in der Darstellung des Lebenslaufs und der Lebensformen seiner frühen Protagonisten deren geheimnisvolle und verborgene, zugleich aber ,wahre' Seite heraus. Indem nicht nur die physische, sondern auch die psychische Disposition des jeweiligen Ichs umfangreich und komplex thematisiert wird, findet gerade in diesen Erzählungen eine bis ins Mythologische gehende Literarisierung des menschlichen Ichs statt. Diese literarische Thematik des Außenseiters, der angesichts seiner Lebensuntüchtigkeit und seiner ästhetischen Neigungen Angst vor einer bürgerlichen Entwurzelung und dem Verlust seiner sozialen Identität empfindet, verbindet Thomas Manns frühe Erzählungen in extremer literarischer Stilistisierung und Verdichtung mit dem Grundthema des problematischen Künstlers in der Moderne. Diese Entwicklung reicht von den frühesten Erzählungen Gefallen und Der kleine Herr Friedemann bis zu Der Tod in Venedig. So bildet Manns Frühwerk gleichsam „eine Kette literarischer Stilübungen mit dem Grundthema des problematischen Künstlers als deutlichstem Aspekt von Modernität‘، ${ }^{24}$

Der junge Thomas Mann hat sich über Nietzsches Kritik an Wagners schauspielerisch-artistischer ,Gekonntheit' als Künstler bewusst hinweggesetzt. Er bewundert gerade und namentlich die gegenüber der klassischen Tradition gleichsam ,frevleri-

${ }^{23}$ Renner 1987, S. 8 ff.; zum Narzissmus in Thomas Manns Werk vgl. auch Wyslings Untersuchung des Felix Krull.

${ }^{24}$ Wild 1994, S. 15. 
sche', dekadente Artistik Wagners und nimmt ohne subjektive Kritik Wagners betrügerische und als Charakterverfall des wahren Künstlers kritisierte Artisten-Persönlichkeit wahr - nicht ohne sich dafür psychologisch zu rechtfertigen. Aus Nietzsches kritisierten, als unvereinbar definierten Begriffen stellt er eine Synthese her, die für sein frühes literarisches Werk bestimmend geworden ist.

Der moderne Artist erscheint Thomas Mann menschlich nicht mehr als eine charakterschwache Person und schon gar nicht als bloßer Lügner gegenüber seinem $\mathrm{Pu}-$ blikum oder gar gegenüber sich selbst, wenn er seine künstlerisch-praktische Wirkung zu erzielen versucht, um Geld zu verdienen und in ganz materieller Weise seine Existenz zu sichern. Diese Charakterschwäche des modernen künstlerischen Talents ist Thomas Mann zwar bewusst, er betrachtet sie aber nicht als Verstoß gegen eine künstlerische Moral, an die er sowieso nicht mehr glaubt, sondern im Gegenteil als einen psychologischen Befreiungsprozess des Ich als eines ästhetischen Wesens. Darin besteht seine ,nachträgliche Psychologie“. ${ }^{25}$

Er sieht sich selbst nicht als schuldig in seiner Kunstpraxis, in der er ja musikalische Kunstmittel und künstlerische Techniken wie die Montage- und die Leitmotivtechnik aufgenommen und abgewandelt werden, um sein Publikum zu begeistern. Der moderne Artist benutzt seine Kunst als Mittel, um finanzielle und soziale Vorteile zu erzielen. Infolge dessen wird er in Nietzsches Kritik als schuldig angesehen, da er seine künstlerische Gabe missbrauche; als schuldig kann er darüber hinaus wegen eines durch diese Artistik bloß verdeckten Mangels an künstlerischer Begabung befunden werden. Thomas Mann dagegen betrachtet sich selber als einen unschuldigen Erzeuger eines modernen Kunstwerks. Um die psychische Befreiung seines eigenen Ichs zu verteidigen, die in seinem analytischen Intellekt begründet ist und Prozesse einer mythologischen Verarbeitung eigener intellektueller und seelischer Voraussetzungen einschließen kann, erklärt er: „Bei der Arbeit bin ich unschuldig und selbstgenügsam“. ${ }^{26}$

Vor allem in Thomas Manns Einbeziehung der Musik in seine literarischen Texte - als Thema und als Verfahren etwa der Leitmotivtechnik - wird die Übernahme und Umsetzung der musikalischen Kunst Richard Wagners sichtbar. Der verführerische, berauschende Charakter seiner intellektuell kalkulierten Musik gewinnt instru-

\footnotetext{
${ }^{25}$ Kurzke 1997, S. 116.

${ }^{26}$ Ebd., S. 117.
} 
mentale Funktionen als ein Mittel, mit dem die Kunst die genießende Seele des rezipierenden Ich zur Liebe im dionysischen Sinn führt (oder verführt).

Diese geradezu tödliche, rezeptionspragmatisch-funktionale Seite der Musik Wagners wird von Thomas Mann oft beobachtet und thematisiert: In Tristan und Isolde wird ein Paar zur Liebe und endlich zum Tode verführt. Ihre Liebe entsteht in Wagners Oper gleichsam durch die Suggestion einer musikalischen Begleitung, die die beiden Seelen miteinander auf der Saite des Musik-Instruments tanzen lässt. Als solche seelischen Seiltänzer stehen sie am Ende jedoch vor der Todesgefahr durch die verführerische Kraft der Musik:

Mit Isolde treibt er [Tristan] Musik und Sprachen, gibt ihr auch Unterrichten in der ,Moralität', der Kunst der schönen Sitten, und sie verlieben sich ineinander. $^{27}$

Derselbe Fall eines Todes durch die Musik - wenn auch die geliebte Gestalt der Gerda von Rinnlingen ihm die ersehnte Erwiderung seiner Liebe innerlich versagt betrifft den kleinen Herrn Friedemann, der sich sicherlich nicht grundlos Wagners Oper Lohengrin als sein Lieblingsstück ausgewählt hat. Allerdings wird seine keusche und engelsreine Welt und Lebensform durch den Einfluss der Musik zerstört, und so ist er am Ende selbst dem musikalischen Liebes-Tod erlegen:

Er sah mit einem entsetzten und angstvollen Blick in sich hinein, wie sein Empfinden, das er so sanft gepflegt, so milde und klug stets behandelt hatte, nun emporgerissen war, aufgewirbelt, zerwühlt... Und plötzlich, ganz überwältigt, in einem Zustand von Schwindel, Trunkenheit, Sehnsucht und Qual, lehnte er sich gegen einen Laternenpfahl und flüsterte bebend: „Gerda!‘‘28

Nicht nur Tonio Kröger und seine Mutter, sondern auch Gerda Buddenbrook und ihr Sohn Hanno spielen ein Musikinstrument - und zwar mit einer Leidenschaft und in einer Intensität, die sicherlich nicht der Norm der damaligen Zeit entsprechen, sondern vielmehr als Selbst- und Pflichtvergessenheit zu verstehen sind. In Tonio Kröger spielt die Musik eine nicht weniger relevante Rolle als in der Friedemann-No-

\footnotetext{
${ }^{27}$ Mann 2004, S. 644.

${ }^{28}$ Ebd., S. 79.
} 
velle, wenn Thomas Mann die beiden Tanzveranstaltungen thematisiert und die profane Bedeutung der Musik für gesellschaftlichen Standards und Rituale der bürgerlichen Gesellschaft schildert. Gerade hieraus ergibt sich seine Ironie angesichts der Mittelmäßigkeit der Bürger-Figuren. Vor allem der Tanzmeister Knaak wird als dilettantische und darum lächerliche Gestalt charakterisiert: Er ist kein echter ,Seiltänzer' im romantischen Sinne oder im Sinne Nietzsches. Dagegen findet der musikalisch empfindsame und empfängliche, dekadente Tonio Kröger seine Liebe zu Inge während des Tanzes und leidet:

Tonio Krögers Herz zog sich schmerzlich zusammen bei diesem Gedanken [an Inge] ... Mehr als einmal stand er mit erhitztem Angesicht an einsamen Stellen, wohin Musik, Blumenduft und Gläsergeklirr nur leise drangen, und suchte in dem fernen Festgeräusch deine klingende Stimme zu unterscheiden, stand in Schmerzen um dich und war dennoch glücklich. ${ }^{29}$

Trotz des Liebesdrangs, den die Musik bewirkt hat, kann Tonio Kröger durch den Einsatz seines Geistes und seiner Willenskraft dem gefährlichen Gefühl widerstehen. Die eigentliche Gewalt des Dionysischen trifft ihn erst auf der Seefahrt und überwältigt ihn, so dass er sein Gedicht nicht zu Ende bringen kann - denn er ist nun vollends der Gewalt seines Unbewussten ausgeliefert:

Tonio Kröger hielt sich an irgendeinem gestrafften Tau und blickte hinaus in all den unbändigen Übermut. In ihm schwang sich ein Jauchzen auf, und ihm war, als sei es mächtig genug, um Sturm und Flut zu übertönen. Ein Sang an das Meer, begeistert von Liebe, tönte in ihm. Du meiner Jugend wilder Freund, so sind wir einmal noch vereint, [.... so war es ihm im Halbschlaf wie eine Liebkosung. ${ }^{30}$

Anders als der an Wagners Modernität geschulte Artist Thomas Mann kann seine Figur Tonio Kröger in einem derart unbewussten Zustand kein Kunstwerk formen und schmieden - denn nun ist er gleichsam dem Dionysos erlegen. (Hierauf wird in späteren Kapiteln noch ausführlicher eingegangen.)

\footnotetext{
${ }^{29}$ Mann 2004, S. 261.

${ }^{30}$ Ebd., S. 315.
} 


\section{Nietzsches Kritik an Wagner in Bezug auf die Romantik}

Nietzsches kritische Darlegung über den großen Musiker Richard Wagner vollzieht sich namentlich in einer zynischen, spöttischen und synthetischen Selbstverständigung über die Persönlichkeit des Künstlers überhaupt; dabei werden auch hier Anknüpfungen an die literarisch-philosophische Tradition sichtbar. Deutlich werden Unterschiede zwischen einer traditionellen und einer modernen Auffassung der Kunst und des Künstlers; unter der Annahme, dass alles Künstlerische bzw. das schöpferisch ,Weibliche' im Wesen des Ichs selbst wurzelt, lässt sich Nietzsches Kritik an dem Musiker Wagner nicht anders begreifen denn als eine auf diese schöpferisch-objektive Abstraktion ausgerichtete, sich verteidigende Äußerung zum Künstler als einem ästhetischen Spiele und damit einem Träger dieses ästhetischen Prinzips überhaupt.

Im Gegensatz zur traditionellen metaphysischen Sinngebung der geistesgeschichtlich bezeugten Genieauffassung beschreibt Nietzsches Kritik einen scheinbar objektiv empfundenen Mangel an künstlerischer Begabung, ja Persönlichkeit, ${ }^{31}$ die den als modern angesehenen „Artisten“ reduziert auf einen Lügner gegenüber dem eigenen Talent, als einen music-maker, der lediglich von Geltungssucht und Raffgier getrieben ist, als einen Handwerker mit geizigem Geschäftssinn.

Die Ablösung des modernen Künstlers aus der literarischen Genie-Tradition, der konventionellen Begrifflichkeit und Bestimmung seines schöpferischen Wesens, das sich ursprünglich als göttliche Inspiration verstand, den Künstler zum frommen Diener einer gleichsam als Königin über die Menschheit gesetzten Schönheit und „Natur“ überhöhte und sich damit nur in der einen Hälfte des menschlichen Maßes verborgen hatte - diese Ablösung setzt den eingeschlossene handwerklich-schauspielerischen Aspekt des künstlerischen Schaffens frei und löst seine spielerische Eigenbewegung aus. Der spielerisch-moderne Geist, der sich über die konventionellen Begriffsbestimmungen ebenso wie über das geistesgeschichtlich normative Verständnis des Künstlers erhebt, repräsentiert das Gegenstück zur Genietradition.

In Nietzsches Kritik, im Fall Wagners, ist dies vollzogen. Hier wird der Schauspieler-Künstler Wagner aus der Tradition ausgeschlossen; das von ihm beabsichtigte Handwerkstück wird nicht mehr gemäß der Vorstellung vom poeta vates,

\footnotetext{
${ }^{31}$ Vgl. Jochen Schmidt: Die Geschichte des Genie-Gedankens, Bd. 2, S. 129-168.
} 
also der Vorstellung vom Dichter als einem prophetischen Seher, als gleichsam geoffenbarte Botschaft Gottes für den Menschen aufgefasst, sondern eher als eine künstlerische Sichtweise und Perspektive sowie als die Praxis eines die religiöse Feierlichkeit nur künstlerisch Spielenden: also als ein Spiel mit der Kunst, die nur das Unterbewusste des Publikums aktiviert und berauscht. Folglich kritisiert Nietzsche Wagners artistische Gekonntheit als „Geniestreich“, ${ }^{32}$ der das Publikum verführerisch anregt.

Der Drang nach Stoffen einer mittelalterlichen oder mythologisch-germanischen Überlieferung verbindet sich hier mit einem in einem forschenden Zugriff gründlich erworbenen Wissen, das dann verbunden wird mit einer modernen, auf die Wirkung zielenden künstlerischer Technik: diese Verbindung charakterisiert den Kritisierten als einen im modernen Sinne großen Künstler überhaupt. In gewisser Weise entspricht dies eher den Aussichten Novalis’ auf einen möglich werdenden „Seher“ in der Moderne, der nicht im Dunklen nach Inspiration sucht, wie es die Romantiker zunächst getan hatten. Er bedarf somit keiner Einbildung ins „Unterirdische“ mehr, um das eigene „Schaffen im Unbewussten“ entspringen zu lassen. ${ }^{33}$ Damit wäre sein schöpferischer Geist freigesetzt, bindungslos und beweglich in einem weiteren künstlerischen Spielraum, als Tieck und seine romantischen Anhänger es für möglich gehalten haben, die ,zunächst durch die Aushöhlung des unterirdischen Reiches schwankend und unkräftig werden“ und als Endeffekt der durchlaufenen WartePhase anstelle einer offenbarten, ekstatisch-göttlich inspirierten Botschaft ausschließlich ,affektierte Faseleien“ vor sich sahen. ${ }^{34}$

Nietzsches Umwertung dieser Begriffs- und Sinnbestimmung des Künstlers als eines Schauspielers sind von dem Musiker Wagner und seiner Kunstpraxis verursacht worden. Nietzsche beschreibt Wagner als Erlöser der modernen Seele, indem er ihn zugleich als einen Künstler beschreibt, der aus dem ,genialen' Künstlertum herausfällt, aus der Mittler-Position als Heiliger zwischen Gott und Mensch. Der neue Aufbruch des künstlerischen Selbstverständnisses führt in die Moderne. Im Gegensatz dazu strebten die der romantischen Auffassung verpflichteten großen Musiker und Künstler noch jene heilige Stellung des Mittlers an, so etwa Beethoven, dessen göttlich-tänzerische Melodie noch - wie Thomas Mann in Anspielungen auf das Wort des Apostels Paulus schreibt - „mit Menschen- und Engelzungen“ redete und

\footnotetext{
${ }^{32}$ Nietzsche 1969, S. 37.

${ }^{33}$ Huch 1922, S. 105.

${ }^{34}$ Ebd.
} 
als eine ästhetische Ausdrucksform zur Erhebung des menschliches Geistes zu verstehen war. ${ }^{35}$

Wenn Wagner um der Wirkungsversessenheit seines „Artefakts“ willen als schuldig kritisiert wird, dann hat Nietzsche - oder schon der von ihm beschriebene Wagner selbst - eigentlich mit der künstlerischer Moral, mit dem Echtheits-Verlangen der ,wahren Künstlernatur' gebrochen, wie es in der Geschichte des Geniegedankens immer formuliert worden war. Die herkömmliche Rolle des Künstlers als eines heiligen poetischen Wahrsagers und Sehers, eines poeta vates, der eine Mittlerposition auch zwischen Wahrheit und Schönheit einnahm und als ermächtigtes Instrument Gottes durch seine heilige Sendung der Menschheit einen „Zugang zum Numinosen“ eröffnet hatte, endet somit mehr oder weniger mit Wagners Kunst, seinem Artefakt. ${ }^{36}$

Andererseits geht Nietzsches kritische Äußerung über die Person Wagners als Vorbereitung dazu, sich selbst - nach Deterings Deutung ${ }^{37}$ - als eine göttliche Instanz jenseits des Nihilismus zu ermächtigen, indem er in seinem Spätwerk aus der Kritik der herkömmlichen Religion wie der herkömmlichen Kunstauffassungen heraus zugleich sich selbst als Verkörperung einer künstlerisch synthetisierten Doppelgestalt des Apollinisch-Dionyischen (Die Geburt der Tragödie, Also sprach Zarathustra) darstellt. Damit tritt an die Stelle sowohl der Vorstellung vom künstlerischen Genie bzw. vom poeta vates als einem priesterlich-prophetischen Lehrer und der romantischen Kunstreligion eine neue Form des „Personenkults um einen Künstler“", der beide Traditionen aufnimmt und überbietet. ${ }^{38}$

Die romantische Kunstreligion hatte sich ausgezeichnet durch die Transformation der religiösen Traditionen zur in der Kunst und durch die Kunst vermittelten Erlösung der Menschheit. Dabei wird die Gemeinde, der die göttliche Offenbarung galt, in einer neuen, auf moderne Auffassungen der Kunst und des Künstlers gerichteten Erlösungsvorstellung zum Publikum; die Ästhetik selbst gewinnt utopische Züge. Sie erreichen ihren Höhepunkt in Wagners musikalischen und theatralischen Praktiken, in denen die ästhetischen Formen des Geniekults als der Verehrung des von Gott selbst „geweihten Arms“ (so Klopstock über die Entstehung seines Messias) freigesetzt werden zu Erzeugnissen eines autonomen menschlichen ästhetischen

\footnotetext{
${ }^{35}$ Mann 2004, S. 318.

${ }^{36}$ Detering 2007, S. 124.

${ }^{37}$ Ebd., S. 130, sowie Detering, unveröffentlichter Vortrag bei der Göttinger Tagung „Kunst - Religion - Kunstreligion".

${ }^{38}$ Ebd.
} 
Geistes. Indem das Publikum durch Opern „erlöst“ wird, erliegt es der Zauberei eines Artefakts, dessen wirkliches Ziel - Nietzsche zufolge - nur die Schaffung eines eigenen betrügerischen Vorteils ist. In dieser Kritik wird der Künstler zur „Klapperschlange" ohne die bisher praktizierte kunstreligiöse Moral.

Der sinnig-bewusst kalkulierende Spieler-Musiker, dem es an der Gabe Gottes mangelt, setzt sich schließlich doch mithilfe seines Kalküls durch. Als Grundzug bleibt aber die kunstreligiöse Prägung noch in der modernen Auffassung der Kunst und des Künstlers erkennbar. Das gilt für Wagners musikalische Kunstautonomie, in der die Haupteigenschaft der Musik die Totalität der gestaltlosen Vorstellung ist, das gilt aber auch für die Dichtung, in der Worte und Buchstaben ihre konkreten Realisierungsmittel sind. Gottfried Benn hat das im zwanzigsten Jahrhundert mit der Behauptung resümiert, dass

Worte eine latente Existenz [besäßen], die auf entsprechend Eingestellte als Zauber wirkt und sie befähigt, diesen Zauber weiterzugeben. ${ }^{39}$

Die langen Versuche einer Abgrenzung zwischen dem menschlichen Bewusstsein und dem Unbewussten, die in der literarischen und philosophischen Geschichte der westlichen Kulturen schon seit dem 18. Jahrhundert unternommen wurden, haben in der Moderne um die Jahrhundertwende gleichsam ihr wahres Gesicht gefunden. Auf dem Weg dahin hat sich Wagners musikalische Kunst - wie Nietzsches Kritik zeigt - evident als die spezifische Eigenart moderner Kunst legitimiert. Im Hinblick auf die herkömmlichen, religiösen wie pragmatischen Funktionen der Kunst und des Künstlers und auf ihre Beziehung zueinander haben sich die Perspektiven des Dargestellten ebenso wie die des Darstellenden damit grundlegend geändert. Die Vielfalt der spielerischen und wissensbedingten Möglichkeiten des künstlerischen Geistes nimmt dank dessen, dank dieses Wegfalls einengender Konventionen und Standards bewusst und zielstrebig zu.

Dabei steht der Künstler selbst ganz im Mittelpunkt seines eigenen reflexiven Ich, selbst dann, ja gerade dann, wenn seine Kunstpraktiken als „Verbrechen am Höchsten, am Heiligsten“ angesehen werden. ${ }^{40}$ Das Ich unterliegt demnach nicht mehr den Begrenzungen durch die Trennung von Bewusstsein und Unbewusstem, sondern es

\footnotetext{
${ }^{39}$ Benn 2001, 27.

${ }^{40}$ Nietzsche 1888 , S. 11.
} 
kann autonom mit diesen beiden menschlichen Aspekten spielen und sie bewusst steuern. Dementsprechend kann der moderne Künstler seine Kunstwerke gestalten, und das Publikum kann sich dank der künstlerischen Techniken, der Ausstattung, dank der wachen künstlerischen Gekonntheit ganz seinen beiden Ich-Aspekten überlassen und sich so amüsieren.

Deshalb schwebt Wagners musikalische Kunst in anderen Sphären des menschlichen Seelenlebens als denjenigen, die „zur unendlichen Melodie“ geschaffen wur$\operatorname{den}^{41}$ und die dem Genießenden einen religiösen Übergang in ein himmlisches Reich sichern. ${ }^{42}$ Ist Wagners Publikum wie Tiecks William Lovell oder die anderen Romantiker - außer Novalis - noch gläubig schicksalsergeben, dann wird Wagner mit der modernen Selbstverständlichkeit seiner Praxis einer verführerischen Tonkunst das „unhöflichste Genie“. ${ }^{43}$ Ohne seinen ihn ermächtigenden transzendenten Urheber, als ein mit der menschlichen Psyche spielender, Erlöser' verführt er das seine berauschende Musik trinkende Publikum absichtlich zu einem Trugbild. Wer diesen Schleier der Maja nicht durchschauen kann, wird deshalb zum Spielball seiner Manipulation.

Weil die episch-musikalische Wirkung der Wagnerschen Opern das Publikum im Gegensatz zur apollinischen Musik in eine sentimentale, vermeintlich ,naive' Gefühlswelt verführt und damit einer dionysischen Macht ausliefert, deren wahres Gesicht sich selbst dekorativ vermummt, ist Wagners „Artefakt“ nur ein artistisches Scheingebilde. Es versetzt sein Publikum in einen Trance-Zustand, mit dem der musikalisch gewandte Schauspieler-Künstler bloß raffiniert zu spielen weiß. Gefesselt durch die Grundkonstellationen seiner psychischen Tiefe, beschäftigt sich das $\mathrm{Pu}-$ blikum nicht mit der Gekonntheit der Kunsttechnik.

Mit der Transformation des Genies, das die dionysische Wildheit apollinisch bändigt, zur Literarisierung und Ästhetisierung in der Autonomie des spielenden Geistes ist das Genie erloschen. Diese als schuldig und ungenial verstandene ,Genialität', die jenseits der geistesgeschichtlichen Idealvorstellungen existiert, kritisiert Nietzsche als das „Klapperschlangen-Glück des Meisters“, ${ }^{44}$ das der Spieler des Scheins sich verschafft und das ihn auf eine neue Weise groß macht.

\footnotetext{
${ }^{41}$ Nietzsche 1888, S. 7.

${ }^{42}$ So Nietzsche ironisch-kritisch: „Das Gute ist leicht, alles Göttliche läuft auf zarten Füssen“; ebd., S. 7.

${ }^{43}$ Ebd., S. 8.

${ }^{44}$ Nietzsche 1888, S. 16.
} 


\section{Schopenhauer, Nietzsche, Wagner: Das Streben nach philosophisch- ästhetischer Form}

Interpretiert Hermann Kurzke das Kunstverständnis Thomas Manns als eine Synthese aus den drei großen deutschen Denkern Schopenhauer, Nietzsche und Wagner, dem von Thomas Mann selbst so genannten „Dreigestirn“, so wird hier der Versuch unternommen, sich auf eigene Faust damit auseinander zu setzen und daraus eine Einleitung in die philosophische und literarische Konzeption Thomas Manns zu gewinnen.

Wagners Artistik und seinen „Artefakten“ liegt eine Umdeutung der Mythologie romantisch-germanischer Überlieferungen zugrunde, die als abgeschlossenes Bild anzusehen ist, mit dem dieser Musiker (Nietzsche zufolge) angeblich spielt und verführt, ohne an einen transzendenten Urheber zu denken, was ihn aus der Tradition eines göttlich inspirierten Schöpfertums ausschließt. In seiner Begeisterung darüber findet der junge Thomas Mann eine Bestätigung für eigene Gedanken. Was die Moral und die Wahrhaftigkeit im Künstler angeht, so schreibt Kurzke, bleibt bei Thomas Mann ein moralischer Vorwurf offen. Nietzsche eröffnet ihm den Weg zur Psychologie, Wagner zeigt ihm - in Nietzsches Perspektive - die entlarvte Artistik der Moderne, und Schopenhauer wird ihm zum Wegweiser in die vollkommene Form alles ideal Seienden. Mir scheint, dass Thomas Manns, konfrontiert mit deren psychologischen und artistischen, ideologischen und philosophischen, poetischen und ethischen gedanklichen Kämpfen und Systemen, zu einer Synästhetisierung von „Form, Stil und Ausdruck“ in seinem frühen ästhetischen Denken findet. ${ }^{45}$ Im Mittelpunkt der Diskussion stehen hier nur diese drei Gedankensysteme und deren Rezeption, die Thomas Mann wie eine Offenbarung aufnimmt. $\mathrm{Zu}$ fragen ist, wie weit diese Hypothese gültig ist, benötigt sie doch eine längere Auseinandersetzung.

Thomas Mann lernt in der Nietzsche-Lektüre eine Psychologisierung des menschlichen Schaffensprozesses kennen, die er dann bewusst in seine eigenen Werke umsetzt. Wagner ist laut Nietzsches Kritik eben keine Erleuchtung für sein Publikum, kein Wegweiser zur Erhebung der Seele oder zu einer objektiven Wahrheit. Somit hat er in Hinsicht auf seine Kunstübung mit den alten Genievorstellungen gebrochen. Hierin erblickt Thomas Mann eine lückenhafte Legitimation und Reflexion,

\footnotetext{
${ }^{45}$ Vgl. Kurzke 1994, S. 115 ff.
} 
die durch die bloße Funktion der Kunst zugedeckt wird. Kunstausübung ist danach also ein Selbstverwirklichungs- und Selbstrettungsprozess des Ich, jedes Menschen und namentlich des Künstlers.

Thomas Mann selbst wird überdies angesichts dieser Auffassung von der Funktion der Kunst bewusst, dass sie eine Bestätigung für Schopenhauers Willens- und Vorstellungstheorien bedeutet. Hat Nietzsche Recht gehabt mit seiner psychologischen Relativierung Wagners und seiner Entlarvung als eines „Histrionen“ der Moderne, ${ }^{46}$ so spielt für Thomas Mann Nietzsches Psychologisierung des Künstlers in einem weit größeren Umfang eine wichtige Rolle: Er übernimmt Nietzsches Kritik an Wagner und transformiert sie zu einer praktischen Übung in der eigenen Kunst.

Thomas Mann betrachtet die artistischen, populär-spielerischen Grundzüge in Wagner zwar als ,schuldhaft' hinsichtlich der Moral, begreift sie aber als Ausdruck von Not und Drang eines sich aus der Verbindlichkeit befreienden Geistes, der den - mit Schopenhauers für Thomas Mann so wichtig werdenden Begriff - Schleier der „Maja“ aufdeckt und zerreißt und damit sogar den eigenen Rahmen sprengt. Könnte nicht gerade hier vom Primat des Geistes die Rede sein, wie er unter den Romantikern als Gegenmöglichkeit zur Spannung zwischen Körper und Geist diskutiert wurde, vom künstlerischen Wesen als der Inkarnation eines Ganzen? Alle Erscheinungen werden durch das künstlerische Wirken gleichsam fortgerückt in die Erhabenheit einer menschlichen, „kunstreligiösen“ Verkörperung Gottes überhaupt. Weil Wagner sein Publikum nicht wirklich dahin führt, deshalb bleibt sein Kunstprogramm für Nietzsche bestreitbar. Schritt für Schritt wird das Publikum durch seine kritische Analyse zurückgewiesen in den Untergrund des vermeintlich Erhabenen und seines Urheber selbst - der doch wahrscheinlich nicht ohne Liebe zu seinen Mitmenschen das ausgearbeitet hat, was Nietzsche als das bloß Artistische und Demagogische kritisiert und was doch so populär geworden ist.

Aus dem Kunstprogramm Richard Wagners, das auch in den weiteren Kapiteln im Auge zu behalten ist, ergibt sich namentlich die Frage, ob hier von einer anti-nihilistischen Artistik die Rede sein kann. Klingt diese Aussage annehmbar, dann setzt Thomas Mann über die Wagner-Kritik Nietzsches hinaus nach wie vor Schopenhauers Annahme einer Autonomie des die Welt und das Sein steuernden „Willens“ an; die bewusste Reaktion darauf ermöglicht ihm eine Freisetzung seiner kritischen Erregbarkeit, seines eigenen Stils, der Rettung und Stabilisierung der eigenen künstle-

\footnotetext{
${ }^{46}$ Nietzsche 1888, S. 24.
} 
risch-ethischen Formgebung. Eine Adaptation Nietzsches bleibt dennoch spürbar und erkennbar. Herr des Hauses ist nicht mehr der Wille, sondern der Geist, der mit seinem Vermögen dessen verhüllte Erscheinungen, die „Vorstellung“, überhaupt alle vergängliche Existenz durchdringt und sie im Spiel seiner künstlerischen, illusionärsinnlichen Täuschungen mehr oder weniger zerlegt.

Spricht Thomas Mann Wagners Stil des künstlerischen Spiels an, dann fährt er sogleich fort, dass ein bisschen Lüge nicht unbedingt an den „Armen im Geiste“ moralisch schuldig wird. Denn der Künstler ist ja menschlich, auch die Romantiker oder die genialen Denker der neueren Philosophie waren menschlich, wenn sie auch der Primat der Erkenntnis auszuzeichnen vermag. Der Künstler kann das menschliche Streben zur höheren Form, sogar zur höchsten sublimieren; er verwirklicht damit die menschliche Aufgabe selbst. Wenn der Geist hinreichend verfeinert ist, darf der Mensch selbst nicht bloß ,un-begeistert' existieren, denn dies verrät das Pessimistische im Geiste überhaupt. Thomas Mann ist sich wahrscheinlich weiterhin der Tatsache bewusst, dass die Welt nur in der Vorstellung des Ich existiert und dadurch gesteuert wird. Der Sinn und die Bedeutung der Welt existieren nur in seiner subjektivbedingten Urteilskraft, durch die alle Erscheinungen des Seins erst Inhalt gewinnen, sinn- und wertvoll werden. Das „Ding an sich“ ist nichts Künstlerisches:

Es wird ihm [dem Ich] dann deutlich und gewiss, dass er keine Sonne kennt und keine Erde; sondern immer nur ein Auge, das eine Sonne sieht, eine Hand die eine Erde fühlt; dass die Welt, welche ihn umgibt, nur als Vorstellung vorhanden ist, d.h. durchweg nur in Beziehung auf ein Anderes, das Vorstellende, welches er schließlich selbst darstellt. ${ }^{47}$

So entstehen Beziehungskomplexe und -spannungen zwischen Ich und Welt als Bedingung des eigenen Daseins.

Nietzsches Kampfschrift gegen Wagner weist sozusagen aus der Verneinung heraus auf wesentliche Züge artistischer Modernität. Sie kreist um die Verteidigung eigener subjektiver Erkenntnis, Urteils- oder Konstruktionskraft anderen Wesen gegenüber. Das „Subjektive“ greift in das „Objektive“ über, so bereitet es das Paradoxon des erkennenden Ichs gegenüber dem eigenen „Subjekt“ vor und bewertet es in seiner Sicht - so wie die Menschheit üblicherweise mit dem Objektiven umzugehen

\footnotetext{
${ }^{47}$ Schopenhauer 1911, S. 3; vgl. ebd. S. 5.
} 
pflegt, worin eigentlich im tiefsten Sinne das Menschliche liegt, um einen Anhaltspunkt in der eigenen, die reine Wahrheit umgreifenden Existenz zu gewinnen, um sich Gehör zu verschaffen. Der Geist beseelt die Objekte und ist ihnen darum übergeordnet. Er zieht sich selbst das Erkannte und das mehr oder weniger Anerkannte heran; er bleibt deshalb in seiner Subjektivität immer relativ.

Wo aber liegen die Grenzen des menschlichen Urteils- und Wertungsvermögens? Diese zeigt Schopenhauer in seinem Hauptwerk Die Welt als Wille und Vorstellung, in dem er Auf- und Abstieg des menschlichen Geistes nachzeichnet. Seine Deutung führt vor Augen, wie wir Menschen nicht mehr Herren im eigenen Haus sind, dass unsere Willenskraft im metaphysischen Willen erlischt. Indem er dies erkennt, kann er aber dem Erkannten gegenüber ,pessimistisch' existieren, kann er mehr oder weniger bewusst und nachdrücklich nach dem Sinn des Lebens fragen. Entsprechendes wird in den folgenden Kapiteln genauer anhand der drei Beispielstexte erörtert, auch wenn Thomas Manns Erzählungen nicht einfach auf eine Ableitung aus der Schopenhauerschen Lehre reduziert werden sollen.

Der frühe Thomas Mann bleibt Schopenhauers Philosophie treu und stimmt der metaphysischen Erkenntnistheorie des Philosophen prinzipiell zu. Er tut das jedoch nur in bestimmten Maßen. Die Welt entsteht zwar auch hier erst aus dem vorstellenden Ich, empfängt von ihm ihre Definition und alle Geistigkeit. Aber Thomas Mann interpretiert den schopenhauerschen Willen neu: Dieser Wille ist in Thomas Manns Menschenbild kein allein herrschender Herr im menschlichen Hause mehr - wie dies bei den Romantikern und sogar bei dem großen Lehrmeister Schopenhauer selbst oft der Fall war. ${ }^{48}$ Vielmehr wird das Dasein des Ich gesteuert durch den Intellekt. Nicht lediglich der „Wille“ führt das erkennende Ich zum weltlichen Auslöschen im pessimistischen Sinn. Sondern der Geist bringt den durch die eigene Einbildungskraft getriebenen Willen zum Ziel, jedoch nicht zur Auf- und Erlösung des Seins ins Nichts. Vielmehr zieht er sich durch eigene mental-ästhetische, psychischmoralische und ethisch-wohlmeinende Verarbeitungsprozesse die unabdingbare geistige Sphäre in der tiefen Untergründigkeit des erkannten Seins heran, in der das ästhetische Ich erlöst wird und das Ich sich subjektiv von verbindlichen Urteilen und Wertungen rettet. ${ }^{49}$

\footnotetext{
${ }^{48}$ Vgl. Sorg 1975, S. 84.

${ }^{49}$ Kurzke 1994, S. 118.
} 
Dies macht die eigentliche Funktion der Kunst aus, die aus Schopenhauers Philosophie abgeleitet ist. Gemeint ist bei Thomas Mann jedoch nicht dasjenige „Quietiv“, das nach Schopenhauer mit dem Ende eines ästhetizistisch-objektiven Ästheten ohne menschliche Wärme gleichgesetzt und deshalb als seine letzte, verengte Genesung des Seins und als dessen Heilung begriffen werden kann. Im Gegenteil ist für Thomas Mann diese heilende Sphäre kein Ende seines Schöpfungsgeistes, sondern es ist sein Kurort, eine literarische Praxis, in der er sich mit der die reine Wahrheit verschleiernden Illusion der „Maja“50 auseinandersetzt, sie verarbeitet und schließlich auch bearbeitet. Dazu braucht auch Thomas Mann das Spiel mit literarischen Effekten, wie der von Nietzsche geschilderte Wagner. Dies ist Manns Antwort auf die Willenslehre Schopenhauers.

Der menschliche, sich selbst und andere Erscheinungen beobachtende, verzweifelnde Geist dient hier als ein geistiges Werkzeug des (um die romantische Bildlichkeit wieder aufzunehmen, die Thomas Mann durch Vermittlung Ricarda Huchs kennengelernt hatte) lichterfüllten, geistig-leiblichen Wesens der „Maja“, ein Werkzeug, das diese Begrenzungen sprengen kann, um „das Ding an sich“ zu erkennen. Eine synthetisierte Bestätigung für solch ein Spiel mit schleierhaft scheinenden, kunstvoll abgebildeten und damit durchschaubar gemachten Erscheinungen fand der junge Thomas Mann in dem mit Nietzsches Augen gesehenen großen Musiker und Epiker Richard Wagner. Begeistert ihn dessen „Artistik“ unmittelbar, so distanziert er sich doch wieder davon und findet die Ursache der kritisierten „Erzeugung von organischer Geschlossenheit ${ }^{* 51}$ wahrscheinlich in einer Aneinanderreihung von unverbrauchten Ideen, „Ideensymphonien“, die einem Künstler stets innewohnen.

Notwendig ist jedoch die Frage danach, wie diese Ästhetisierung geschieht. Denn das Publikum soll ja nicht schon vergeistigt sein. Es ist eher des Künstlers Aufgabe, eine Relativierung des Abgebildeten, letztlich alles Seienden zu erzeugen und das Publikum oder den Leser in die ,Urform' des menschlichen Gepräges zu versetzen mit einem selbst bereits kreativen, bereits ,informiertem' Intellekt, der nicht die vermeintlich objektiv-dogmatische und deshalb trocken-geschmacklose ,Wahrheit' bestätigen, sondern vor allen Dingen das Wesentliche zeigen und das Publikum mit künstlerischen Mitteln zu einer Synthetisierung von Wahrheit und Schönheit bringen soll.

\footnotetext{
${ }^{50}$ Schopenhauer 1911, S. 3.

${ }^{51}$ Kurzke 1994, S. 117.
} 
Die angeblich schuldige ethische Sphäre lässt Thomas Mann mit der metaphysischen Offenbarungs-Sphäre der Kunst verschmelzen, in der der Künstler sich mit dem „Ureinen“, der vollkommenen Form identifiziert. Dies ist eine unumgängliche Notwendigkeit für den Künstler, wenn sein Geist verfeinert ist: Er strebt sein Heil in einer Kunst an, der Schopenhauers Philosophie zugrunde liegt - so interpretiert Kurzke. Es ist die Not des schöpfenden Geistes, sich in der Kunst zu retten und in ihr die eigene Not zu kompensieren. Somit treibt er sich selbst an, verzehrt sich im vitalen Willen zum Sich-Aufrechterhalten und gewinnt so seinen eigenen Lebenswillen zurück - eine Überwindung der Décadence. 


\section{Textanalysen}

\subsection{Zur Künstlerproblematik in Der kleine Herr Friedemann}

\subsubsection{Das Stigma der Behinderung und die Künstlernatur}

Wenn die schicksalhafte Andersartigkeit als ein Hauptthema im Frühwerk Thomas Manns gelten kann, dann ist die kurze Geschichte des kleinen Herrn Friedemann dafür ein guter Beleg. Hierin ist ein kleinwüchsiges, körperlich behindertes Wesen literarisiert. Thomas Manns literarische Absicht bei der Gestaltung seines philosophisch stilisierten Objekts, des kleinen Johannes Friedemann, wird früh erkennbar. Bereits in der ersten Passage des Kapitels I wird der Leser auf dieses merkwürdigmittleiderregende, fromm-unerwünschte und vor allem traurige „Geschöpf“ aufmerksam gemacht. ${ }^{52}$ Später wird für diese Einstellung die Charakterisierung der vorgeschobenen Unterlippe Gerdas leitmotivisch. ${ }^{53}$ Vorausdeutend werden bereits in der Einleitung Grundzüge der philosophischen Stilisierung und Literarisierung Friedemanns akzentuiert: Die alkoholisierte, stiefmütterliche Amme ist es gleich in der ersten Zeile der Erzählung, die Friedemanns verwachsene Merkmale, die Physis des gekrümmten und zuckenden kleinen Wesens, verursacht. ${ }^{54}$ In auktorialer Perspektive wird der Grund für das Behindertsein Friedemanns als Unfall und Schicksal zugleich gedeutet, als eine angeborene Konstellation dem Leser zu verstehen gegeben; daraus ergibt sich dann seine Haltung und Charakterisierung:

Er war nicht schön, der kleine Johannes, und wie er so mit seiner spitzen und hohen Brust, seinem weit ausladendem Rücken und seinen viel zu langen, mageren Armen auf dem Schemel hockte [...]..$^{55}$

Die weiteren Schilderungen seines Äußeren dienen zwar dem Verständnis seiner Hässlichkeit, aber sie weisen zugleich auf einen wesentlichen Widerspruch hin:

\footnotetext{
${ }^{52}$ Mann 2004, S. 87.

${ }^{53}$ Vgl. ebd., S. 107.

${ }^{54}$ Vgl. ebd., S. 118.

${ }^{55}$ Ebd., S. 89.
} 
„Seine Hände und Füße aber waren zartgeformt und schmal.“ Die physische Äußerlichkeit des betrachteten Wesens wird sogleich wieder entschärft, sie fällt kaum ins Gewicht, ja ihr Besitzer kann durchaus als „beinahe schön“ empfunden werden. ${ }^{56}$ Diese Darstellungsweise zur Sonderstellung des kleinen Johannes gegenüber allen anderen Gestalten der erzählten Welt formuliert bereits die thematische Grundvoraussetzung für die Darstellung eines künstlerischen Wesens; damit nimmt der Text eine deutlich herausgehobene Stellung im Frühwerk des Autors ein. Wenn in der Folge des Nachdenkens über Schopenhauer, Wagner und Nietzsche das Ästhetische als ein gewichtiger Teilbereich des menschlichen Lebens gilt und es dadurch verfeinert wird, dann lässt sich in dieser Hinsicht Thomas Manns kurze Erzählung als Experiment und Diskussion über den geheimnisvollsten Teil der Menschheit verstehen, als eine literarische Auseinandersetzung mit einer ästhetisch-individuellen Existenz.

Der kleine Johannes erscheint als literarischer Inbegriff für beide Begriffe, Ästhetik und Leben. Überdies gibt diese kleine Erzählung eine Einleitung in die literarische Thematik des frühen Thomas Mann, in die Kontrastierung von Bürgertumsund Künstlertumswelt mitsamt den damit jeweils verbundenen Formen von Weltanschauung und Selbstverständnis. Die Geschichte erzählt von einer niederländischen, bürgerlichen, aber kärglich lebenden und - im Sinne des zeitgenössischen Konzepts - , dekadenten' Familie, deren Familienoberhaupt verstorben ist:

Die arme Frau hatte es noch vor der Geburt des Kindes erleben müssen, daß ihr Gatte, der niederländische Konsul, von einer ebenso plötzlichen wie heftigen Krankheit dahingerafft wurde. ${ }^{57}$

Wie es scheint, ist der kleine Johannes die einzige Hoffnung seiner Mutter. Durch seine im bürgerlichen Sinne berufliche Untauglichkeit und seine sozusagen schicksalsbedingte Krankheit vermag diese Hoffnung jedoch nicht in Erfüllung zu gehen. Ihr bleibt deshalb nichts anderes übrig, als sich damit abzufinden. Der Erzähler gibt bereits hier eine deutliche Vorausdeutung auf ein morbide-frommes, friedlich-genügsames Bild dem sinnbildlichen Garten gegenüber, für das der immer wiederkehrende Satz „Gott weiß es“ ein Beleg ist: ${ }^{.8}$

\footnotetext{
${ }^{56}$ Ebd.

${ }^{57}$ Ebd., S. 87.

${ }^{58}$ Ebd., S. 95.
} 
Der Blick der Mutter aber hob sich oft von ihrer Handarbeit, um mit wehmütiger Freundlichkeit zu dem Kinde hinüberzugleiten. ${ }^{59}$

Friedemanns Schwestern sind gleichfalls nicht gesünder, obwohl sie nicht physisch behindert sind. Nicht nur Friedemann selbst, sondern auch sie sind unerwünscht. Gleich ob es genetisch bedingt ist oder durch einen Unfall verursacht sein soll, sind die Kinder dieser Familie allesamt schwächlich oder entsprechend den Konventionen der Zeit unansehnlich und infolgedessen auch unverheiratet, also faktisch unfruchtbar:

Verheiratet waren sie leider noch immer nicht; aber sie waren längst in einem Alter, in dem man sich bescheidet, denn Friederike, die Älteste, hatte siebzehn Jahre vor Herrn Friedemann voraus. Sie und ihre Schwester Henriette waren ein wenig zu lang und dünn, während Pfiffi, die Jüngste, allzu klein und beleibt erschien. Letztere übrigens hatte eine drollige Art, sich bei jedem Worte zu schütteln und Feuchtigkeit dabei in die Mundwinkel zu bekommen. ${ }^{60}$

Dabei vertreten sie durchaus eine Art lüstern-lächerlicher Sittlichkeit und ernsthafter Naivität im Vergleich zu Friedemann, wenn sie versuchen, die sittlichen Bedingungen ihrer gesellschaftlichen Existenz zu wahren:

[...] die drei Mädchen [...] aber hielten treu zusammen und waren stets einer Meinung. Besonders wenn eine Verlobung in ihrer Bekanntschaft sich ereignete, betonten sie einstimmig, daß dies ja sehr erfreulich sei. ${ }^{61}$

Trotz seiner gebrechlichen Gesundheit versucht der kleine Johannes, eine Lehre als Kaufmann zu machen und ein selbstständiges Geschäft zu eröffnen, auch wenn dieser Maßstab eines bürgerlichen Weltbilds im Vergleich mit anderen Erzählungen des Frühwerks wie z. B. Tonio Kröger weniger akzentuiert ist.

Stattdessen wird hier das ästhetische Bild Friedemanns entfaltet. Die Thematik des Außenseitertums ist ebenfalls ausgeprägt schon in dieser kurzen Erzählung zu

\footnotetext{
${ }^{59}$ Ebd., S. 89.

${ }^{60}$ Ebd., S. 93.

${ }^{61}$ Ebd.
} 
finden. Hervorgehoben und verschärft wird sie durch das, was man die ästhetische Kapitulation vor der Aufgabe einer Fortpflanzung des Menschengeschlechts nennen könnte. Latent ist sie bereits beim Blick der armen Mutter auf ihr mit seinen Büchern beschäftigendes Kind im Garten abzulesen. 


\subsubsection{Der Ästhet unter Triebdruck}

Hinsichtlich der Darstellung des kleinen Herrn Friedemann als eines ästhetischen Wesens ist das Paradox zwischen dem Ästheten selbst und den Verhältnissen seiner Herkunft erkennbar. Die Weltanschauung des kleinen und verwachsenen Menschen ist der Inbegriff seiner Ästhetik. Der kleine Herr Friedemann trägt ästhetische, und das heißt in der Fortschreibung der von der Romantik und ihrer Darstellung bei Ricarda Huch übernommenen Geschlechter-Rollen: weibliche Grundzüge. Als exotisch ist er charakterisiert. Seine Hände und Füße sind ,zartgeformt“; er hat

große, rehbraune Augen, einen weichgeschnittenen Mund und feines, lichtbraunes Haar. ${ }^{62}$

Obwohl der Gegensatz zu den anderen Gestalten nicht evident akzentuiert wird, spürt der Leser immerhin hinsichtlich seiner ästhetisch geprägten Anschauung den Widerspruch gegen seine menschliche Umwelt, der ihn als einen empfindsamen und genießenden Ästheten kennzeichnet. Friedemann hat keine Kameraden, nicht weil sie ihn aggressiv ausschließen, sondern weil er sich nicht für sie interessiert und sich eher mit ästhetischen Dingen beschäftigt. Er bekommt sogar regelmäßig Einladungen „von seinen Altersgenossen“, hat aber „nicht viel Freude am Verkehr mit ihnen“. Zu „Schwärmereien für dies und jenes Mädchen“ äußert er sich unter seinen Kameraden nicht. ${ }^{63}$

Die erste triebhafte und plötzliche Liebes-Neigung zu einem wie später im Tonio Kröger „blonden, ausgelassen fröhlichen Geschöpf", das Friedemanns keusch-ästhetische Welt sprengen könnte, spürt er mit sechzehn Jahren. Diesem Mädchen entsagt er um seines Friedens willen, sie wird entsprechend Thomas Manns literarischer Konzeption des Ästheten Friedmann auf das bloß Ästhetische reduziert, und er lässt seinen Protagonisten eine Entscheidung für die Ästhetik und gegen die körperliche Sinnlichkeit fällen:

\footnotetext{
${ }^{62}$ Mann 2004, S. 89.

${ }^{63}$ Ebd., S. 89 f.
} 
Diese Dinge, sagte er sich, von denen die Anderen ersichtlich ganz erfüllt waren, gehörten zu denen, für die er sich nicht eignete, wie Turnen und Ballwerfen.

Ohne Liebe ist er zwar

ein wenig traurig; am Ende aber war er von jeher daran gewöhnt, für sich zu stehen und die Interessen anderer nicht zu teilen. ${ }^{64}$

Friedemanns Kampf gegen seinen natürlichen Trieb, gegen die Liebe deutet auf einen ästhetisch-asketischen Drang zu einer ästhetischen Lebensführung gegenüber der Forderung der Natur, in Abgrenzung von ihr:

Sein Kopf saß tiefer als je zwischen den Schultern, seine Hände zitterten, und ein scharfer, drängender Schmerz stieg ihm aus der Brust in den Hals hinauf. Aber er würgte ihn hinunter und richtete sich entschlossen auf, so gut wie er vermochte. ${ }^{65}$

Um der Kontemplation willen wendet er sich seiner Beschäftigung mit den Büchern zu und spielt Violine, „was er trotz seiner verwachsenen Brust erlernt hatte. “66 Friedemanns Ziel, außerhalb seiner passiv-ästhetischen Welt zu leben, ist gescheitert, und so entsagt er jedem weiteren Umgang mit der als zerstörerisch erlebten Liebe:

„Gut", sagte er zu sich, „das ist zu Ende. Ich will mich niemals um dies alles kümmern. Den anderen gewährt es Glück und Freude, mir aber vermag es immer nur Gram und Leid zu bringen. Ich bin fertig damit. Es ist für mich abgethan. Nie wieder. ${ }^{67}$

Klingt diese Haltung ästhetizistisch und individualistisch, egozentrisch oder dekadent, so kann das Ästhetische für das Ende des Menschengeschlechts stehen.

\footnotetext{
${ }^{64}$ Ebd., S. 90.

${ }^{65}$ Ebd., S. 90 f.

${ }^{66}$ Ebd., S. 91.

${ }^{67}$ Ebd.
} 


\subsubsection{Epikureer und Künstler}

Thomas Mann stellt seinen kleinen Herrn Friedemann ausdrücklich als einen Epikureer dar, der das Ästhetische bis in den tiefsten Grund seiner Erkenntnis und Empfindung genießt und sich vor jeder schädlichen Ablenkung davon zu schützen weiß. Wenn er Schmerzen empfindet, dann kostet er sie gleichsam aus - wie diejenigen, die er durch den Tod seiner Mutter erfährt. Er weiß Bescheid darüber, wie er mit Schmerzen und Empfindungen umzugehen hat:

Das war großer Schmerz für Johannes Friedemann, den er sich lange bewahrte. Er genoß ihn, diesen Schmerz, er gab sich ihm hin, wie man sich einem großen Glücke hingiebt, er pflegte ihn mit tausend Kindheitserinnerungen und beutete ihn aus als sein erstes starkes Erlebnis. ${ }^{68}$

Um seiner „Genußfähigkeit“ willen benötigt er eine „Bildung“ ${ }^{69}$ die ihm einen weiteren ästhetischen Genuss höchsten Grades und zugleich eine Übung bedeutet:

Er liebte die Musik und besuchte alle Konzerte, die etwa in der Stadt veranstaltet wurden. Er selbst spielte allmählich, obgleich er sich ungemein merkwürdig dabei ausnahm, die Geige nicht übel und freute sich an jedem schönen und weichen Ton, der ihm gelang. Auch hatte er sich durch viele Lektüre mit der Zeit einen litterarischen Geschmack angeeignet, den er wohl in der Stadt mit niemandem teilte. Er war unterrichtet über die neueren Erscheinungen des In- und Auslandes, er wußte den rhythmischen Reiz eines Gedichtes auszukosten, die intime Stimmung einer fein geschriebenen Novelle auf sich wirken zu lassen... ${ }^{70}$

Hier wird einerseits eine passive Künstlernatur am Beispiel Friedemanns diskutiert; andererseits wird aus auktorialer Perspektive eine weitere Frage nach einem anderen produktiven Künstlertyp gestellt, der sich von diesem ersten unterscheidet. Der kleine Johannes besitzt dank seines Lernens zwar eine rezeptive ästhetische Fähigkeit, er genießt die schöne Natur, die „Frühlingszeit“, in der die Blumen blühen und

\footnotetext{
${ }^{68}$ Ebd.

${ }^{69}$ Ebd., S. 92.

${ }^{70}$ Ebd.
} 
duften, die Vögel singen und sich paaren. Diese von der Natur gegebene Inspiration zur Fortpflanzung des Menschengeschlechts ist ihm scheinbar nichts wert, denn das „Glück“ seines Lebens beruht auf „Verzicht“; sein Trunk ist ein ästhetischer. ${ }^{71}$ Die Erlebnisse bedeuten ihm einen Zugang zum Schönen, aber zur Kunstproduktion und Wiedergabe führen sie ihn nicht. Für ihn ist ästhetischer Genuss dem Leben gleich, beide bedingen einander; ohne das eine existiert das andere nicht. Die Ästhetik ist somit für ihn eine ins Leben selbst integrierte Sphäre, die für ihn einen Verlust an Realität zur Folge hat:

Er lernte begreifen, daß alles genießenswert, und daß es beinahe thöricht ist, zwischen glücklichen und unglücklichen Erlebnissen zu unterscheiden. ${ }^{72}$

Das Gesamtbild der Künstlernatur Friedemanns fügt sich somit in Thomas Manns Auseinandersetzung mit einem typischen Epikureer ein, der friedlich und inkognito lebt und in seiner besonderen Form von Irrationalität, seinem Verlust an intuitiver Sinnesorientierung gefestigt ist. Dadurch vermag er, beschränkt auf ein ästhetischrezeptives Vermögen, kein schönes Produkt hervorzubringen: Er ist kein kreativer Lichtkörper im Sinne Ricarda Huchs. Wie sein abgenutzter, jedoch reiner und „,blanker Cylinder“ ironisch signalisiert, ${ }^{73}$ kann dieser Bürger keine kreative Leistung für die Menschheit oder auch nur für sich selbst schaffen.

Der Epikuräer erregt keine ,großen Affekte“, das ästhetisch-übersinnliche Genossene wird nicht zur praktischen Handlung. ${ }^{74}$ Friedlich-fromm, wartet er auf das Jenseits, nachdenklich ist er zwar und versucht, seinem physisch bedingten Leben einen metaphysischen Sinn abzugewinnen, eine Bedeutung zu definieren. Tatsächlich besitzt er ja einen befähigten Zugang dazu, er ist dazu begabt, das Metaphysische auf seine konkrete physische Situation zu beziehen. Sie dauerhaft unter Kontrolle zu bringen, vermag er angesichts des Selbstverlustes in der illusionären Vorstellung aber nicht. Das Lauschen und Flüstern in seinem „Bureau“ und das Gefestigtsein in „verblichenen Landschaften“ ist unerwünscht; die Selbstbeherrschung gehört zu seiner „putzigen Wichtigkeit“, die verstandesmäßig und vernünftig gerei-

\footnotetext{
${ }^{71}$ Ebd., S. 91.

${ }^{72}$ Ebd., S. 92.

${ }^{73}$ Ebd.

${ }^{74}$ Ebd.
} 
nigt werden soll. So kann dieser Lichtkörper, der Leib Friedemanns, jenen „hellen Überzieher" anziehen, der seine Absichten anschaulich macht. ${ }^{75}$

So wie er in Sinnesglut und -genuss verloren ist, bezeichnet es das ästhetische Wesen Friedemanns, dass er einseitig das relativ Geprägte zärtlich und intim-ästhetisch genießt, die weltlichen Erscheinungen. Dies ist ein wesentlicher Teil der Diskussion über die Künstlernatur, eine Korrektur des Mittler-Konzepts und ein Beitrag zur klaren Definition der beiden Begriffe Künstler und Natur.

${ }^{75}$ Ebd. 


\subsubsection{Der Ästhet und sein Heimweh}

Der kleine Johannes kann sich noch in seiner ästhetischen Sphäre aufrechterhalten, indem er mehr oder weniger willensgesteuert seine triebhafte Neigung zu einer Kameradin noch unterdrücken kann und sein Leben durch ästhetisch intensivierte Sinneswahrnehmungen fortführt. Diese Darstellung bezeichnet wesentliche funktionale Wesenszüge der Kunst, die ihm als kompensatorische Beschäftigung dient, als Zuwendungsobjekt und Ersatz einer intim-kontemplativen Sphäre. An ihr hält der Ästhet Friedemann fest, in ihr hält er vor dem Abgrund seiner intim-sinnlichen Empfindungen inne - temporär, bis zu seinem dreißigsten Lebensjahr.

Es kann hier rückblickend nur von einer Zwischenstation die Rede sein, vom Versuch eines Ausgleichs seines Ichs, durch den jedoch keine stabile und reflektierte Synthese entsteht. Sein individueller geistiger Ehrgeiz führt zu keinem befriedigenden Resultat, das ihn als kreativen Künstler zeigen würde. Friedemann unterdrückt lediglich seine Empfindungen von Naturmächten, die ihn zur sinnlichen Empfindung und zur praktischen Handlung animieren, anstatt mithilfe seines Schöpfergeistes daraus Kunstwerke für die Menschheit und vor allem für das eigene Ich, seine dauernde Existenz zu erschaffen.

Insofern verlieren die oben genannten Orts-Varianten ihren eigentlichen Wert- und Funktionsgehalt, durch die der Ästhet infolge seines schöpferisch unergiebigen Verarbeitungsprozesses und seines geistig passiven Reflexionsvermögens nichts aus sich heraus schafft - weder das aus seinem zerrissenen Ich heraus zum Überleben Notwendigste noch das durch das körperlich beeinträchtigte Ich Gefilterte, das konkret Ästhetische. Die Vermittlung eines primär Überweltlich-Unfassbaren, das im Medium der Kunst offenbart wird, reduziert sich somit schließlich nur auf seine asketisch-fromme Idealvorstellung.

Thomas Manns ästhetisch-naturalistische Darstellung der psychisch angefochtenen und ästhetizistisch geneigten Persönlichkeit Friedemanns kulminiert in seiner literarischen Darstellung der Verschränkung zwischen dem Metaphysischen und dem Ästhetischen. Friedemann glaubt an ein Jenseits, wo er sich einst vereint mit seinen Eltern wiederzufinden hofft und den vollkommenen Frieden finden wird: 
„Das wären nun dreißig Jahre. Nun kommen vielleicht noch zehn, oder auch noch zwanzig, Gott weiß es. Sie werden still und geräuschlos daherkommen und vorüberziehen wie die verflossenen, und ich erwarte sie mit Seelenfrieden.““76

Mit dieser Hoffnung auf das Jenseits und die harmonische Wiedervereinigung mit dem „Ureinen“ kann Friedemann sich noch bis zu seinem dreißigsten Lebensjahr am Leben halten - auf Kosten seiner Kunst. Friedemanns Absage an sein menschlich-warmes Gefühl, das die ruhige Sphäre seiner Enthaltsamkeit zerstören kann, kann als Absage ans Irdische und Physische überhaupt verstanden werden. Davon ausgehend ist die strikte Einhaltung seiner umgrenzten ästhetischen Sphäre mit der Ablehnung einer menschlichen ,Heimat' gleichzusetzen, welche die Voraussetzung für die Fortsetzung des Menschengeschlechts wäre. Die tödliche Gefahr seiner Absage erfährt Friedemann eigentlich erst nach dem Theatererlebnis im neunten und schließlich durch die Heimsuchung im Garten im letzten Kapitel.

Charakteristischerweise wird die Titelfigur im Grunde „,androgyn“ dargestellt. Ihr Gegenstück bilden die Charakterzüge Gerdas, der Heldin dieser Erzählung. Den Haltungen des androgynen Ästheten stehen diejenigen der Heldin gegenüber. Sie trägt mehr oder weniger männliche Züge, er hingegen „mann-weibliche“ (siehe oben). In einer an traditionellen Geschlechterrollen festhaltenden Gesellschaft kann sich infolgedessen niemand in Gerda verlieben, ausgenommen der kleine Johannes Friedemann. In auktorialer Perspektive wird in die Thematik des ästhetischen ,Zwitterzustandes' unauffällig eingeführt:

Die Herren waren verblüfft und hatten vorderhand noch kein Urteil; die Damen aber waren geradeheraus nicht einverstanden mit dem Sein und Wesen Gerdas von Rinnlingen.

Frau Hagenström erläutert das noch etwas detaillierter:

„Sehen Sie, sie ist durchaus nicht häßlich, man könnte sie sogar hübsch finden: und dennoch entbehrt sie jedes weiblichen Reizes, und ihrem Blick, ihrem Lachen, ihren Bewegungen fehlt alles, was Männer lieben. “777

\footnotetext{
${ }^{76}$ Ebd., S. 94.

${ }^{77}$ Ebd., S. 95.
} 
Gerdas weibliche Männlichkeit steht somit Friedemanns männlicher Weiblichkeit in den Charakterzügen gegenüber. Darin äußert sich Thomas Manns Auseinandersetzung mit einem ästhetischen ,Zwitterwesen', das im Frühwerk allgemein in den unterschiedlichen Außenseiter-Rollen durchgespielt wird und sich vor allem auf künstlerische Eigenschaften bezieht.

Diese zwiespältigen Eigenschaften, d.h. die Nicht-Definierbarkeit der weiblichen oder männlichen Geschlechterrollen erscheint dabei als Grundvoraussetzung für die Erlangung eines ästhetischen Zuganges, wenn sie nicht sogar als Träger dieses Ästhetischen selbst zu verstehen ist. So sind es genau die zu ihrer ästhetischen Absicherung und Stabilisierung notwendigen Haltungen und Charaktereigenschaften der Held(in)nen, die den angestrebten Frieden zerstören. Um dieses Paradox drehen sich Thomas Manns frühe Künstlergeschichten.

Friedemanns Scheitern im Garten im Sinne der - dann in der Erzählung Der Tod in Venedig explizit thematisierten - „Heimsuchung“ wird bereits im sechsten Kapitel vorbereitet. Es kostet den kleinen Johannes das Leben; es ist das Heimweh, die Suche nach menschlicher Wonne und Wärme, was ihm im letzten Kapitel den Tod bringt, vor dem er sich bis dahin so konsequent geschützt hat. Friedemanns metaphysische Weltsicht, sein frommer Glaube, sein idyllisch-asketischer Selbstschutz gegen die menschlich-natürliche Sinnlichkeit, die er bereits in seiner Pubertät erlebt hat: dies alles wird in der vorangestellten Garten-Szene noch einmal knapp zusammengefasst; das Theater-, genauer: das Lohengrin-Kapitel wird anschließend als Höhepunkt etabliert. Friedemanns Verlust des psychischen Gleichgewichts nach dem Theaterbesuch und sein Tod im weitläufigen und großzügigen Garten der Villa des Herrn Oberstlieutenant, und zwar in Gerdas Gegenwart, sind schon in diesem Theaterkapitel mit seiner Hervorhebung der sinnlich erregenden Funktion der $\mathrm{Mu}-$ sik programmiert.

In der Mythologie der Edda bezeichnen Gerda / Gerd die Schönheit und Fruchtbarkeit des Menschengeschlechts und zugleich die Sicherung von dessen Fortpflanzung, ${ }^{78}$ wie sie hier dem ,Wohngemach“ mit dem - Fruchtbarkeit und menschliche Lust bezeichnenden - Garten des Oberstlieutenants zugesprochen werden. Friedemanns Werbung um Gerda und sein Kampf um eine eigentlich in seinem ganzen Leben angestrebte Ausgeglichenheit und Selbsterhaltung erinnern an die Werbung

\footnotetext{
${ }^{78}$ http://de.wikipedia.org/wiki/Gerda.
} 
Freyrs um Gerd, die den Wohlstand und die Heiterkeit seines Heimes und Hofs sichert. ${ }^{79}$ Ein Ästhet wie der kleine Johannes Friedemann, der sich den Zugang zum Ästhetischen sichern und erhalten will und der dazu gewissermaßen die höhere Geschmackslehre erlernt, wird am Ende eben durch eine künstlerische Anregung und Erregung buchstäblich entindividualisiert und zugrunde gerichtet, was zugleich das Ende seines Lebens bedeutet.

Friedemanns Selbstverlust ist bereits im siebten Kapitel bemerkbar, wo er Gerdas Pferd auf den Garten hinlenkt - das schon in der Kindheitsdarstellung eingeführte Garten-Motiv klingt damit bereits unheilvoll wieder an. Nach dem Gespräch mit Herrn Stephens ist Friedemann geistig abwesend, dort, auf dem Weg irgendwohin, ist jedoch seine seelische Kapitulation vor menschlich-natürlicher Sinnlichkeit nur latent erkennbar, wenn der Großkaufmann beiläufig sagt, Gerda habe „eine Spazier-

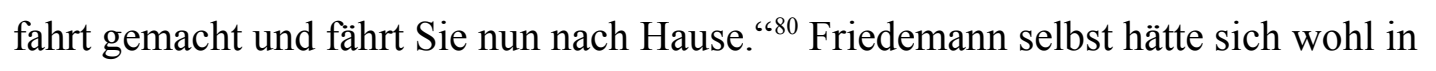
jenem Augenblick überlegen müssen, was das neuerliche Treffen mit ihr für ihn bedeutet und für sein Leben bewirken kann. Seine Gedanken kreisen um ein Haus, das aber nicht mit seinem Elternhaus gleichzusetzen ist, nicht mit dem „Büreau“ und dem „Landschaftszimmer ${ }^{\star 61}$ und einem Garten, in dem er sich meistens allein beschäftigte, erfüllt von Sehnsucht nach der himmlischen Ferne des Jenseits. Hier geht es vielmehr um ein neues Haus voller menschlicher Wärme, die durch die Gestalt Gerdas gewährleistet sein soll. Deshalb „blickte er vor sich nieder auf das Pflaster“, auf den Weg, den er in diesem Moment nicht mehr zu gehen wüsste, wenn ihm das auch eine ,scharfsinnige Bemerkung“ einbringt. ${ }^{82}$

Die aus der sinnlichen Empfindung von Gerdas physischer Schönheit resultierende innere Unruhe, die für seine ästhetische Genussfähigkeit eine geradezu lehrhafterzieherische Funktion besitzt, ist für den Leser zum einen bemerkbar, wenn Friedemann dem Treffen aus dem Weg geht, als sie mit ihrem Mann zu Besuch kommt. Friedemanns Kampf gegen die sinnliche Neigung zu Gerda, die ja verheiratet ist, gestaltet sich als Kampf gegen eine menschlich-natürliche Eigenschaft, an der jemand anders gar nicht leiden würde. Somit wird er zunehmend einem asketischen Einsiedler gleich, der im ästhetischen Schatten lebt.

\footnotetext{
${ }^{79} \mathrm{Ebd}$.

${ }^{80}$ Mann 2004, S. 97.

${ }^{81}$ Ebd., S. 98. Dies ist dieselbe Szenerie, die der Leser auch aus Buddenbrooks kennt (wie auch den Namen „Hagenström“) und die als autobiographisches Signal Thomas Manns lesbar ist.

${ }^{82}$ Ebd., S. 97.
} 
Denn allein zu diesem Schatten hat er einen Zugang; durch ihn kann er fliehen, dort kann er sich kontemplativ aufhalten. Mit dem inneren Angriff der Sinnlichkeit, seiner Triebwelt, die eben durch seine metaphysisch-geistige Konnotations- und Einbildungsfähigkeit angeregt wird, sieht er sich konfrontiert mit einer tödlichen Gefahr. Er kämpft dagegen an, um sich durch Selbstdisziplinierung selbst aufrechterhalten zu können. Der innere Konflikt wird sichtbar, wenn Friedemann sich verweigert, Gerda zu sehen:

Und er ging die Treppe hinauf. Oben schritt er über den Vorplatz und er hatte schon den Griff der hohen, weißen Thür in der Hand, die zum „Landschaftszimmer“ führte, als er plötzlich innehielt, einen Schritt zurücktrat, kehrt machte und langsam wieder davon ging, wie er gekommen war. Und obgleich er vollkommen allein war, sagte er ganz laut vor sich hin:

„Nein. Lieber nicht. - “683

An anderer Stelle, wo er sich möglichst objektiv über die Figur Gerda zu äußern bemüht und seine Worte künstlich und distanziert klingen, scheint ihm zu Gerda nichts einzufallen als die Floskel:

„Ja, so? Das ist liebenswürdig. ${ }^{\left({ }^{*} 4\right.}$

Solch eine ,neutrale' Verhaltensform, in der seine sinnliche Empfindung gleichsam vergraben ist, stellt sich aus der Perspektive des Erzählers folgendermaßen dar:

Herr Friedemann hatte die Frage ganz überhört und aß mit einer stillen und ängstlichen Miene seine Suppe. Es war, als ob er irgendwohin horchte, auf irgendein unheimliches Geräusch. ${ }^{85}$

In der zitierten Passage verbirgt sich darüber hinaus ein nur angedeutetes Signal, das auf eine Ahnung des bevorstehenden Todes im letzten Kapitel hinweist. Dies könnte es sein, wovor Friedemann Angst hat; es verbindet sich zugleich mit seiner

\footnotetext{
${ }^{83}$ Ebd., S. 98.

${ }^{84}$ Ebd., S. 99.

${ }^{85}$ Ebd.
} 
metaphysisch-religiösen Einstellung auf das Jenseits, das eben nicht mehr Teil des Lebens ist. 


\subsubsection{Musik als sinnliches Anregungsmittel}

Thomas Mann schreibt Friedemann einen voll entwickelten Zugang zum Erlebnis des Ästhetischen zu. Im neunten Kapitel ist Manns Anspielung auf Richard Wagners Oper Lohengrin und auf die ästhetischen und seelischen Funktionen der Musik erkennbar. Beides spielt hier eine wichtige Rolle; der psychologische Aspekt aber überwiegt. Die in die Erzählung integrierte Wirkung der sinnlich-evozierenden $\mathrm{Mu}$ sik stellt die musikalisch-ästhetische Funktionsdifferenzierung in den Vordergrund. Die sinnliche Raffinesse, die von Wagners Musik ausgeht, verwirklicht sich demnach in der Wirkung auf den passiv-genialen, asketisch-frommen Ästheten Friedemann - als ob sie geradezu auf ihn zugeschrieben sei, als ob sie auf ihn ziele.

Die zusammengestellten und zu interpretierenden, in den Geschehenszusammenhang eingebetteten Motive, die in diesem neunten Kapitel resümiert sind, verknüpfen sich erst im letzten, dem Todes-Kapitel ganz. Die Wirkung des musikalischen Genusses hat dort den absoluten Entzug der Lebenskraft des Ästheten zur Folge. Das gibt Anlass zu einer Diskussion über den Horizont der künstlerischen Funktionalität und zugleich einen Beleg für Thomas Manns experimentelle, auf das Modellhafte zielende erzählerische Praxis, in der die Ästhetik mit dem „Leben“ als ihrem Widerpart konfrontiert wird.

Der Asket Friedemann gerät von Beginn an in eine verführerische Stimmung, die Luft scheint „erfüllt von summendem Geräusch, Gasgeruch und Parfums. “ ${ }^{\text {"86 Gerdas }}$ Sinnlichkeit präsentiert sich Friedemanns Empfindungsfähigkeit und seinem natürlichen Trieb als der ihn zugrunde richtende Widerpart zu seiner ästhetisch-asketischen Lebensführung. Friedemann ist im Theater konfrontiert mit Gerdas sexuellen Reizen, wenn sie sich in einer „Gesellschaftstoilette“ präsentiert, die ihren Körper und ihr Dekolleté zur Geltung bringt:

Ihre Gestalt hatte heute etwas Üppiges, was neulich, als sie die weite Jacke trug, nicht bemerkbar gewesen war; ihr Busen hob und senkte sich voll und langsam, und der Knoten des rotblonden Haares fiel tief und schwer in den Nacken. ${ }^{87}$

\footnotetext{
${ }^{86} \mathrm{Ebd}$.

${ }^{87}$ Ebd., S. 100.
} 
Friedemanns zunehmend bemerkbarer, natürlicher Geschlechtstrieb wird aber, so scheint es, nicht nur durch die sinnliche Gestalt Gerdas angeregt, sondern heimlich und unbewusst auch durch die solche Empfindungen evozierende Ouvertüre der Wagnerschen Opern, die für die Erzählung eine so wichtige Rolle spielt. Denn es scheint, als verliere er diesmal unter dem Einfluss der Musik seine gewohnte Selbstkontrolle. Angesprochen ist durch sie jetzt mehr oder weniger ebenjener biologische Trieb zur menschlichen Fortpflanzung, den er bisher zu unterdrücken suchte. Friedemann ist dadurch überwältigt; er fühlt sich ergriffen von sexueller Begierde, die ihn die Tiefe seines Triebes stürzen lässt; so sieht sein Gesicht mit einem Mal „,viel bleicher, als gewöhnlich“ aus. ${ }^{88}$

Die ins Komische verzerrte, auf das Lächerliche fixierte Szene, in der Friedemann sich seines Kontrollverlusts bewusst wird, indem er seinen Kopf zwischen die verwachsenen Schultern zieht, und gleichzeitig dem Trieb unbewusst verfällt, bezeichnet die eigentliche Wirkung der musikalischen Mächte, die Friedemanns sexuellen Grundtrieb beinahe zur Handlung führen könnten. Gerade sie aber weisen seinen eigentlich ästhetischen Zugang auf, wenn er sich selbst mit der Figur Telramunds assoziiert und ein genaues Unterscheidungsvermögen zwischen Gutem und Bösem aufbringt, das ihm Gerda als eine verheiratete Frau vor Augen stellt.

Während das Publikum in die Hände klatscht, bleibt er still sitzen, fühlt sich selbst ertappt in Bezug auf seine sinnlichen Vorstellungen über seinen Widerpart, der ja denselben Zwitterzustand aufweist wie er selbst:

Die Geigen sangen, die Posaunen schmetterten darein, Telramund fiel, im Orchester herrschte allgemeiner Jubel, und der kleine Herr Friedemann saß unbeweglich, blaß und still, den Kopf tief zwischen den Schultern, einen Zeigefinger am Munde und die andere Hand im Aufschlage seines Rockes. ${ }^{89}$

Der Ästhet mit der ästhetisch-enthaltsamen Lebenseinstellung fühlt sich nun getrieben durch die tiefe Naturmacht in sich selbst, der die Vernunft nicht widerstehen kann. Dieses sexuelle Verlangen ist mehr oder weniger von seinen inneren Zwängen angetrieben, so dass der prinzipielle Versuch, die asketische Haltung aufrechter zu erhalten, nun an verteidigendem Gegengewicht verliert. Das spontan entstandene

\footnotetext{
${ }^{88} \mathrm{Ebd}$.

${ }^{89}$ Ebd.
} 
Wärmegefühl gegenüber Gerda, die verbotene Sinnlichkeit, die den Held seelisch beinahe zu deren Befriedigung erregt, entlarvt das vermeintlich heldenhafte Wesen als einen Menschen, der den sinnlichen Drang bisher lediglich unterdrückt hat, und der Trieb bringt erst hier, ausgerechnet im Musik-Theater seine Macht dem Ästheten gegenüber zur Geltung - eine Macht, zu der gerade die Kunst unübersehbar ihren Beitrag leistet. Der Verlust seiner individuellen Selbstkontrolle, die Bedrohung seines enthaltsamen und behüteten Lebens löst in ihm zunächst Verlegenheit, dann Pein aus:

Als ihre Blicke sich trafen, sah sie durchaus nicht beiseite, sondern fuhr fort, ihn ohne eine Spur von Verlegenheit aufmerksam zu betrachten, bis er selbst bezwungen und gedemütigt, die Augen niederschlug. ${ }^{90}$

Friedemann erkennt sein sinnliches Gefühl zu Gerda, es liegt in seinem inneren Trieb; er kann nichts dafür. Es ist ein Gefühl der Wärme, das ihn im Theater überkommt, und er ärgert sich über sich selbst, weil er sich nicht im Griff hat. Er fühlt sich ertappt als jemand, der seiner Sinnlichkeit erlegen ist:

Er ward noch bleicher dabei, und ein seltsamer, süßlich beizender Zorn stieg in ihm auf...91

Aus den diskreten Bewertungen des Erzählers wird erkennbar, dass Friedemann selbst diese sinnlich zerstörerische Macht des Triebes bemerkt, an der er schwer zu tragen hat und der abzusagen ihm doch noch schwerer erscheint. Sie wirkt so ,gräßlich schwer und wuchtig“" auf ihn, ${ }^{92}$ dass der Ästhet Friedemann vor einer sinnlichen Bedrohung steht, die ihm das Ende seines asketischen Lebens bedeutet.

Es ist der endgültige Bruch seines asketisch-keuschen Lebensideals, als dessen Feind die gegenüber der Gestalt Gerdas empfundene, in ihr verkörperte Sexualität erscheint. Sich dieser zu enthalten, fällt ihm so schwer, „daß ihm der Atem verging ${ }^{693}$ - jener Lebens-Atem, in dem die zerstörerische Kraft auflauert und auf ihren Durchbruch wartet. Friedemann erlebt nun das Paradox zwischen seinem Na-

\footnotetext{
${ }^{90}$ Ebd., S. 101.

${ }^{91}$ Ebd.

${ }_{92}$ Ebd.

${ }^{93}$ Ebd.
} 
turtrieb und seiner asketischen Idealvorstellung, bei dem der Sieg des einen das Ende der anderen bedeutet, als eine tödliche Spannung. 


\subsubsection{Der Tod als ein letzter Zufluchtsort? Der Ästhet in der Gewalt der Begierde}

Es gelingt Friedemann diesmal nicht mehr, seiner Empfindungen für Gerda Herr zu werden. Er vermag sie nicht mehr zu unterdrücken. Nach dem Theaterbesuch wird er seelisch (oder psychosomatisch) krank. Was in erlebter Rede vermittelt wird, ist eine Täuschung:

Ein Gefühl von Behaglichkeit und Vertrauen überkam den kleinen Herrn Friedemann. Wovor ängstigte er sich? War nicht alles wie sonst? Zugegeben, daß es gestern ein schlimmer Anfall gewesen war; nun, aber damit sollte es ein Ende haben! Noch war es nicht zu spät, noch konnte er dem Verderben entrinnen! Jeder Veranlassung mußte er ausweichen, die den Anfall erneuern könnte; er fühlte die Kraft dazu. Er fühlte die Kraft, es zu überwinden und es gänzlich in sich zu ersticken... ${ }^{94}$

Hier äußert sich eigentlich der Grundtenor der Position des Erzählers in dieser Erzählung. Es klingt beinahe, als wolle der Erzähler seinem Protagonisten Friedemann helfen. Im Modus der erlebten Rede formuliert er eine Rückfrage, die eine solche sexuelle Empfindung für einen Ästheten üblich und zulässig erscheinen lässt, und wenn sie einst oder mehrere Male wieder entstehen würde, müsste der Ästhet doch damit kämpfen, um sich wieder zu heilen. Von den Befürchtungen des Erzählers scheint Friedemann nichts zu spüren, er hört ihn gewissermaßen nicht; und er ist nicht mehr zu retten.

Friedemann spürt keine seelischen Kräfte mehr in sich. Er ist völlig krank, geschwächt, bewusstlos. Psychologisch betrachtet verliert er sein Gleichgewicht im Kampf; seine „so milde und klug stets behandelte“ Sphäre ist durch die Begegnung mit der Sinnlichkeit Gerdas gesprengt worden, sie ist für ihn so übermächtig geworden, dass diese Sphäre „emporgerissen, aufgewirbelt, zerwühlt“ und plötzlich „ganz überwältigt“ ist. ${ }^{95}$ „Gerda!“ flüstert er im Selbstverlust seines unvernünftigen Zu-

\footnotetext{
${ }^{94}$ Ebd., S. 104.

${ }^{95}$ Ebd., S. 102.
} 
stands, in dem „Schwindel, Trunkenheit, Sehnsucht und Qual“ herrschen, ${ }^{96}$ so dass er in seinem hilflosen Stoßseufzer zweimal Gott selbst um Hilfe anrufen muss:

[...] und er blieb zum zweiten Male stehen, beugte den verwachsenen Oberkörper zurück, zog die Luft durch die Zähne ein und murmelte dann abermals völlig ratlos, verzweifelt, außer sich:

„Mein Gott! Mein Gott!‘

Friedemann versucht trotzdem, sich selbst, seine Kräfte zusammenzureißen; die Anstrengung bleibt jedoch vergebens, denn er spürt immer wieder die tödlich drohende Macht der Sinnlichkeit, diese zugleich fruchtbare und zerstörerische Kraft, die sich für ihn in der Gestalt Gerdas verkörpert hat. In dem Maße, in dem sie in ihm aufsteigt, agiert er nur noch bewusstlos und „mechanisch“.$^{98}$ Friedemann kann diese Empfindung nicht mehr überwinden, er wird beinahe wahnsinnig und verliert das Vermögen der Unterscheidung zwischen Wahn und Realität. Die ästhetisch gestaltete Erfahrung, die bisher für die Aufrechterhaltung seiner Existenz gesorgt hat, spielt ihm nun ihr Spiel vor, so dass eine Sinnestäuschung entsteht. Er ist überwältigt und bereit, zugrunde zu gehen. Auch Wachheit und Schlaf bedeuten ihm keinen Unterschied mehr, auch wenn der Schlaf ihm Vergessen bedeuten könnte. Denn der Körper existiert ja doch noch immer, und der Schlaf wäre da nur ein Zwischenzustand und könnte ihm somit nicht helfen.

Anders wäre es, wenn er sich mit dem Tod vereinigte, der ja ausschließlich seine Seele zurückließe. Der Schlaf gilt ihm so fortan - und auch vielleicht in der Absicht des Verfassers - nur als ein Probe-Zustand, in dem das Leiden nicht getilgt ist. Andernfalls gäbe es keine „Tragik [...] in der Geschlechtlichkeit“ mehr. ${ }^{99}$ Der Erzähler analysiert deshalb seinen Protagonisten mit psychologischem Scharfblick:

Wie todmüde und schwach er wurde! Sein Kopf war so leer, und seine Verzweiflung begann, in eine große, sanfte Wehmut sich aufzulösen. Ein paar Gedichtzeilen flatterten ihm durch den Sinn, die Lohengrin-Musik klang ihm wieder in den Ohren, er sah doch einmal Frau von Rinnlingens Gestalt vor sich, ih-

\footnotetext{
${ }^{96}$ Ebd.

${ }^{97}$ Ebd., S. $102 \mathrm{f}$.

${ }^{98}$ Ebd.

${ }^{99}$ Reed 2004, S. 48.
} 
ren weißen Arm auf dem roten Sammet, und dann verfiel in einen schweren, fieberdumpfen Schlaf.

So endet das zehnte Kapitel. Der Beginn des elften setzt diese Schilderung unmittelbar fort:

Oft war er dicht am Erwachen, aber er fürchtete sich davor und versank jedes Mal aufs neue in Bewußtlosigkeit. Als es aber völlig hell geworden war, schlug er die Augen auf und sah mit einem großen, schmerzlichen Blick um sich. Alles stand ihm klar vor der Seele; es war, als sei sein Leiden durch den Schlaf gar nicht unterbrochen worden. ${ }^{100}$

Friedemann findet keine innere Ruhe mehr, auch wenn er es ablehnt, Gerda mit seinen Schwestern zu besuchen, und auch wenn er noch einmal die schöne Natur genießen kann. Dieser Genuss bleibt doch nur vorübergehend; letztlich kann er dem Verlangen nicht widerstehen, sie allein zu besuchen:

[...] plötzlich, ohne einen Nebengedanken, stieg mit einem süßen Schrecken der Gedanke in ihm auf: wenn ich zu ihr ginge? - Und indem er, förmlich mit einer Muskelanstrengung, alles in sich unterdrückte, was angstvoll warnte, fügte er mit einer glückseligen Entschlossenheit hinzu: Ich will zu ihr gehen! ${ }^{101}$

Was Friedemann bei Gerda erlebt hat, ist ihre kalte Haltung ihm gegenüber. Er findet trotzdem die Ruhe nicht wieder, die er zuvor hatte. Der Erzähler charakterisiert Gerdas zerstörerisch-kaltes Verhältnis zu Friedemann, wieder in einer erlebten Rede, die seine Skepsis anklingen lässt:

Lag noch immer nicht ihr Blick auf ihm? Aber nicht wie zuletzt, leer und ohne Ausdruck, sondern wie vorher, mit dieser zitternden Grausamkeit, nachdem sie eben noch in jener seltsam stillen Art zu ihm gesprochen hatte? Ach, ergötzte es sie, ihn hilflos zu machen und außer sich zu bringen? Konnte sie, wenn sie ihn durchschaute, nicht ein wenig Mitleid mit ihm haben?... ${ }^{102}$

\footnotetext{
${ }^{100}$ Mann 2004, S. 103.

${ }^{101}$ Ebd., S. 105; meine Hervorhebung.

102 Ebd., S. 110.
} 
Davon ausgehend wird der schwache und passive Ästhet Friedemann durch Gerdas kaltes Gefühl und hartherziges Empfinden behandelt wie ein „Hund““ ${ }^{103}$ der einer Hündin hinterher läuft und sie um eine Gunst bedrängt, die er doch nie erreicht. Das Leiden Friedemanns wird im folgenden Absatz ganz deutlich. Da hört er auf, mit seinem Trieb zu kämpfen; er sucht dennoch nach seinem verlorenen Glück. Aber wo kann er diesen „sanftbesonnten Frieden“ finden, ${ }^{104}$ wenn er immer noch vom Jasmingebüsch und seinem betörenden Duft berauscht ist?

Fraglich ist ebenfalls, ob er trotz des Todes einen „,neutralen Nirwana-Frieden“ finden kann: ${ }^{105}$

Wie müde und abgehetzt er sich fühlte, und wie doch alles in ihm in qualvollem Aufruhr war! War es nicht das beste, noch einmal um sich zu blicken und dann hinunter in das stille Wasser zu gehen, um nach einem kurzen Leiden befreit und hinübergerettet zu sein in die Ruhe? Ach, Ruhe, Ruhe war es ja, was er wollte! Aber nicht die Ruhe im leeren und tauben Nichts, sondern ein sanftbesonnter Friede, erfüllt von guten, stillen Gedanken. ${ }^{106}$

Der Erzähler fasst in den letzten Absätzen des dreizehnten Kapitels noch einmal die gesamte Geschichte Friedemanns zusammen und veranschaulicht seine zerstörte Gedankenwelt im Hinblick auf das Leben. Wie er in diesem Moment so gleichgültig der schönen Natur gegenübersteht, das lässt sich aus dem Grundton des Erzählers entnehmen, der das Geschehene als Schicksal zu verstehen gibt. Indem Friedemann in diesem zerrissenen Zustand die Notwendigkeit seines Daseins zu verstehen und die Vergänglichkeit seiner Existenz anzuerkennen beginnt, wird er sich auch über sein ganzes Leben klar. Damit wird an das Todes-Kapitel angeknüpft.

Eigentlich hat Friedemann bisher nur in einer Schattenwelt gelebt, in die kein Sonnenschein fiel. Es ist kein produktiver Ästhet, dem sein Kopf zwischen die Schultern sinkt, der „die Stirne in beide Hände“ stützt, ${ }^{107}$ der über sein Schicksal jammert und sich unter der Gewalt seiner sinnlichen Begierden quält. In der folgenden Passage wird die Sexualität der Frau diesem Ästheten gegenüber als „Gift“ dar-

\footnotetext{
${ }^{103}$ Reed 2004, S. 48. Friedemann fühlt sich von Gerda behandelt „,wie ein Hund“, Mann 2004, S. 118.

${ }^{104}$ Mann 2004, S. 111.

${ }^{105}$ Reed 2004, S. 48.

${ }^{106}$ Mann 2004, S. 111.

${ }^{107}$ Mann 2004, S. 112.
} 
gestellt, ${ }^{108}$ das Friedemann mit seiner ,überstarken, peinigend süßen Macht“ bedroht, ${ }^{109}$ also mit der Macht des Dionysischen, wenn er sich nicht mit den apollinischen Kräften der Vernunft und des Verstandes dagegen durchsetzen kann. Und wozu sollte er eigentlich damit kämpfen? Um sich noch mehr zu quälen? Diese Fragestellung klingt in der Erzählerperspektive an, wenn sie uns den künstlerischen Prototyp erahnen lässt, als dessen Verkörperung der kleine Johannes Friedemann in der psychologischen Betrachtung seines Verfassers erscheint (wieder gebrochen durch die erlebte Rede):

[...] diese Frau [...] war sein Schicksal, sie allein! [...] Und ob er auch versucht hatte, seinen Frieden zu verteidigen, - für sie mußte sich alles in ihm empören, was er von Jugend auf in sich unterdrückt hatte, weil er fühlte, daß es für ihn Qual und Untergang bedeutete; es hatte ihn mit furchtbarer, unwiderstehlicher Gewalt ergriffen und richtete ihn zu Grunde!

Es richtete ihn zu Grunde, das fühlte er. Aber wozu noch kämpfen und sich quälen? Mochte alles seinen Lauf nehmen! ${ }^{110}$

Die zugleich giftige und sinnlich reizende Naturinspiration, deren Erleben den bis jetzt so gefestigt erscheinenden Ästheten Friedemann erschüttert, deretwegen er beinahe wahnsinnig geworden ist und vor der er am Ende kapituliert: dies ist das erste und dominierende Thema in Thomas Manns Frühwerk.

Dennoch weist sein literarischer Versuch das Bemühen auf, im ,Medium' der Gestalt Friedemanns einen „,neutralen Nirwana-Frieden“ zu konzipieren, dem der Sieg über den sinnlich-geschlechtlichen Abgrund, diese menschlich-natürliche Anziehungskraft, der „,nicht zu entgehen“ ist, ${ }^{111}$ doch gelingen könnte.

\footnotetext{
${ }^{108}$ Reed 2004, S. 48.

${ }^{109}$ Mann 2004, S. 112.

${ }^{110}$ Ebd.

${ }^{111}$ Reed 2004, 48.
} 


\subsection{7 Ästhetischer Tod}

Nicht zum ersten Mal im Laufe der Kapitel wird Friedemanns Erscheinung durch Anzeichen des Todes charakterisiert. Im vierzehnten Kapitel ist es am weitesten ausgeprägt; die Passage liest sich mehr oder weniger wie die Darstellung einer lebendigen Leiche:

Es war erstaunlich, was für eine Veränderung in diesen acht Tagen mit dem kleinen Herrn Friedemann sich ereignet hatte. Vielleicht lag es zum Teil an dem weißen Glühlicht [...], daß sein Gesicht so erschreckend bleich erschien: aber seine Wangen waren eingefallen, seine geröteten und dunkel umschatteten Augen zeigten einen unsäglich traurigen Schimmer, und es sah aus, als sei seine Gestalt verkrüppelter als je. - Er trank viel Wein [...]. ${ }^{112}$

Die Darstellung von Gerdas Grausamkeit und Sinnlichkeit als dem Widerpart des Ästheten, der sich geradezu das Leben nehmen würde, wiederholt sich in der Szene, in der Gerda wieder in einer bürgerlichen Gesellschaft gezeigt wird, in ,leichter Toilette“, mit einem „weißen Hals“, der sich als sinnliches Objekt darbietet, und jener „Maréchal-Niel-Rose“, die den Sieg über den Ästheten markiert. ${ }^{113}$ Die sowohl moralisch als auch unmoralisch animierenden Funktionen der Musik im Hinblick auf Sinnlichkeit und Sexualität werden noch einmal kurz mit dem Hinweis auf Beethoven angedeutet. Friedemann selbst gibt keine klare Antwort auf die Frage, ob er Wagner oder Beethoven liebe; anscheinend zieht er Wagners Musikdrama vor.

Friedemann selbst verbringt seine Zeit nun im Garten, im Büro und im Landschaftszimmer, wo er die Menschen und die Natur, auf den entscheidenden Moment wartend, beobachtet und genießt. Dort im Garten ist er jedoch allein. Diesmal kann sich Friedemann das „Wohngemach“ der Rinnlingens anschauen - und vor allen Dingen ihren Garten, in dem er zugrunde geht: 
Aber er setzte sich mit seiner Cigarre und seinem Kaffee an die Thür des altdeutschen Zimmers, in dem einige Herren plaudernd beisammen standen, und blickte in das Wohngemach hinein. ${ }^{114}$

Vorherbestimmt erscheint Friedemanns Tod in der Kontrastierung dieser beiden Schauplätze: Der Ästhet, der seine keusche und unschuldige Lebensführung behüten will, kommt nun dem Totenreich näher. Er schaut „,in einer schlaffen Haltung“ Gerda an, ${ }^{115}$ und diesmal spürt er fast keinen Schmerz mehr, sondern nur noch „etwas Stumpfes und Totes“. ${ }^{116}$ Er ist nun wirklich ein Toter bei lebendigem Leibe, in dem kein kraftvoller und willensfähiger, kämpfender Menschengeist existiert. Der bloße Leichnam bleibt übrig, er scheint auf Gerdas Einladung in ihren Gartengang, auf ihren Befehl, sie zu begleiten, zu warten:

„Haben Sie Lust, mich in den Garten zu begleiten, Herr Friedemann?““117

So kommt Friedemann dem Tode immer näher, wenn er das Tor zu seinem Todesreich in Gerdas Garten durchschreitet -

Frau von Rinnlingen wies in die Ferne, wo der zierliche und duftende Blumengarten zum Park sich verdunkelte. [...]

Am Eingange standen zwei niedrige, breite Obelisken. ${ }^{118}$

Im Gespräch mit Gerda gesteht er seine Verzweiflung über den Begriff des „Glücks“. Er ist jetzt nicht mehr sicher, welche Art von Lebensführung, die asketische und kühle oder die nun versuchte warme, sein Glück bedeutet. Aber er hat ja seinen Weg zu gehen versucht, was auch Gerda als „tapfer“ bewertet. ${ }^{119} \mathrm{Er}$, der mit einem „neutralen Nirwana-Frieden“"120 experimentiert hat, liegt jetzt vor ihr wie gehetzt und erschöpft.

\footnotetext{
${ }^{114}$ Ebd., S. 114.

${ }^{115}$ Ebd., S. 115.

116 Ebd.

${ }^{117}$ Ebd.

${ }^{118}$ Ebd., S. 116.

${ }^{119}$ Ebd., S. 117.

${ }^{120}$ Reed 2004, S. 48.
} 
Das Muster der tödlichen Bedrohung durch die sinnliche Frau als die Feindin seiner Selbstkontrolle zeigt nun sein wahres Gesicht. Friedemanns Entschluss, sich der Sinnlichkeit zu beugen, bedeutet den Verlust seines individuellen Ichs. Er sinkt ihr gegenüber auf die Knie, zu Boden. Es ist ein „Klagelaut“ aus seinem Innersten heraus zu hören, der seine Begierde in diesem Moment auslöst und bald danach sein Leben auslöscht:

[...] während dieser kleine, gänzlich verwachsene Mensch zitternd und zuckend vor ihr auf den Knieen lag und sein Gesicht in ihren Schoß drückte, stammelte er mit einer unmenschlichen, keuchenden Stimme:

„Sie wissen es ja... Laß mich... ich kann nicht mehr... Mein Gott... Mein Gott..."121

Durch Gerdas Reaktion erfahren wir, dass sie nicht mehr als ein kaltes Gefühl empfindet:

Sie wehrte ihm nicht, sie beute sich auch nicht zu ihm nieder. Sie saß hoch aufgerichtet, ein wenig von ihm zurückgelehnt, und ihre kleinen, nahe beieinander liegenden Augen, in denen sich der feuchte Schimmer des Wassers zu spiegeln schien, blickten starr und gespannt gradeaus, über ihn fort, ins Weite. ${ }^{122}$

Ebenso deutlich wird die Grausamkeit ihres Gemüts, die Friedemanns keusche und unschuldige Seelen-Empfindung im Grunde nur gnadenlos verachtet:

Und dann, plötzlich, mit einem Ruck, mit einem kurzen, stolzen, verächtlichen Lachen hatte sie ihre Hände seinen heißen Fingern entrissen, hatte ihn am Arm gepackt, ihn seitwärts vollends zu Boden geschleudert, war aufgesprungen und in der Allee verschwunden. ${ }^{123}$

Damit liegt Friedemann endgültig wie ein verwachsener, unerwünschter Hund auf dem sumpfigen Boden, verlassen von seiner Herrin -

\footnotetext{
${ }^{121}$ Mann 2004, S. 118.

${ }^{122}$ Ebd.

${ }^{123}$ Ebd.
} 
Er lag da, das Gesicht im Grase, betäubt, außer sich, und ein Zucken lief jeden Augenblick durch seinen Körper. ${ }^{124}$

Der Erzähler psychologisiert ihn in diesem Moment besonders deutlich: Seine Todeslust ist vermischt mit „wollüstigem Haß“, mit der Enttäuschung seines sinnlichen Liebesverlangens, mit der demütigenden Erfahrung der kalten Nähe Gerdas. ${ }^{125}$ Und nun ist er in seiner „Wut“ er Selbstvernichtung wirklich ,irrsinnig““ ${ }^{126}$ Zerrüttet vom Verlust seiner Wahrnehmungsfähigkeit, erfüllt von Selbstverachtung im Hinblick auf seine Disziplin und Moral, empfindet der einstige Ästhet ein ihm so ekelhaftes Selbstgefühl, ja einen solchen Selbsthass, dass der Durst nach dem Tod übermächtig wird, der alles Ekelhafte in ihm selbst auslöschen würde und alles, was diese individuelle Existenz namens Friedemann ausgemacht hat, in die natürlichen Elemente wie Wasser und Luft hinein befreien würde, der seine befreite Seele an das jenseitige Ufer (zurück)kehren ließe, an dem er, so lebendig wie tot, schon eine Woche zuvor war. Nun kehrt er wirklich endgültig dorthin zurück; die Seele eines Hundes geht ein ins Dionysische. ${ }^{127}$

\footnotetext{
${ }^{124}$ Ebd.

${ }^{125}$ Ebd.

${ }^{126} \mathrm{Ebd}$

${ }^{127}$ Vgl. Detering, S. 59.
} 


\subsection{Zur Künstlerproblematik in Schwere Stunde}

\subsubsection{Zum werkgeschichtlichen Hintergrund: Schillers Gegenwart}

Meine Überlegungen zu der kleinen Schiller-Erzählung Schwere Stunde möchte ich mit einem Blick auf Thomas Manns Arbeitstechnik an seiner literarischen Praxis beginnen, woraus sich dann andere zu behandelnde Teilthemen ergeben. Zeller betrachtet Thomas Manns Technik in dieser „Skizze“ als die eines literarischen „Mosaiks“" ${ }^{128}$ in der meines Erachtens der große Dichter wirklich wie lebendig komponiert erscheint, und zwar in der besonderen Lesart zahlreicher einfühlsam montierter Bezüge zu Schillers (im Text nicht namentlich genannter) Person selbst.

Darüber hinaus ergibt sich aus dieser intertextuellen Komposition ein Indikator für Thomas Manns eigenes Denken und Handeln als Student. Es sind seine gleichzeitig geliebten und zur Identifikation herangezogenen Vorstellungen von „Größe“, ${ }^{129}$ die in seiner Arbeitstechnik, im Mosaik-Bild der „,spezifischen Größe dieses Genius“ Schiller umgesetzt werden. ${ }^{130}$ Vergegenwärtigt werden sollen somit die Genialität des Dichters mitsamt der Authentizität ihres historischen dichterischen Aromas in der Brechung durch das eigene schriftstellerische Ich Thomas Manns:

[...] das Ganze formt sich zu einer in sich geschlossenen Einheit, exakt in der Zeichnung des Porträts, echt und überzeugend in der Schilderung der Atmosphäre. ${ }^{131}$

Das in dieser kleinen Erzählung als aus den Quellen ${ }^{132}$ recherchierte intertextuelle Mosaik und frei gestaltete Stimmungsbild der leidenden und schöpferischen Persönlichkeit Schillers sowie die als Bestätigung der eigenen Existenz erlebte Identifikation sind verschmolzen zu einem stets aktuell werdenden und auf die eigene Person

\footnotetext{
${ }^{128}$ Zeller 2004, S. 289.

${ }^{129}$ Vgl. ebd., S. 33 ff..

${ }^{130}$ So im Brief an den Sonntag.

${ }^{131}$ Zeller 1975, S. 35 f.

${ }^{132}$ Außer Schillers Dichtungen sind das vor allem einige Beiträge des Marbacher Schiller-Buches; vgl. im einzelnen den Kommentar der Neuausgabe in der Großen kommentierten Frankfurter Ausgabe.
} 
und Geisteslage wirkenden Aroma des menschlichen Genies, dessen Merkmale vielleicht implizit auf das schöpferische Vermögen Manns selbst verweisen.

Die Belebung der genialen Sphäre, die Verkörperung der menschlichen Selbstzucht und die Darstellung der schöpferischen „Ichsucht“ des kranken und schließlich früh verstorbenen deutschen Dichters als eines Inbegriffs dieses menschlich-genialen Schöpfertums bleiben in diesem Mosaik-Bild wahrhaft aktuell. Es bezeugt den Duft des Genies Schiller, der nie verflogen ist und auf den Thomas Mann durch das „Weihnachtsgeschenk“ assoziativ aufmerksam wurde. ${ }^{133}$

Thomas Manns literarisch im Tonio Kröger schon früh bezeugte und intim aufgenommene Erfahrung mit Schillers menschlich großer und deshalb seiner Überzeugung nach zwangsläufig leidender Figur des König Philipp (in dem Schauspiel Don Carlos), der in Zusammenhang mit Tonios Außenseiterrolle gebracht wird, zeigt Thomas Manns frühe Schiller-Rezeption ${ }^{134}$ und erinnert zugleich an Schillers $\ddot{A}$ sthetische Schriften. In Absetzung von der auf naturwidrige Täuschung ausgerichteten, französisch-dilettantischen Künstlerfigur des Tanzlehrers Knaak, der ja Leiden und Zucht nicht kenne, hebt Thomas Mann mit Schiller das Pathetische am Menschen als Verwirklichung des in der griechischen Klassik formulierten Bildes der „menschlichen Natur“ hervor. Für ihn zeigt Schiller diese Seite des Menschen in seinem so naturhaft wirkenden Helden, dem am Betrug leidenden und darum weinenden König Philipp. ${ }^{135}$

Darüber hinaus wird vor allem im literarischen Gespräch mit der Künstlerin Lisaweta Iwanowna, einer Ausprägung seines Konzepts vom literarischen „Weiblichen“, Thomas Manns an Schillers naive und sentimentalische Dichtung anschließendes transzendentales Kunstverständnis evident. Wo Tonio Kröger vom „Aufs-Eis-Legen“ der sentimentalen Gefühle zur Beruhigung und Tilgung des ,,artistischen Nervensystems“ und zur Vermeindung eines literarischen Wirkungs-,,Fiaskos“ redet, ${ }^{136}$ bezieht er sich in instruktiver Weise auf jene Schillersche Abhandlung.

Was hier formuliert wird, ist, so scheint mir, eine reflexiv fortentwickelte Reflexion Manns zur Bestimmung der Sphäre jenes Ideals, in der das gefasste Ich schwebt, das abgesetzt von der modern naiven Ich-Erkrankung seiner Zeit in einem gewissen Abstand dazu existiert. Eine Distanz gegenüber dem Schiller vernachlässigenden

\footnotetext{
${ }^{133}$ Zeller 1975, S. 35.

${ }^{134}$ Vgl. ebd.

${ }^{135}$ Schiller S. 513 f.

${ }^{136}$ Mann 2004, S. 289 ff.
} 
„Linksruck“ der Moderne ist in dieser doch ebenfalls distanzierten „Mosaik-Skizze“ bemerkbar, die sich doch „mit liebender Mühe“ auf den Dichter bezieht. ${ }^{137}$ Hierzu bedarf es noch weiterer Untersuchungen.

Wie nirgends zuvor eröffnet diese Mosaik-Skizze Thomas Manns insgeheim einen Zugang zu seinem Verhältnis zur Genieästhetik am Beispiel des großen Dichters und zu seiner kunsttheoretischen Konzeption. ${ }^{138}$ Anhand dieses kleinen Traktats, das die Erzählung Schwere Stunde bildet, möchte ich im Folgenden einen Blick auf das werfen, was Bernhard Zeller als die „bewundernde Verbundenheit“ Thomas Manns mit Schiller bezeichnet hat. Um die Frage danach zu beantworten, soll erarbeitet werden, wofür Thomas Manns intime „Liebe“ zur Person Schillers steht, und zwar im Blick über Schillers Selbstverständnis hinaus auf die Moderne als seine Epoche.

Die Bezugnahme auf Schillers Ästhetik in dieser Erzählung bezeichnet seine Distanz zu anderen Stilrichtungen, wie er sie dann auch in anderen Abhandlungen über Schiller formulierte; ${ }^{139}$ über Thomas Manns „Selbstzeugnisse“ sowie sein „,biographisches Dokument" hinaus besagt eigentlich diese Prosa die Unzeitgemäßheit Schillers, an die sich deren Verfasser gebunden fühlt.

\footnotetext{
${ }^{137}$ Vgl. Zeller 1975, S. 34 f.

${ }^{138}$ Vgl. Zeller 1975, S. 36.

${ }^{139}$ Vgl. Zeller 1975, S. 35.
} 


\subsubsection{Schiller und Thomas Mann im Licht der Antike}

Die Hemmung ist des Willens bester Freund. -

Den Helden grüß' ich, der Friedrich Schiller heißt.

Thomas Mann. ${ }^{140}$

In Thomas Manns Künstlererzählung wird das Bild Schillers als menschliches Genie, als Genie in seiner Menschlichkeit (plastisch) und anschaulich geschildert, sodass seine Ausstrahlung bis in die moderne literarische Praxis Thomas Manns hinein sichtbar wird. Davon ausgehend möchte ich hier die Beziehung zwischen Schiller und Thomas Mann erläutern, vor allem die bis zur Ich-Verschmelzung gehende Identifikation im Blick auf die ihre dichterische und schriftstellerische Existenz begründende ideale Sphäre. Entweder wird das Existenzielle des Ich in der Spannung aufs Spiel gesetzt, woraus die Autonomie des Künstlerischen in der Moderne folgt, oder das Geniale übertrifft diese, und zwar auf Kosten der Akzeptanz und Liebe.

Die Heldentat, diese „kleine Wohltat“" ${ }^{141}$ die sich der namentlich nie genannte Dichter wünscht, ist vollzogen nicht nur durch Herausstellung des Ästhetischen als eines Ideals, sondern zeigt sich eher in der anschaulich-exemplarischen Umkehrung des „Helden“ namens Schiller in die leidende und genial begeisterte Gestalt, wie die vom Verfasser sorgfältig erarbeiteten Studien und Recherchen sie zeigen. ${ }^{142}$ Wenn Zeller schreibt, Schiller sei für Thomas Manns der Inbegriff des heroischen (oder heroisch-erhabenen) Menschen gewesen, ${ }^{143}$ dann belegt diese Erzählung, dass sich der moderne Schriftsteller im zeitlich und räumlich großen Abstand zu jenem genialen Klassizisten der Weimarer Epoche bewegt. Und wenn Thomas Mann schreibt, er sei dessen Student gewesen, ${ }^{144}$ dann können daraus mehrere Schlüsse gezogen werden: einmal dass er sich nicht an das Kunstverständnis seiner Zeitgenossen hielt, sondern an den menschlich-genialen Maßstab, der über den Horizont des Genies hinaus bis in die antike Kunst zurückreicht. ${ }^{145}$

\footnotetext{
${ }^{140}$ Mann 2002, S. 83

${ }^{141}$ Mann 1975, S. 364.

${ }^{142}$ Vgl. Reed 2004, S. 289 f.

${ }^{143}$ Zeller 1975, S. 36.

${ }^{144}$ Vgl. ebd.

${ }^{145}$ Marbacher Schillerbuch, S. 6.
} 
Der „Held“, als der Schiller im eingangs zitierten Zweizeiler für die Zeitung Die Zeit gerühmt wird, ${ }^{146}$ fordert konsequenterweise die assoziativ-imaginäre Umwandlung des im griechisch-antiken Erbe und in der Helden-Gestalt des Herkules verkörperten Bildes ins Menschlich-Erhabene; Schiller erscheint in einer Art Doppelbetrachtung als Genie, dessen Größe im Geiste der Poesie in den Göttergestalten des in Griechenland offenbarten Heldentums wurzelt, ${ }^{147}$ und als leidender Mensch.

Wenn der moderne Dichter, so kommentiert Reed, sich ins künstlerische Bewusstsein und in die Persönlichkeit Schillers hineinversetzen könnte, hieße das, dass er darin einen lehrreichen Standpunkt als Schriftsteller finden könnte und dass seine Schiller-Rezeption seit der Jugend künstlerisch nicht umsonst gewesen wäre. Sein schriftstellerisches Vermögen, das er sich mehr oder weniger mit jener Rezeption angeeignet hatte, vergleichbar den (allerdings unerfüllt bleibenden) Wunschträumen des kleinen Herrn Friedemann, ermöglicht ihm, diesen Text zu gestalten, nachdem er womöglich bereits in Tonio Kröger 1903 eine stilistische Schiller-Rezeption praktiziert hatte.

Gemeint sind damit seine aus Schillers ästhetischen Schriften erworbenen und fortgeführten Begriffe ,naiv' und ,sentimentalisch', die wiederum in Der Tod in Venedig von großer Bedeutung sind. ${ }^{148}$ Wenn sich der Verfasser der Erzählung hier eine eigene literarische Sphäre erschafft, wie er sie in Der kleine Herr Friedemann geschildert hat, ${ }^{149}$ also einen unberührten und literaturfrommen Schutzort, dann zeigen sich beide Erzählungen als zweierlei Maskierungen Thomas Manns selbst. ${ }^{150}$ Die erste richtet ihren biographisch-psychologischen Blick auf die literarische und private Lebenssphäre Thomas Manns, der unter seiner Außenseiterposition leidet, sowie auf die praktische Wirkung literarischer Kontemplation. Dieses literarische Phänomen, in dem der Autor sein ,abenteuerliches“ Leben imaginär auslebt oder kompensiert, und das wohl den Scheideweg des beschriebenen Lebens legitimiert, bringt ihn im Anschluss an diese Schiller-Erzählung über die bürgerliche Existenz hinaus auf die literarische Laufbahn. Diesen Vorgang kommentiert Reed als den eigentlichen „schöpferischen Durchbruch““. ${ }^{151}$

\footnotetext{
${ }^{146}$ Vgl. Zeller 1975, S. 36.

${ }^{147}$ Vgl. Marbacher Schillerbuch 1975, S. 9.

${ }^{148}$ Nach Reed 2004, S. 291 f.

${ }^{149} \mathrm{Vgl}$. hier das Kapitel dazu.

${ }^{150}$ Vgl. Reed 2004, S. 292.

${ }^{151}$ Reed 2004, S. 45.
} 
Wenn mit dem Tonio Kröger das problematische Außenseitertum und das Verhältnis von „Kunst und Leben“ vollends ins Zentrum des Frühwerks rücken, dann erscheint Tonio Kröger wie eine Variante, eine fortgesetzte Figur Friedemanns, in dessen Darstellung die Entfaltung dieses Gegensatzpaares wurzelt. Gemindert wird die Spannung nur, wenn sich Thomas Mann durch den Mund Tonios voller Pathos über das zweideutige „Glück“ äußert, dass es ein „Dienst“ ist, ${ }^{152}$ den er mit der Erarbeitung von Schwere Stunde leistete. ${ }^{153}$

Die Erzählung lässt sich demnach lesen als eine zweite Maskierung von Thomas Manns ,abenteuerlichem“ (vielleicht homosexuellen) Leben, das er in den pubertierenden literarischen Figuren erzählt und psychologisiert hat - so wenn Tonio Kröger sich sowohl in Hansen und Inge verliebt, dennoch mit keinem zusammen kommt und stattdessen seinen literarischen „Irrweg“ einschlägt (so Tonio).

Das bereits im Friedemann-Kapitel erwähnte, dort psychologisch-implizit gehandhabte Paradox von der „Frau“ als begehrtem Objekt und Feindin scheint in der Schiller-Erzählung endgültig hinsichtlich eines „Eheglücks“ gelöst worden zu sein, das deutlich an Thomas Manns eigene Eheschließung erinnert. ${ }^{154}$ Mit diesem Problem hätte sich der Dichter am Weimarer Hof ebenfalls konfrontieren müssen, wenn Thomas Mann es in der Erzählung in Betracht gezogen hätte. Was hätte in der jeweiligen $\mathrm{Zu}$ - oder Abwendung des Verfassers von Schwere Stunde und des Autors von Wallenstein von dieser „Frau“ als „Feind“ ein überbegrifflich-künstlerisch assoziativ eingestelltes Leben ausmachen können? Ist dies alles nicht in die auf den Dichter lebenspraktisch wirkende Offenbarung jener griechischen bildenden Kunst verschmolzen, etwa der Statue des Herkules, der u. a. mit Hebe verheiratet war und zahlreiche Kinder hatte, die Schiller in Mannheim empfangen hatte? Mit Zellers Worten:

Der unausgeführte Plan einer Vermählung des Herkules und der Hebe hätte den Weg des Heros von irdischer Pein zu des Äthers leichten Lüsten ausführlicher und reicher dargestellt, in dem Schiller das Symbol seiner eigenen Lebensbahn sah. ${ }^{155}$

${ }^{152}$ Vgl. ebd., S. 311.

${ }^{153}$ Vgl. ebd., S. 289 ff.

${ }^{154}$ Ebd., S. 311.

${ }^{155}$ Zeller, Marbacher Schillerbuch, S. 9. 
Ist es nicht das Menschlich-Geniale, das Schiller kraft seines genialen Vermögens aus jener griechischen Kunst praktisch-schöpferisch gewinnen konnte, das den jungen und vielleicht noch den alten Thomas Mann begeistert hat? Und wenn Tonio Kröger die „Wonnen des Gewöhnlichen“ begehrt, ist nicht vielleicht im Grunde dasselbe mit jenem „Nektar“ gemeint, dessen „Äther“ Friedemann unter der Gewalt des Dionysischen nicht bekommt (wie auch Aschenbach), weil er nur durch einen „Dienst" des versöhnlich integrierenden Lebens geerntet werden kann, das die gesamte ethisch-ästhetische Sphäre des Ideals umschließt und das im Verhältnis zur „Frau“ als „Feind“ konkret greifbar wird? ${ }^{156}$

Dies macht meines Erachtens die oben genannte Ich-Ideal-Sphäre in menschlicher wie in ästhetischer Hinsicht überhaupt erst aus; und wenn Schiller oder Thomas Mann vor ihrer „Schaffenskrise“ wirklich hätten bestehen sollen, dann hätte sie diese Sphäre als gro $\beta$ auszeichnen müssen. 


\subsubsection{Genie und Menschlichkeit in Schwere Stunde}

Die Erzählung eröffnet einen Blick in den literarischen Arbeitsprozess eines menschlichen Künstlers, der mit einer dramatisch-einfühlsamen Schilderung der Person Schillers verbunden wird. Es wird erzählt von der Lebensbahn des Dichters, der eine Familie hat.

Die plastisch dargestellte Situation ist diejenige, in der die ehelichen und die künstlerischen Entwicklungslinien im Leben des Dichters sich gleichsam schneiden, in dem sich das Verlangen nach menschlichem „Glück“157 und der künstlerische Schöpfungsgeist begegnen und einander nicht mehr ausschließen lassen. Diese Situation verlangt ein geistiges Ausgleichsvermögen, das einen Mittler-Zustand des genial-menschlichen Künstlers hervorbringen könnte. Menschlich bleibt dieser, sofern er das genannte Lebensglück voller Akzeptanz und Verantwortung in sein eigenes Ich integriert, das den „Künstleregoismus“ mit einschließt, ohne dass er sich diesem jedoch ganz hingeben könnte; sein schöpferischer Geist verlangt eine Distanz gegenüber dem, was er menschlich ersehnt.

Hier wird das Gegensatzpaar von „Geist“ und „Leben“" weiter entwickelt, das in Tonio Kröger entfaltet ist, wo es nur als Vorzeichen dessen erscheint, was hier in dieser Prosaskizze fortgesetzt wird. Tonio Kröger gesteht dort, als Sprachrohr seines Autors, der Künstlerin Lisaweta:

„Schelten Sie diese Liebe nicht, Lisaweta; sie ist gut und fruchtbar. Sehnsucht ist darin und schwermütiger Neid und ein klein wenig Verachtung und eine ganze keusche Seligkeit.“158

Nun vermittelt Thomas Mann im Namen des realen Dichters Schiller jenes menschlich-bürgerliche Glück mit seiner künstlerischen und bürgerlichen Verantwortung und Selbstanerkennung. Hier sollen die beiden Pole ausgeglichen und ineinander integriert werden: Die vorbildliche und bildnerische Leuchtkraft jenes Dichters, der sich für das Menschliche entschlossen und sich dieses als eine Aufgabe gestellt hat, belichtet sozusagen jene zwei Welten, deren sich die Titelfigur bewusst ist und deren

\footnotetext{
${ }^{157}$ Ebd., S. 371.

${ }^{158}$ Mann 2004, S. 318.
} 
Gegensatz vielleicht im Licht jenes dem Menschlichen vorarbeitenden Vorkämpfers nur gemildert wird. So einfühlsam wie erlebt klingt die rhetorische Frage, die jene Sehnsucht nach demselben Glück aufgreift, von dem auch in Tonios Monolog die Rede war:

Mein Weib! Geliebte! Folgtest du meiner Sehnsucht und tratest du zu mir, mein Glück zu sein? ${ }^{159}$

Hier scheint der Dichter bei flüchtiger Betrachtung ganz glücklich zu sein. Doch das Bewusstsein seiner künstlerischen Aufgabe lässt ein Glück für ihn nicht dauerhaft zu. Das Bewusstsein dieses Umstandes ist es, das sein Künstlertum ausmacht.

Das Problem ist der Umgang eines Künstlers mit der Liebe, der vielleicht dem „Weltlauf“ zuliebe menschlich ${ }^{160}$ und schöpferisch zugleich bleiben möchte oder muss, der sich um eine Versöhnung beider Pole bemüht und also in einer Art Zwitterzustand lebt. Es geht um den leidenden Geist eines Ich, das sich um seiner künstlerischen Form willen vor der nie ganz erfüllten Liebe zu retten sucht und sich über das im eigenen Innersten glühende „Chaos“ hinweg zum geistig-schöpferischen Lichtreich erheben will. Nur als schöpferischer Künstler kann der „Handelnde“ seine Ideen in Gestalten verwandeln.

Der ganze Prozess der Arbeit beruht auf einem verhängnisvollen „Zwielicht seiner Seele“, eben deshalb verlangt er einen „Übergang“ zum Licht, ${ }^{161}$ das die Bewältigung der Arbeit sichert. Das gilt nun auch in seiner ganz privaten Sphäre mit der Geliebten:

schlafe! [...] ich liebe dich sehr! Ich kann mein Gefühl nur zuweilen nicht finden, weil ich oft sehr müde vom Leiden bin und vom Ringen mit jener Aufgabe, welche mein Selbst mir stellt. Und ich darf nicht allzusehr dein, nie ganz in dir glücklich sein, um dessentwillen, was meine Sendung ist... ${ }^{162}$

\footnotetext{
${ }^{159}$ Ebd., S. 427.

${ }^{160}$ Kommerell 1934, S. 15.

${ }^{161}$ Ebd., S. 5 ff.

162 Mann 2004, S. 427 f.
} 
So imperativ wie nirgendwo sonst in Thomas Manns Frühwerk erklingt aus der einfühlsam entfalteten internen Fokalisierung heraus allen in dieselbe Not geratenden Menschen gegenüber die in erlebter Rede inszenierte Selbstmotivierung Schillers:

Nicht grübeln: Arbeiten! Begrenzen, ausschalten, gestalten, fertig werden... ${ }^{163}$

Dies ist das Verhängnis, die Geißel eines kreativ handelnden Schaffenden, der in der Gestalt Tonio Krögers nur auf dem Weg war und erst mit dieser Gestalt Schillers ganz realisiert ist. Jedoch erkennen er und sein Autor im Grunde den genannten „Luxus des Nichthandelnden“: $1{ }^{164}$ Im Sinne Schillers weist der Erzähler in Tonio Kröger psychologisch effektiv auf das Kunstverständnis seines Verfassers zurück:

Es ist aus mit dem Künstler, sobald er Mensch wird und zu empfinden beginnt. $^{165}$

Nicht künstlerisch zu arbeiten, nicht metaphysisches Denken in die Tat umzusetzen bedeutet im Grunde schon Sterben - so wie der kleine Herr Friedemann stirbt, wenn die Möglichkeiten seines Kunstgenusses enden, der sich fiktiv in noch fragwürdigerer Weise dem menschlichen und geschichtlichen „Weltlauf“ entzog. Nun verschmilzt seine Lebenssituation mit der von Schiller erlebten Kunstbeglückung und Lebensnot. So sehr mit dem Privatesten und Persönlichsten verschmolzen ist Thomas Manns Bezugsnahme auf des Dichters „Geliebte“, dass ihre Haut sogar die gleiche „Blässe der Perlen“ hat wie diejenige Katja Pringsheims. ${ }^{166}$ Wenn Thomas Mann selbst die Befürchtung hatte, als verheirateter Mann nicht mehr arbeiten zu können, ${ }^{167}$ dann bezeichnet Schwere Stunde eine beachtliche literarische und biographische Dokumentation über den Dichter und sein Ringen um die angestrebte Form.

Thomas Mann schildert mit dem Schiller seiner Schweren Stunde einen Menschen, der in seiner Arbeit nur mit kämpfender Mühe vorankommen kann. Explizit erfährt der Leser gar nicht, dass es hier um eine literarische Darstellung Schiller

\footnotetext{
${ }^{163}$ Ebd., S. 428.

${ }^{164}$ Kommerell 1934, S. 15.

165 So in „Tonio Kröger“, Mann 2004, S. 271.

${ }^{166}$ Mann 2004, S. 427; dazu Reed 2004, S. 312. Dasselbe Merkmal trägt auch Imma Spoelmann im Roman „Königliche Hoheit“.

${ }^{167}$ Vgl. Mann 2004, S. 42; dazu Detering 2005, 4. Kapitel.
} 
geht, obwohl u. a. die Stadt Jena im zweiten Absatz und später das Drama Don Carlos erwähnt werden, aber der Leser kann den Gemeinten leicht erschließen. Hierzu kommentiert Reed:

die Identität Schillers, deren schrittweise Enthüllung durch biographische und literarische Hinweise zur dramatischen Wirkung der Geschichte gehört, war für die ersten Leser von vornherein offenkundig, da der Erstdruck inmitten von anderen Schiller-Beiträgen zur Zentenarnummer des Simplicissimus erschien. ${ }^{168}$

Doch nicht um die Frage, wie der Leser literarische Bezüge zu dem großen Dichter erkennt, geht es hier, sondern um die Wirkung der dramatisch-einfühlsamen Komposition dieser Prosa, die auf den Dramatiker des Wallensteins knapp und prägnant Bezug nimmt und ihn zur Figur einer eigenen Dichtung macht.

Der Text entwirft ein dramatisch-narratives Portrait und ein Selbstportrait zugleich. Er zeigt zwei Menschen, die in der Unauflöslichkeit ihrer menschlichen und ästhetischen Aufgaben, ihrer bürgerlichen und künstlerischen Lebensumstände einander spiegeln. Dieser Doppelaspekt hat m E. nicht (nur) dank der verschiedenen Quellen entnommenen Zitate und Anspielungen und nicht nur wegen der miteinander identifizierten Formen des „Leidens“ für den Autor, ${ }^{169}$ sondern eben wegen der Integration seiner eigenen Gefühls- und Gedankenwelt, die in der Projektion auf die des anderen dessen Leuchtkraft zum Maßstab nimmt. Der heterodiegetische Erzähler bedient sich der Unmittelbarkeit der internen Fokalisierung sowie der erlebten Gedankenrede - als verwandle sich ein Regisseur in seine Charaktere und sagte, er sei jetzt diese Figur selber.

\footnotetext{
${ }^{168}$ Reed 2004, S. 295.

${ }^{169}$ Vgl. ebd., S. 289.
} 


\subsubsection{Textanalyse}

In dieser szenischen, passagenweise einer dramatischen Szene ähnlichen Erzählsituation begegnet der Leser dem Leiden des bürgerlich gewordenen Dichters, der in seinem Arbeitszimmer, dem ,sechseckigen Zimmer ${ }^{\text {“ }}{ }^{170}$ ratlos und hilflos in seiner Arbeit am Wallenstein stockt und sich für einen Augenblick vom Manuskript entfernt, in der Hoffnung, etwas Wärme vom Ofen zu empfangen.

So verwirrt und armselig erscheint der Dichter in seinem verblichenen Spitzenjabot, eigentlich einem Zeichen bürgerlichen Wohlstands des Dichters, dessen Schreibtisch ebenso „gebrechlich“ ist wie er selbst. Der Ofen, dessen erhoffte Wärme seinen beiden Hände mitten in der grauen Dezembernacht zum Aufwärmen behilflich sein soll, ist nicht mehr der aufflammende und ersehnte Freund der Jugendzeit. Kein Feuer im Ofen und kein dadurch aufgewärmtes Blut, das die körperlichen Organe in Bewegung setzt; seine Hände, die doch die Ideen vom matt „hängenden Kopf" aufs Papier bringen sollen, sind beinahe kraftlos oder betäubt. Die Starre gemahnt fast an den Tod.

Hier drängt die dramatische Schilderung auf ein Miterleben. Der handelnde Held ist konfrontiert mit den seine Existenz bedrohenden Naturmächten, in doppelter Hinsicht: Zum einen ist er in äußerer Hinsicht in den Bereich von klimatischen Naturgewalten geraten, die seiner Existenz ein raumzeitliches Ende setzen, und zum anderen plagt ihn in seinem Innersten, im Körper, die Brustkrankheit, „der ewige Katarrh und die Krämpfe“, die nicht mehr heilbar sind: ${ }^{171}$ Der Dichter kämpft um sein Werk, trotz seines längst ernsthaft, ja lebensbedrohend erkrankten Körpers. Der ganze Leib sieht beinahe aus wie ein Toter:

Das war ein besonderer und unheimlicher Schnupfen, der ihn fast nie völlig verließ. Seine Augenlider waren ganz wund davon, und in Kopf und Gliedern lag dieser Schnupfen ihm wie eine schwere, schmerzliche Trunkenheit. ${ }^{172}$

Diese dramatisierende Beschreibung geht auf die stets im Hintergrund stehende Biographie des Dichters zurück; halb in erlebter Rede, halb aus der Position eines

\footnotetext{
${ }^{170}$ Mann 2004, S. 420.

${ }^{171}$ Ebd., S. 419.

172 Ebd.
} 
nullfokalisierten Erzählers wird darauf in einer rhetorischen Frage verwiesen, die der Autor selbst zu beantworten wüsste:

Oder war an all der Schlaffheit und Schwere das leidige Zimmergewahrsam schuld, das der Arzt nun schon wieder seit Wochen über ihn verhängt hielt? ${ }^{173}$

Demnach ist für das Verständnis seiner jetzigen, geplagten Lebensweise das Wissen vorauszusetzen, dass der Dichter in der Jugend manche Abenteuer durchgemacht hat. Beiläufig taucht der Stadtname „Jena“ auf: Dort hat das Spitzenjabot als Inbegriff seiner bürgerlichen Tätigkeit fungiert und ihn als seinen Träger legitimiert.

Auch wird zur Dramatisierung seines Leidens das Wetter mit einbezogen. Dies unterstreicht den kämpferischen Charakter des Dichters. Nun reizt die Kälte sein gesamtes Nervensystem, bis hinein in die gleichsam angeborene Quelle der sich geistig anstrengenden ästhetischen „Leuchtkraft", aus der sein be-geisterter Wallenstein hervorgeht, ${ }^{174}$ an dem er hängt und $\mathrm{zu}$ dessen Vollendung er niemanden $\mathrm{zu}$ Rate zu ziehen weiß. Selbst Gott, so scheint es, hilft ihm nicht: Ihn umgibt

ein miserables und hassenswertes Wetter, das man in allen Nerven spürte, wüst, finster und kalt, und der Dezemberwind heulte im Ofenrohr, verwahrlost und gottverlassen, daß es klang nach nächtiger Heide im Sturm und Irrsal und heillosem Gram der Seele. ${ }^{175}$

Darüber hinaus wird das Wahrgenommene vom Erzähler mit der genialen Eigenart des Dichters, mit seiner Leidenschaft und seiner intellektuellen Reflektion in Verbindung gesetzt. Die Verzweiflung, vor der er sich im Leiden hüten muss, lässt womöglich einerseits diese sentimentalische Dichternatur erkennen. Andererseits zeigt diese sich auch in seinem Streben nach einer Verwirklichung seines Ich, das empfangene Ideen und eigene Gedanken konkret zu gestalten strebt.

Es ist ein inneres Kampffeld, das uns in dieser Erzählung veranschaulicht wird, „die Stätte des Ringens“, an der das Genie unter seiner „geweihten Empfängnis“ leidet, dem Zugang zum Unendlichen des Seins, das so weit ist wie das als endlos

\footnotetext{
${ }^{173}$ Ebd.

${ }^{174}$ Vgl. Reed 2004, S. 296.

${ }^{175}$ Mann 2004, S. 419.
} 
empfundene Meer. Um dies austrinken (oder: künstlerisch ausformen) zu können, ist die Kraft eines Menschen zu schwach und ist ein Leben zu kurz.

Wenn ihn beim Arbeiten das körperliche Leiden übermannt und er ihm „,pathetisch“ (im Schillerschen Sinne) ${ }^{176}$ gegenübertreten will, sollte er davon Abstand nehmen, so wie er es in dieser Szene gerade tut. Über die Einbildungskraft hinaus ist für diesen Künstler zuweilen auch die Wissenschaftlichkeit notwendig, um die „ungeheuere Kunst“ zu konkretisieren. Aus Reeds Kommentar ergibt sich dazu eine psychologische Sicht auf einen Zweifel an seinem historischen Wissen, der den Dichter und Geschichtsprofessor der Jenaer Universität während der Arbeit an seinem Wallenstein überkommt wie seinen Autor selbst während dessen Arbeit an seinem Drama Fiorenza (auf das hier auch angespielt wird).

Die Schwierigkeiten, die sich dort ergeben, wo die Imagination und die historische Wissenschaft ineinander übergehen, dramatisiert Thomas Mann als „Bankrott“ bzw. Misserfolg bei der Vollendung von Wallensteins Lager. Dies bezeichnet Reed als den stilistisch-dramatischen Effekt von Thomas Manns Erzählstil, der meines Erachtens aus der erzählten Diegese heraus indirekt die sentimentalische Dichternatur als ihm und seinem Protagonisten gemeinsame Eigenschaft zu akzentuieren und sich gegen Alfred Kerrs abschätzigen Kommentar über sein historisches Wissen zur Wehr zu setzen versucht ${ }^{177}$ - wenngleich hier wohl auch dieselbe geheime Zaghaftigkeit dem Kritiker gegenüber zu erkennen ist, die in der Erzählung als diejenige des erzählten Dichters unter Kollegen fiktionalisiert ist. Hier wie dort wird das Imaginationsvermögens des Dichters betont; diesbezüglich ist hinzuweisen auf die Verhältnisse des Dichters am Schreibtisch als seinem ganz bürgerlichen Arbeitsplatz, wohin er ,aus dem Freibeutertum des Geistes“ mit Elan gegangen ist. ${ }^{178}$

Die Kritik an der „trockenen und schwunglosen“ Wissenschaftlichkeit der Arbeitskollegen gilt implizite auch für die Situation des Autors, der beim Verfertigen historischer Heldendramen wie des Don Carlos oder eben des Wallenstein eine „ungeheure Kunst" beweist, ${ }^{179}$ für die die Einbildungskraft eine ebenso wichtige Rolle spielt wie die Geschichtskenntnis. Bleibt die Letztere im wissenschaftlichen Diskurs ohne jene „Leuchtkraft“, ohne ein „genialisch leidenschaftliches Licht“, so dass sie merklich „unedel und kalt“ auf das Publikum wirken muss, so kann der

\footnotetext{
${ }^{176}$ Das Wort fällt in Thomas Manns Erzählung nebenbei: „Gesund genug sein, um pathetisch zu sein - um über das Körperliche hinwegsehen, hinwegfühlen zu können!“`Mann 2004, S. 424.

${ }^{177}$ Ebd., S. 421.

${ }^{178}$ Mann 2004, S. 422.

${ }^{179}$ Ebd., S. 421.
} 
Dichter die Gestalt des Wallenstein mit seinem eigenen Schwung auf die Schaubühne bringen.

Gerade weil es hier um die schöpferische Imagination des Künstlers geht, wird exemplarisch Wallenstein als das Leidenswerk Schillers dargestellt. Das Leiden an der Arbeit scheint endlos, und der Dichter muss sich durchs Leben kämpfen. Denn das Werk ist sein Leben, und zwischen beiden befindet sich nur „Leiden“. Um „den Sieg“ über dieses Leiden zu gewinnen, wie er es schon einmal mit dem Don Carlos geschafft hat, ringt Schiller mental mit der „Finsternis“ um das geniale „Licht“ seines Gemüts und mit der „Lähmung“ des Auslösers, seiner schöpferischen Kraft, wie er sie nun im Wallenstein bewusst und erlebt zu Darstellung bringt:

Nein, es mißlang, und alles war vergebens! Die Armee! Die Armee hätte gezeigt werden müssen! Da sie nicht vors Auge gebracht werden konnte [...] Die Anlage war falsch, und die Sprach war falsch, und es war ein trockenes und schwungloses Kolleg in Historie, breit, nüchtern und für die Schaubühne verloren! ${ }^{180}$

Darüber hinaus ist in Schwere Stunde im Hinblick auf die Eigenschaften des Künstlers und den Lebensstil Schillers ein Vergleich mit Eigenschaften und dem Lebensstil Goethes naheliegend. Dieser warnt Schiller ja vor dem Genuss von Kaffee und Likör, die ihm zwar körperlich und vielleicht auch gedanklich dazu verhelfen, alle „Hemmnis“ beim Dichten zu überwinden, aber keine weise Lebensart darstellen, wie Goethe sie praktiziert:

[...] der Andere, der dort, in Weimar, dn er mit einer sehnsüchtigen Feindschaft liebte. Der war weise. Der wußte zu leben, zu schafffen; mißhandelte sich nicht; war voller Rücksicht gegen sich selbst... ${ }^{181}$

Im Gegenteil dazu ist dem Dichter, wesensbedingt, eine andere künstlerische Form eigen, die seinem Freund Goethe jene „fünf Jahre“ Mitleid und Mitgefühl erregt hat. Aber sie legitimiert doch die eigenste Künstlernatur des Dichters, ${ }^{182}$ die in der Zucht und im Leiden glühend zum Vorschein kam und ihr Schwebespiel über dem

\footnotetext{
${ }^{180}$ Ebd.

${ }^{181}$ Ebd., S. 421.

${ }^{182}$ Vgl. Mann 1960.
} 
Werk entfaltetet: Der Dichter hat unter seiner Sphäre gelitten, die in dieser Erzählung als „leidiges Zimmergewahrsam“ der Ich-Zucht bildlich dargestellt wird. Die Darstellung des Arbeitszimmers in Jena, das „kahl, nüchtern und unbequem“ erscheint und szenisch als „Stätte des Ringens“ mit seinem „Monstre-Werk“ geschildert wird, ${ }^{183}$ wird hier in einen Zusammenhang mit der Krankheit des Dichters gebracht und erscheint geradezu als der Inbegriff seiner körperlich und seelisch anstrengenden Zucht.

Daraus geht nun das eigenständige, ästhetisch und ethisch souveräne Ich hervor, das sich über sein physisches und psychisches Leiden erhebt und dieses Leiden zum Thema seiner Dichtung macht. Dieses Licht war seinem Freund Goethe schon in seiner Natur zu eigen gewesen, wenn er, „,der unmittelbar und mit göttlichem Mund die besonnten Dinge beim Namen nannte“, ohne die Zuhilfenahme der Kerzenflamme aus seinem inspirierten Geist heraus dichtete. Dies ist die enorme Differenzierung, die hier in der kleinen Erzählung zwischen dem fiktiven Schiller und der anderen freundschaftlich mit ihm verbundenen und kreativen Lichtgestalt der deutschen Literaturgeschichte angedeutet wird.

Der bürgerlichen Existenz des Dichters als Geschichtsprofessor wird diejenige exemplarisch und spekulativ gegenübergestellt, die er in philosophischer Spekulation und deshalb als ein sich vorübergehend seiner dichterischen Praxis enthaltender Vagabund in den geplagten Jahren durchlebte. Die Frage nach dem Warum führt tief hinein in Thomas Manns Spekulation über den Genius des Dichters überhaupt: ${ }^{184}$ die Frage, ob der Mann mit Amt und Familie nun jenen kindlich-genialen Schöpfergeist noch im Blut hat.

Jener Moment der meditativen Anstrengung eines Geistes, der ganz in sich versunken und auf sein Arbeiten konzentriert ist, wird sowohl in dieser Erzählung als auch im Versuch über Schiller herausgehoben, um jenen „Erkenntnisekel“ eines artistischen Dämons gegenüber dem dilettantischen Selbstverständnis kritisch und anschaulich in den Vordergrund der künstlerischen Spekulation zu stellen. Im Versuch über Schiller bezeichnet Thomas Mann diesen Moment ausdrücklich als „Schwere Stunde! ${ }^{6185}$

Das geistige Licht, das Schiller um der Bewältigung seines Wallensteins willen erreicht, zeichnet diesen Dichter in der Opposition zum bloßen Dilettantentum als

\footnotetext{
${ }^{183}$ Vgl. ebd., S. 913.

${ }^{184}$ Vgl. ebd., S. 881.

${ }^{185}$ Ebd., S. 913.
} 
einen sentimentalischen Künstler aus, der über jeden Verdacht erhaben ist. Die spekulative, „verzweifelte Wahrheit“ entsteht aus den fünf Jahren des Elends, die im Text als „Nichtigkeit““ und zugleich als Reichtum und eine Zeit der Fruchtbarkeit seines erhabenen Geistes bezeichnet werden. Die historische Richtigkeit dieser Darstellung ist hinsichtlich der Jugendzeit und besonders der Rekrutenausbildung des Dichters nicht mehr zu bezweifeln. ${ }^{186}$ Diese unbezweifelbare Wahrheit, die der Dichter bewiesen hat, ist die des Reinigungsprozesses des Geistes, seine Erhebung zur philosophischen Ideal-Sphäre und zur künstlerischen Produktivität dieser Schweren Stunde. Es gelingt ihm, sich von sinnlichen, geistigen und sogar körperlichen Fesseln freizumachen, die symbolisch und begrifflich in der Erzählung dargestellt werden: Leiden, Sinnesglut, verstandesgemäße und intellektuelle Begriffe. ${ }^{187}$ Somit wird ihm anstelle einer arglosen Künstlernatur im Sinne des Genie-Konzepts das zu eigen, was der Dichter selbst als „Kunstmäßigkeit zur Natur“ bezeichnet. ${ }^{188}$

Es wird damit m. E. eine Doppelperspektive auf das Verhältnis des Dichters zu seiner Kunst eröffnet. Zugleich geht es dabei um die Bestrebung des künstlerisches Wesens, ganz mit dem bereits durch seinen eigenen Geist gebändigten natürlichen Ursprung zu verschmelzen. Überdies kann man von einem Kreis des Ringens um die unter der Wirkung der Naturmächte erkämpfte, gegen die allen anderen Tätigkeiten übergeordnete, ausnahmsweise im Spiel willenlose Freiheit von allen vitalen Bindungen und Begriffen sprechen. Durch deren Verschmelzungsmoment wird der Künstler in seinem ganzen Wesen spielerisch gefasst und erscheint wie ein mit seinem Spielzeug spielendes Kind, das seiner kindlich-spontanen Natur gemäß ganz außer aller Begrifflichkeit und Fassung ist, die es vom Spiel mit Spielzeug abhalten könnten. ${ }^{189}$

Er will als Kunst-Wesen ganz Spieler, ganz geniales Kind sein, wie dies in der Perspektive der Erzählung das Wesen seines Freundes Goethe ganz und gar gewesen ist. Oder besteht ein Schwebezustand des Geistes, in dem er voller Liebe und Ruhe das Gespielte beobachtet und erzieherisch das Spiel steuert? Man könnte diese Sphäre als übergenial bezeichnen. Im Zustand der Willenleere erst wird als allerletzter Willensdrang die Liebe zur Menschheit fassbar, eine Liebe, deren handlungsloser „Beglückergeist“ nicht mehr in der Leiche im Grab, sondern nur in den gleich-

\footnotetext{
${ }^{186}$ Mann 2004, S. 422.

${ }^{187}$ Vgl. Mann 1960, S. $881 \mathrm{f}$.

${ }^{188}$ Ebd., S. 882.

${ }^{189}$ Vgl. Mann 1960, S. 882.
} 
sam über der Menschheit schwebenden „Lichtesspuren“ spürbar ist, wie dies in der Schweren Stunde andeutet ist. ${ }^{190}$

Dieses Licht, das ein anderes ist als dasjenige einer „konventionellen Glorie“ und ihres „himmelblau-idealistischen Nimbus“, ${ }^{191}$ hätte der Dichter in den folgenden Sätzen implizit vorausgesehen - er, der bereits damals vom Herzog Carl August und von Goethe anerkannt wurde, aber nun erst, nach seinem Tode, als Held bezeichnet werden kann, als nun ewiger, zugleich gebändigter und freier Stern über der Nation. ${ }^{192}$ Fast sein ganzes Leben lang hat er sein Leiden und seine Verzweiflung am Dasein ertragen, um dann mit seiner werdenden „Glorie“ in das deutsche Land und darüber hinaus ausstrahlen zu können.

In seiner Erzählung lässt Thomas Mann ihn selbst explizit darüber reflektieren:

Ich sehe mich jetzt erschaffen und bilden, ich beobachte das Spiel der Begeisterung, und meine Einbildungskraft beträgt sich mit minderer Freiheit, seitdem sie sich nicht mehr ohne Zeugen weiß. Bin ich aber erst so weit, daß mir KunstmäBigkeit zur Natur wird, wie einem wohlgesitteten Mensch die Erziehung, so erhält auch die Phantasie ihre ewige Freiheit zurück und setzt sich keine andern als freiwillige Schranken. ${ }^{193}$

Der Versuch des Dichters, sich von Begriffen und Bindungen zu befreien, die hier als überwundene „Schranken“ bezeichnet werden, reicht nach Thomas Manns Versuch über Schiller biographisch zurück in die „Leidens- und Prüfungsjahre“ Schillers. ${ }^{194}$ Aus ihnen geht eigentlich der ewige und von Liebe bewirkte Sieg des „Helden“ auf der höchsten Stufe des Geistes hervor - jener Stufe, auf der Schiller die das Instinktive reinigende Kunstwirkung wieder erkannte und anerkannte und sich sodann als humanistisch wohlerzogen und klassischen Maßstäben gerecht werdend in Begleitung seines Freundes Goethe darstellen konnte.

Der Sturm und Drang der melancholischen Gefühle, die das von Zweifeln begleitete Leiden und die Rücksichtslosigkeit gegenüber der Gesundheit verursachen, sind grundlegend für einen leidenschaftlichen Dichter, sie müssen aber anderseits gebändigt werden. Denn der Drang zu einer besseren Kunstform, der als ursprüngli-

\footnotetext{
${ }^{190}$ Ebd., S. 873.

${ }^{191}$ Ebd.

192 Mann 2004, S. 367.

${ }^{193}$ Mann 1960, S. 882.

194 Ebd.
} 
che Anlage in seinem Talent lebt, entwickelt sein „zartes Instrument“ weiter und weiter zu jener „echten Souveränität“ des eigenes Geistes, bis er neben dem Intuitiven seines Freundes in gleicher Größe auf dem gleichen Rang stehen kann.

Über diese beiden Dichtarten schreibt der Dichter selbst in seiner großen Abhandlung Über naive und sentimentalische Dichtung. Sie ist ,geistvoll wie nichts in der Welt“, kommentiert Thomas Mann abschließend in seinem Versuch über Schiller. 


\subsubsection{2 „Talent“ als Grundbedürfnis nach schöpferischer Form}

In einem ganz kurzen, aber für unser Thema wichtigen Aphorismus aus dem Jahr 1912 formuliert Thomas Mann unter der Überschrift Talent den folgenden allgemeinen Gedanken:

Das Talent ist nichts Leichtes, nichts Tändelndes, es ist nicht ohne Weiteres ein Können. In der Wurzel ist es Bedürfnis, ein kritisches Wissen um das Ideal, eine Ungenügsamkeit, die sich ihr Können nicht ohne Qual erst schafft und steigert. Und den Größten, den Ungenügsamsten ist ihr Talent die schärfste Geißel. ${ }^{195}$

Dieser Aphorismus ist wörtlich der Erzählung Schwere Stunde entnommen und wird hier zur allgemeinen Sentenz erhoben. ${ }^{196}$ Die körperliche Quälerei unter dem glühenden Drang zur Bewältigung des mächtigen Stoffes besagt viel über das Talent des siebenunddreißigjährigen Dichters. Die Figuration seines ganzen gebrechlichen Körpers kommt dem spekulativ entwickelten Verständnis über künstlerische Begabung nahe. Wie ein lebender Leichnam wird der Dichter geschildert, wie er vom wärmenden Ofen schmerzlich und verzweifelt zu seinem Werk hinüber blinzelt. Sein ganzer Körper sieht aus wie derjenige eines Toten, der aber noch lebt, „tragisch“vielleicht auch Goethe gegenüber.

Es scheint, als wartete er auf eine blitzschnelle Erleuchtung seines Wissens, die buchstäblich als Intuition zu bezeichnet wäre. Die aber wird ihm erst dann gegönnt, wenn der Geist unabhängig vom leidenden Körper ist, wenn er diesen unterdrückt und keiner der doch bestehenden Schmerzen im ganzen Körper empfunden wird so dass der Geist ganz auf den dichterischen Stoff konzentriert ist und nur in diesem Wunder-Moment intuitiv und unmittelbar empfänglich ist für die Sendung jenes Lichts. Dann erst kann er den gewussten Stoff geistig gestalten. Könnte dies von einem meditativ-intuitiven Arbeitsprozess gesagt werden, in dem nichts anderes als die befehlende Stimme klänge, wenn doch Thomas Mann diese Krankheit später im

\footnotetext{
${ }^{195}$ Essays I, S. 364. Vgl. im Kommentarband dazu S. 473f.

196 „Denn das Talent, meine Damen und Herren dort unten, weithin im Parkett, das Talent ist nichts Leichtes, nichts Tändelndes, es ist nicht ohne Weiteres ein Können. In der Wurzel ist es Bedürfnis, ein kritisches Wissen um das Ideal, eine Ungenügsamkeit, die sich ihr Können nicht ohne Qual erst schafft und steigert. Und den Größten, den Ungenügsamsten ist ihr Talent die schärfste Geißel..." Mann 2004, S. 424.
} 
Versuch über Schiller als erste praktische Übung des zu verfeinernden, zu sensibilisierenden Geistes betrachtet, der von kindlicher Natureinfalt zum Licht des Gedankens geführt werden muss, um kein Dilettant mit bloß wissenschaftlich-kaltem Wissen zu werden? ${ }^{197}$ Und ist es vielleicht wiederum eine Krankheit, eine Unterwerfung und Bändigung der Natur im genialen Sinn, die den beiden kreativen Lichtgestalten Goethe und Schiller gemeinsam ist?

Gesund genug sein, um pathetisch sein - um über das Körperliche hinwegsehen, hinwegfühlen zu können! Nur hierin [im Stoff] naiv sein, wenn auch sonst wissend in allem! Glauben, an den Schmerz glauben können... Aber er glaubte ja an den Schmerz, so tief, so innig, daß etwas, was unter Schmerzen geschah, diesem Glauben zufolge weder nutzlos noch schlecht sein konnte. ${ }^{198}$

Die spekulative Leistung des genialen Talents geht nämlich über das menschliche Leiden, die rohe Natur hinaus bis in die schöpferische Beschaffenheit des begeisternden Lichtes, das von leidenschaftlichem Drang, körperlicher Leidenszucht seiner rohen Natur und bewusster Disziplin im eigenen Ich bedingt ist.

Das geniale Licht, das ein Dilettant nicht besitzen kann, quillt sozusagen aus dem tiefsten Bedürfnis ,im Parterre“ des wissend-skeptischen und idealistisch ungenügsamen Talents, in dem das im Leiden an der Verbesserung der wirklichen Wahrheit der eigenen Sendung glühende, unauslöschliche Feuer, die alle rohe Natur bändigende „Lohe“ aufgeht, um dann im Übergang von der den Künstler ausmachenden, leidenschaftlichen Flamme ins reine Licht den Geist zu erlangen, der den „Stümpern und Dilettanten“ einschließlich der bloß wissenschaftlich-kalten Menschen fehlt, die noch nie diesen „schärfsten“ Geißelschlag in sich empfunden haben. Es ist die Grundlage jener „Lohe“ um des genialen Lichts willen. ${ }^{199}$

Wenn dies auch aus der Sicht Goethes bloß als eine unvernünftige gesundheitliche Selbstquälerei erscheint, die ,ppathologische Stellen“ Schillers widerspiegelt, ${ }^{200}$ so handelt es sich in Absetzung vom dilettantischen Selbstverständnis doch eher um eine heroische - im Sinne Schillers: um eine ,pathetische“ - künstlerische Selbstverwirklichung eines um die Veredelung seines natürlichen Stoffes ringenden wah-

\footnotetext{
${ }^{197}$ Vgl. Mann 1960, S. 882.

${ }^{198}$ Mann 2004, S. 424.

${ }^{199}$ Ebd., S. 425.

${ }^{200}$ Vgl. Mann 1960, S. 914
} 
ren, menschlichen, poetischen Geistes in der Ich-Ideal-Sphäre, ${ }^{201}$ eines Geistes, der sich zur Ausgestaltung der in seiner Sinnenwelt vereinzelten natürlichen Erscheinungen mit Ideen plagt, bis er in sich alle Fratzenphänomene in der Poesie getilgt hat. ${ }^{202}$ Nicht die Fratze eines Mannes mit einem bloßen „Affentalent“ will er sein, wie er unter Dilettanten zu finden ist, sondern ein edles und erwachsenes „Kind im Manne“ mit einer geläuterten, menschlich wahren, gemüthaft sanften und sittlichen Natur. ${ }^{203}$

Die Aufzehrung der körperlichen Natur und die uneigennützige Aufopferung zu dieser abgeschlossenen Größe, die in der Not entsteht, wo die absolute, erwachsene und folglich gefasste Idee im Übergang ins Kindlich-Ungefasste ist, verbinden sich in diesen um seine Grenze ringenden menschlich-genialen Geist, in seinem kindlich-unschuldigen, subjektiv-moralisch rettenden, „treuen Gemälde““. ${ }^{204}$ Hier treffen sich poetisch-ästhetische Ich-Kraft und wissenschaftliche Logik auf der höchsten Stufe des Geistes, der willig über die durch das persönliche Geheimnis bedingte „diskrete Indiskretion der Kunst“ eintritt in die von Schiller aufgesuchte gleichsam übergeniale (natur-göttliche) Wesenssphäre (hier bietet sich ein Vergleich mit dem Buddhismus an), der die Materie beseelt und im wörtlichen Sinne be-geistert.

Er trägt die Gestalten in sich, er thront in seiner siegreichen, höchsten Kälte gegenüber den Begrenzungen der bloßen Wissenschaftlichkeit objektiv in und hinter dem Werk, so wie die Gottheit in und hinter dem Gebäude der Kirche thront. Nur intuitiv und subjektiv-ästhetisch wird er erspürt; niemals macht er sich seinen Rezipienten gleich. ${ }^{205}$ Gerade so bleibt er die gemeinte Größe ${ }^{206}$ wie die Kindheit entfaltet sich seine Sittlichkeit hinter den Bildern, zumeist über Leiden und Verzweiflung hinweg. Erst hier begegnet der sentimentalische Dichter diesem natürlich-göttlichen Zustand, nach dem - wie Thomas Mann im Versuch über Schiller spekuliert - der Dichter strebt. Erst hier neigt er sich wieder zur Seite Goethes, der gottgleich Gestalten schuf:

Und dies war seine Eifersucht: daß niemand größer werde als er, der nicht auch tiefer als er um dieses Hohe gelitten.

\footnotetext{
${ }^{201}$ Vgl. Schiller 2005, S. 497.

${ }^{202}$ Schiller 2005, S. 497.

${ }^{203}$ Mann 1960, S. 881.

${ }^{204}$ Schiller 2005, 497.

${ }^{205}$ Vgl. ebd., S. 453.

${ }^{206}$ Ebd.
} 
Niemand!... ${ }^{207}$

Selbst in der Abhandlung Über naive und sentimentalische Dichtung findet sich eine ausführliche Beschreibung jenes dichterischen Genies in der Jugendwelt. Und wenn in Thomas Manns Tonio Kröger über das „Aufs-Eis-Legen“ der Empfindung spekuliert wird, das für das Genie zur Voraussetzung für das Dichten wird, dann wird auch dort die übergeniale Natur folgendermaßen erstrebt:

Nichts erwidert er [der Dichter], nichts kann ihn schmelzen oder den strengen Gürtel seiner Nüchternheit lösen. Die trockene Wahrheit, womit er den Gegenstand behandelt, erscheint nicht selten als Unempfindlichkeit. Das Objekt besitzt ihn gänzlich, sein Herz liegt nicht wie ein schlechtes Metall gleich unter der Oberfläche, sondern will wie das Gold in der Tiefe gesucht sein. Wie die Gottheit hinter dem Weltgebäude, so steht er hinter seinem Werk; er ist das Werk und das Werk ist er; man muss des erstern schon nicht wert oder nicht mächtig oder schon satt sein, um nach ihm nur zu fragen. ${ }^{208}$

Diese Göttlichkeit des geistigen Zustands des Dichters, der ebenfalls in der Erzählung von der Schweren Stunde thematisiert ist, wird in Verbindung mit Dichtart und Dichtprozess der beiden großen Dichter Goethe und Schiller gebracht, und zwar, wie mir scheint, zur Differenzierung der beiden Genies aus ihrer jeweiligen Jugendwelt heraus mit jenen Kategorien, die Schiller in der oben genannten Schrift behandelt hat, dem „Naiven“ bzw. „Sentimentalischen“.

Die oben genannte übergeniale Geistessphäre sowie die göttlich-kalte Erscheinung der Persönlichkeit des Genies, „Homers unter den Alten und Shakespeares unter den Neuern“, 209 sind

zwei höchst verschiedene, durch den unermesslichen Abstand der Zeitalter getrennte Naturen, aber gerade in diesem Charakterzuge völlig eins. ${ }^{210}$

\footnotetext{
${ }^{207}$ Mann 2004, S. 425.

${ }^{208}$ Mann 1960.

${ }^{209}$ Ebd., 452.

${ }^{210}$ Ebd., meine Hervorhebung.
} 
Die vergebens gesuchte Herzlichkeit, die ,kalte' Empfindung im Werk z. B. Shakespeares, denen Schiller begegnet und die ihn faszinieren, die er bewundert, sind gemeint mit jenem übergenial-normativen Geist als dem natürlichen Vorbild des früheren Genies, das hinter seinem Werk zu ahnen ist wie der Naturgeist hinter den Naturerscheinungen, im Jenseits der Vernunft und des Verstandes des Publikums.

Der ,übergeniale' Geist existiert sozusagen auf einer höheren Entwicklungs- und Reflexionsstufe des ursprünglich Genialen, wo er in jedem natürlichen Gegenstand begriffen ist, der ganz objektiv existiert und nicht von subjektiver Bewertung bedingt ist, wie die Natur bzw. Gegenstände, die nur bloß subjektiv als schön oder hässlich empfunden werden, ohne sich selbst nach der Betrachtungsweise des Betrachters zu richten.

Der in diesem Sinne vergeistigte geniale Geist des Genies bleibt deshalb ebenfalls objektiv. Wie er ,eigentlich ist', bleibt außerhalb unseres Fassungsvermögens, denn er gleicht der dem Menschen begegnenden Natur. Im eben zitierten Abschnitt wird dieser ,übergeniale' Zustand deutlich erkennbar, der nicht mit dem ursprünglich genialen zu verwechseln ist. Genial ist demgegenüber für meine Begriffe ein praxisbezogener, funktionaler und bewusster Akt des Genies, wie wenn man den aus dem genialen Impuls kommenden Pinselstrich eines Künstlers betrachtet.

Meines Erachtens ist die übergeniale Sphäre ein Zustand, in dem das Geniale ruht und schaut, nachdem es „die trockene Wahrheit“, die unbeseelten Gegenstände, die Stoffe mittels des Geistes gestaltet hat. Dieser übergenial-normative Geisteszustand markiert einen grundlegenden Unterschied gegenüber dem, wovon im folgenden Kapitel über Ein Wunderkind zu handeln ist: Dort wird meiner Meinung nach ein moderner, übergenial-autonomer Geist mit einem kindlich-spielerischen Gemüt dargestellt. 


\subsubsection{Goethe und Schiller - „naiver“ und „,sentimentalischer“ Dichter}

Auf jeden Fall ist die höchste Geistessphäre als dem Göttlichen nahe zu denken. Dies ist es, wonach Goethe und Schiller, als menschliche Dichter, immer wieder strebten. Die Unterscheidung der beiden Aspekte besteht zwar darin, dass das Genie menschlich und geschöpflich war und bleibt. Allerdings versucht Schiller, durch den Funken göttlicher Genialität in sich selbst, mit der empfangenen Sendung auch die anderen „Sendungslosen“ zu begeistern:

Zuweilen brauchte er nur seine Hand zu betrachten, um von einer begeisterten Zärtlichkeit für sich selbst erfüllt zu werden, in deren Dienst er alles, was ihm an Waffen des Talentes und der Kunst gegeben war, zu stellen beschloß. ${ }^{211}$

Wie der im Innersten sanftmütig-kindliche Künstler, leidenschaftlich Empfangende und Begabte von seiner Natur entflammt wird, zeigt Der kleine Herr Friedemann. Hier aber ist ein wahrer Dichter-Held am Werk, der sich in seinem genialen Arbeitsprozess quält, um in jene höchste Sphäre des Geistes zu gelangen.

Diese Fragen, in denen Thomas Mann das sentimentalische Genie Friedrich Schillers reflektiert, weil er selber ein solches ist, gehen auf die unterschiedlichen Reflexionen der Genieästhetik im Werk der beiden deutschen Dichter zurück, die selbst als Repräsentanten des naiven bzw. des sentimentalischen Dichtens gelten. Die Begriffe sind in großem Abstand zur eigenen Jugendzeitalt entstanden, und Schiller selbst nahm an, es gäbe nur diese beiden Arten ihrer Unterteilung. ${ }^{212}$ Jenseits der „Zucht“ und „Selbstüberwindung“ versucht der Dichter, bildlich dargestellt, das um einen Satz, um Bild und Gestalt des „Absoluten“ mit feuriger Leidenschaft ringende Arbeiten darzustellen, ${ }^{213}$ und er leidet an seinem heroischen Künstlertum, dem „,blutenden Trotzdem“ des „Talents“, in dem allein er sich als „Held“ beweisen kann. ${ }^{214}$

Seine zur Formung, zur Gestaltung, zur Begrenzung und zur Konkretisierung der von ihm erkannten absoluten Ideen aufzubringende musikalische und poetische Kraft zielt voller Eifer und Leidenschaft darauf, die in seinem tiefsten Inneren ge-

\footnotetext{
${ }^{211}$ Mann 2004, S. 425.

${ }^{212}$ Vgl. Schiller 2005, S. 452.

${ }^{213}$ Ebd., S. 455.

${ }^{214}$ Ebd.
} 
staltete rohe Natur mit seinem erkennenden Geist der Menschheit als „Urbild des Seins“ vor Augen zu stellen. Sie zielt auf eine Einheit der Menschheit im Ganzen. Sein glühender dichterischer Geist sucht in seinem Werk die vereinzelten Menschen hineinzuführen in die melodiöse Unendlichkeit der göttlich-liebevollen Botschaft was immer nur relativ und vorläufig machbar ist. Sie entspringt aus seinem schonungslos ausgelebten, zarten „Instrument“; auf ihren Empfang ist sein ganzes körperliches Organ ausgerichtet.

Denn das Wissen und die Wissenschaft dienen dem Dichter ausschließlich als „Mittel und Vorwände“, mit denen er seine seiltänzerische Gestalt im „verborgenen Saitenspiel“ zur heiligen Form, zur Freiheit, zur Bildung der Menschheit bewegt. So entsagt der dichterisch Schaffende selbst dem menschlichen Glück, „dieser seidenen Fessel“", und ist innerlich entfernt auch von seiner Frau, die den doch auch vom Genie selbst als verpflichtend empfundenen Weltlauf weiter fortführt und die in seiner schweren Stunde im Bett liegt und schläft.

Einerseits geht es also um ein Lebenswerk, andererseits aber um die das Genie voran peitschende Leidensbahn eines Störers der etablierten Grenzen, der zusammen mit seinem Freund Goethe, dem „Göttlich-Unbewussten“, als erkennender „Held, der Friedrich Schiller heißt“, seinen Dienst tut, mit Goethe gemeinsam in wechselseitiger Bedingtheit dazu beiträgt, das Lebensrad der Menschheit weiter zu drehen, und dessen aufopfernde, sich selbst schädigende Heldentat den poetischen Geist des Liedes von der Glocke hervorbringt: dies ist es, was in dieser Mosaikskiz$z e$ Thomas Manns beleuchtet wird. ${ }^{215}$

\footnotetext{
${ }^{215}$ Muncker 1906, S. 247.
} 


\subsection{Zur Künstlerproblematik in Das Wunderkind}

\subsubsection{Der ,übergeniale' Zustand des Künstlers in Das Wunderkind}

Thomas Manns Besuch des in München veranstalteten Klavierkonzert eines wirklichen, aus Griechenland stammenden Wunderkindes, Loris Margaritis regte ihn zur Gestaltung der Knabenfigur Bibi Saccelaphylaccas in seiner kleinen Erzählung an. Es handelt sich um eine Figur, die einen Blick auf die Charakterzüge des genialen Künstlers bzw. Dichters und seiner artistischen Gekonntheit öffnet, die sogar in die Geschichte des Genies zurückreicht, von der Goethezeit bis in die Moderne.

Die Spekulation über Kunst und Geld steht unmittelbar dem Diskurs über den konventionellen Begriffsgebrauch des genialen Talents und der Moral gegenüber. Darüber hinaus vermeidet dieser kindliche Virtuose äußerst offenkundig und reflektiert jeden künstlerischen Schicksalsschlag jener Künstler, die in der deutschen Genieästhetik und ihrer Transformation in der Weimarer Klassik mit der Geißel Gottes lebte. Sogar den beiden großen deutschen Dichtern Goethe und Schiller könnte dieses begabte Kind hinsichtlich seiner Virtuosität, mit seinem deutlichen Abstand zu Schmerz und Verzweiflung beinahe eins auswischen, wenn man dabei an Goethe als einen im Sinne der eben untersuchten Erzählung Schwere Stunde „göttlich-unbewusst“ schaffenden und an Schiller als einen „,sentimentalischen“ Künstler denkt.

In diesem als modernes Modell des Artistischen im Kindesgewand dargestellten Wesen realisiert sich in der übergenialen Sphäre ganz das geniale Licht, das anbricht und sich diesem kleinen Griechen gleichsam in seinem Körper zur Hervorbringung einer ,genialen' Schöpfung anbietet. ${ }^{216}$ In der Tradition wird es teils im Hinblick auf Gott, teils im Hinblick auf den Geist diskutiert. Über jene Sphäre möchte ich zwei Gesichtspunkte klarstellen, die sogleich das Bild vom genialen Licht differenzieren, auch wenn sie auf denselben übergenialen Geist hin ausgerichtet sein können.

\footnotetext{
${ }^{216}$ Mann 2004, S. 369.
} 
Die erste Art ist meines Erachtens diejenige, die von Schiller in Schwere Stunde angestrebt wird: eine meditativ-geniale Form des künstlerischen Schaffens, die den Versuch eines Übergangs zur Seite Goethes, also zum intuitiv-spontanen Schöpfungsprozess des Natur-Genies darstellt. Dabei werden der Schöpfungsgeist der Natur und die von ihm hervorgebrachten Naturerscheinungen bewusst erkannt, durchschaut und reflektiert; die Reflexion kommt erst an jenem Punkt zur Ruhe, an dem es um die Fähigkeit zur Begeisterung geht. Kurz gesagt: Hier geht es um einen $\mathrm{zu}$ erreichenden ,göttlich-genialen' Geisteszustand in der komplex gewordenen Kultur, der die einstige Spontaneität des ,Genies' in der Jugendwelt fehlt. ${ }^{217}$

Die zweite Variante ist in dieser modernen Prosa zu finden; sie nenne ich die spielerisch-übergeniale. In ihr produziert der Künstler sein Werk jenseits von Schmerz und Verzweiflung: Er spielt mit dem „Talent“, er berechnet Wirkung und Erfolg und lügt vielleicht auch ein bisschen. Dafür gibt „das Wunderkind“ ein Beispiel. Es schwebt über Leiden und Reflexion, denn es ist einfach ein begabtes Kind, dessen Artistik reflektiert an die Geistigkeit Wagners und Nietzsches anknüpft - an die Kritik des Letzteren an dem Ersteren, und an das Spiel des Ersteren mit dem ursprünglichen Göttlich-Intuitiven.

Was in Thomas Manns Erörterungen zu kurz kommt, ist diejenige Natur des Genies überhaupt, die darin besteht, dass in einem produktiven Menschen beide Geisteszustände, der naive und der sentimentalische, gemischt vorkommen können, dass der Mensch also einmal sentimentalisch und dann wieder naiv sein kann. Beides könnte von den oben genannten Dichtern und Denkern gesagt werden. Das aber, was ihnen fehlen könnte, ist dieser kindlich-spielerische, ewig-übergeniale Schöpfungsgeist, der im Kind stabil bleibt und ein „Wunder“ darstellt. Ein Erwachsener hingegen kann diesen Zustand nur vorübergehend in den Griff bekommen, denn auch der Geist selbst ist in der Moderne komplexer geworden wie die ihn umgebenden Kultur; er kann folglich nicht mehr kindlich-intuitiv und schöpferisch-naiv bleiben.

Dies hat Thomas Mann im Wunderkind erkannt, deshalb gibt er uns mit ihm eine Anschauung davon, wie riskant sein unschuldiges, artistisches Spiel sein kann, wenn es unreflektiert vom Kind im Manne ausgeübt wird. Jedenfalls fehlt es den sentimentalischen Künstlern Schiller oder Nietzsche, weshalb sie dem Leiden und der Selbstquälerei ausgeliefert bleiben. Womöglich könnte sie dieses wunderbare, 
kindlich-geniale Geistesmoment heilen, das bei erwachsenen Dichtern und Denkern freilich nur intellektuell und kontemplativ bedingt sein könnte, verbunden mit Maske oder Lüge: eine bloße Spielerei mit einer wahren eigenen Eigenschaft. Zwar wird die Not getilgt, doch Maske und Lüge bedecken das Wahre, das einem oder mehreren schaden könnte. Und dies alles gehört zum Künstlerischen, das die starre und öde, trockene und unbewegliche ,wahre Natur“ schöner macht und verklärt. Alles andere objektiv Schuldige der Verstellung und des Spiels ist sekundär; es erweist sich als vital für einen schöpferischen Geist. Zwar schwebt der subjektiv unschuldige Künstler über dem schuldigen Tun allein subjektiv gerettet, als ob er sich dessen nicht bewusst wäre, aber gerade so wirkt seine Arbeit auf die Massen.

Geld und Gaben besaß Thomas Mann selbst ja ganz zweifellos. Es ist der Drang zur Größe und die eigene Not auch hinsichtlich seiner Mittel, wenn er in dieser Prosa den Wunder-Knaben mehr oder minder mit seiner Augenwischerei in Sachen der künstlerischen Moral vorführt und ihn doch auf seine Weise als genialen Ästheten zeigt. Ganz rein persönlich und subjektiv unschuldig kommt der artistische Pianist jener Genialität gleich, die einer traditionellen Genieauffassung zufolge jenseits des objektiven Verstandes existiert; er teilt sein Wunder jedem im Publikum mit und lindert das Leid am Leib und in der Seele, wenn er die „Majestät der Genußseligkeit“ in der „gaité“ der Moderne aufweist und unschuldig in seiner Knabenhaftigkeit eben um sie kreist. ${ }^{218}$

${ }^{218}$ Vgl. Mann 2004, S. 398. 


\subsubsection{Textanalyse}

\subsubsection{Der (Ver-) Kauf der Kunst}

Es beginnt reflexiv mit der Stille im Konzertsaal. Die Leute klatschen in die Hände, sogar bevor Bibi Saccellphylaccas die Bühne betritt und noch ehe sie eine Melodie gehört haben: Der griechische Knabe gerät als Werbe-Objekt in die ästhetischökonomische Maschinerie der Reklame,

[...] denn ein gewaltiger Reklameapparat hat dem Wunderkinde vorgearbeitet, und die Leute sind schon betört, ob sie es wissen oder nicht. ${ }^{219}$

Über seinen Namen und sein Alter weiß niemand genau Bescheid, ausgenommen sein Agent, der Impresario, der zwar genau weiß, dass die „Koseform“ seines Namens, „Bibi“, schon Kunst bedeutet, und der sich sehr gut mit seiner geschäftlichen Kunst, dem mehr oder weniger geheim zu haltenden „Geschäftsgeheimnis“ auskennt ${ }^{220}$ - der aber den Sinn und die Bedeutung der Musik wahrscheinlich gar nicht begreift. Sollte er es doch tun, dann spielt er nur damit: Er bietet dieses neue „Jesuskind“221 einer modernen Kunstreligion zur Tilgung der Not an, und auf seinen Handel würden seine Kundinnen und Kunden gern eingehen. So geraten sie hinein in das notwendige, geheimnisvoll spekulative ökonomische Kunstgeschäft dieses Künstler-Agenten.

Die Ausstattung des Konzertsaals, die eigentlich einem „Gasthof ersten Ranges“ entspricht, ${ }^{222}$ hebt das Wunderkind hervor, bringt die zweideutige Bedeutung seiner listigen, „pechschwarzen Mausaugen“ in harmonische Kombination mit dem Kontext, ebenso wie die unklare Angabe seines Alters; das Publikum weiß nicht genau, wie alt er eigentlich ist. Dies alles steigert seine artistischen Geheimnisse und die Neugier auf seine eigentliche Persönlichkeit beim Publikum, das zuweilen denkt, dass dieses Konzert scheinbar eine unmittelbare Kunstausübung darstellt, die

\footnotetext{
${ }^{219}$ Mann 2004, S. 396.

${ }^{220}$ Ebd.

${ }^{221}$ Ebd., S. 402; ein Besucher denkt: „Es ist etwas wie mit dem Jesuskind. Man darf sich vor einem Kinde beugen, ohne sich schämen zu müssen. Wie seltsam wohltuend das ist!“"

${ }^{222}$ Ebd., S. 398.
} 
zwar unkonventionell, aber doch eine unfassbare Spielerei mit dem „modernen Schein“ ist, und dessen Sinnesorgane in eine Art von Starre versetzt werden.

Sichtbar wird so die musikalisch-geschichtlich veränderte Funktionalität, die hier die traditionelle „Erbauung und Erhebung“ der Seele erfährt, die Verfeinerung des menschlichen Geistes und dessen Veredelung in der Wahrheit. Die Artistik des putzigen Pianisten bringt in ihre „Leutehirne“ leider kein ästhetisches Licht mehr, sondern löst nur einen spielerisch-artistischen Schein aus. ${ }^{223}$ An „Empirekränze und große Fabelblumen“ erinnert seine geheimnisvolle Tonkunst, ${ }^{224}$ die dem Publikum allerdings noch gar nicht zuteil wird, das vorerst lediglich seinen spielerisch-naiven Auftritt genießt.

Seine putzige kindliche Gestalt und Haltung, seine entschlossene Selbstinszenierung sind für die Zuschauer ein betörendes Angebot; so wird er bejubelt. Der Applaus ist für ihn ein „freundliches Element“, auch wenn das Publikum nur von der zierlich-elastischen, damenhaft-lieblichen Art seines ganzen Wesens „,betört“ ist:

Es geht an den Rand des Podiums vor, lächelt, als sollte es photographiert werden, und dankt mit einem kleinen, schüchternen und lieblichen Damengruß, obgleich es ein Knabe ist. ${ }^{225}$

\subsubsection{2 „Jesuskind“ und „,Teufelskerl“}

$\mathrm{Zu}$ beachten ist bereits die Kleidung Bibis, des Wunderkindes: Es ist ganz in weiße Seide gekleidet; es wird ganz ausdrücklich als „Jesuskind“ in diesen Unschuld signalisierenden Gewändern dargestellt. ${ }^{226} \mathrm{Er}$ ist bekleidet mit einem „weißseidenem Jäckchen von phantastischem Schnitt mit einer Schärpe darunter“ (eine nicht alltägliche Tracht) ${ }^{227}$ und hat Schuhe aus weißer Seide an. Sogar die

\footnotetext{
${ }^{223}$ Ebd., S. 397.

${ }^{224}$ Ebd., S. 396.

${ }^{225}$ Ebd.

${ }^{226}$ Vgl. hier Anm. 221.

${ }^{227}$ Ebd.
} 
Hose ist aus Seide. Durchaus dem Künstler-Klischee entsprechend, ist seine Hautfarbe „braun“, und die Haare sind „schwarz“. 228

Dementsprechend wird er hier selbst als ein Kunstwesen dargestellt. Sein ganzer Körper besteht aus weichen, als rein und unschuldig zu begreifenden Teilen, wie dem „harmlosesten Kindergesichtchen von der Welt“ (einer „Welt“", die dagegen als moralisch verschmutzt zu denken ist), „einem unfertigen Näschen“ - das also ewig kindlich-künstlerisch bleibt - „und einem ahnungslosen Mund“. ${ }^{229}$ Vor allem fallen seine „weißseidenen Füße“ und sein „bräunliches naives Kinderhändchen“ ins Auge. ${ }^{230}$ Er ist der Träger, der sorgsam kostümierte Repräsentant der Kunst überhaupt - was am deutlichsten durch den Seidestreifen auf seiner Stirn zum Ausdruck gebracht wird, der ebenfalls an ein Jenseits von List und Moral denken lässt, der jedoch im Gegensatz zu seinen ,,pechschwarzen Mausaugen“ steht.

Ebenso wie seine unentschiedenen Charakterzüge, die seine mann-weibliche Geschlechtlichkeit dem Publikum anziehend präsentieren, hebt diese Ausstattung das Wesen der Kunst hervor und inszeniert ihn als Mittler zwischen Publikum und Kunst wie zwischen beiden Geschlechtern. Gerade so aber gerät er nun als ein Objekt kommerzieller Werbung in die dekorative Reklamemaschinerie, an der auch sein Publikum teilhat. Mit dieser Ausnutzung der heiklen Eigenschaft der Kunst und des stumpfen, rohen Geistes seines Publikums kennt sich der Agent des Künstlers gut aus. Seine kindlichen Kompositionen sind rühmenswert;

Es scheint, daß der Impresario dieses Zugeständnis seiner kritischen Natur in harten Kämpfen (ums Geld) abgerungen hat. ${ }^{231}$

Das Jesuskind einer vermeintlich unschuldigen Kunst wird also vom Publikum als ein kommerzielles Objekt erworben, es wird gekauft. Darin gerade besteht der Erfolg des Impresarios, der dem Publikum in genuin ,moderner' Haltung gegenübertritt, der also nicht mehr versucht, die „rohe Natur“" des Publikums mittels der Kunst zu bändigen, sondern der selbst virtuos mit dem Maja-Schleier zwischen Schein und Wahrheit zu spielen weiß; eine Figur des Zwielichts.

\footnotetext{
${ }^{228} \mathrm{Ebd}$

${ }^{229}$ Ebd.

${ }^{230}$ Ebd., S. 397.

${ }^{231}$ Ebd.
} 
So ist es denn die Aufgabe dieses modernen Pianisten-Wunderkindes, diese MajaSpielerei $\mathrm{zu}$ bedienen. Damit wird die theoretisch konventionell geforderte Disziplin des Künstlers mitsamt seiner erzieherischen Aufgabe gestrichen. Im Konzertsaal wird dieses Spiel sowieso nicht erkannt:

Ein wenig Lüge, denken sie gehört zur Schönheit. Wo, denken sie, bliebe die Erbauung und Erhebung nach dem Alltag, wenn man nicht ein bißchen guten Willen mitbrächte, fünf gerade sein zu lassen? Und sie haben ganz recht in ihren Leutehirnen. ${ }^{232}$

Der mädchenhafte Knabe, dieser Kunst-Protagonist, der die „Leutehirne“ bezaubert, ist im Vergleich mit anderen Figuren wie dem kleinen Herrn Friedemann als hochbegabter, künstlerisch-positiver und lebenskräftiger Außenseiter dargestellt. Er gehört nicht zu den geistig Verfallenen und lebensuntüchtigen Figuren, die sonst die frühen Erzählungen Thomas Manns bevölkern. Er ist ein hochbegabtes Kind:

Das ganze Programm ist von ihm, es sind seine Kompositionen. Er kann sie zwar nicht aufschreiben, aber er hat sie alle in seinen kleinen ungewöhnlichen Kopf, und es muß ihnen künstlerische Beutung zugestanden werden, wie ernst und sachlich auf den Plakaten vermerkt ist, die der Impresario abgefaßt hat. ${ }^{233}$

Im Hinblick auf die Kommentare des Erzählers lässt sich in alldem eine Kritik an der Funktion der Musik im modernen Kunstbetrieb und ihrem Verständnis des Publikums, der „Leutehirne“, erkennen. Die Erzählweise trägt mittels verschiedener Verfahren und Motive dazu bei, die Gestalt des Künstler-Knaben positiv hervorzuheben.

Dementsprechend interpretiert Kurwinkel Thomas Manns Darstellung des Wunderkindes folgendermaßen: Durch seine Darstellungstechnik sowie durch Motive wie dasjenige der Hydra der griechischen Mythologie, unter der die unter den Einfluss der Reklame geratenen, von ihr vergifteten und vielleicht auch

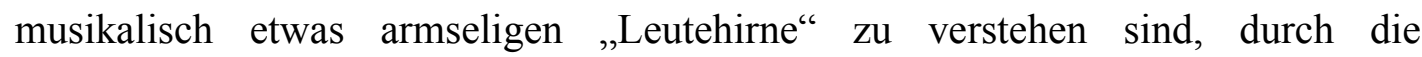


Farbsymbolik (weiße Kleidung aus Seide) wird seine Position als ein Außenseiter, als künstlerisch selbstbewusster, ja hochmütiger Pianist hervorgehoben.

Im Bezug auf seinen Impresario wird der Künstler zugleich im Sinne von Nietzsches Künstler-Kritik in Der Fall Wagner präsentiert, der mit „artistischschauspielerischer Darstellungskunst und seinem musikalischen Können“ das Publikum nur betört. ${ }^{234}$ Das impliziert eine Kritik am kommerziellen Verkauf des ,Erlösers’ einer modernen Kunstreligion. Das Wunderkind als ein neues Jesuskind, das die reine und unschuldige Kunst verkörpern soll, wird zum Werbeobjekt des Impresarios. Aber immerhin spielt dieser Knabe erstaunlich souverän mit dem Publikum, mit seiner doppelten Rolle (der kommerziellen und der künstlerischen) und mit seiner Gabe - als ob sie ursprünglich-unschuldig und ganz unberührt von irdischen Gegenständen bliebe.

Die beiden Akteure, der Impresario und das „Wunderkind“ selbst, können in Bezug auf Nietzsches Kritik an dem Musiker als zwei Seiten ein- und derselben Figur aufgefasst werden, als spielerische Artistik und als Inszenierung des unschuldigen Jesuskinds im kunstreligiösen Sinn, das dem Publikum die Kunst wie eine Botschaft Gottes vermittelt, zur Heilung der groben Seelen und ihrer seligen Erhebung in den Arm Gottes. Unter der Vorspiegelung, dass der Musiker eine ,göttliche Melodie' vermittle und so die Sünde in der menschlichen Seele aufhebe, erweist sich Bibi als ein moderner Musiker, der sein Publikum zu unterhalten weiß.

\footnotetext{
${ }^{234}$ Kurwinkel, S. 6.
} 


\subsubsection{Genie vs. Artist: Das „Kindergemüt“" als anzustrebende Erscheinungsform des modernen Artisten}

Das Wunderkind wird zwar als hochbegabter Künstler dargestellt. Bibi besitzt ein gutes Gedächtnis, einen „kleinen ungewöhnlichen Kopf“;235 er hat die Musik auswendig gelernt und kann sie frei spielen. Er weiß mit seinem Können artistisch und virtuos umzugehen und sich für das Publikum interessant in Szene zu setzen. Vor allem aber weiß er, wie man Applaus bekommt:

Das Thema des Marsches, eine schwunghafte, enthusiastische Melodie, bricht in voller harmonischer Ausstattung noch einmal hervor, breit und prahlerisch, und Bibi wirft bei jedem Takt den Oberkörper zurück, als marschierte er triumphierend im Festzuge. Dann schließt er gewaltig, schiebt sich gebückt und seitwärts vom Sessel herunter und lauert lächelnd auf den Applaus. ${ }^{236}$

Das Konzert dauert von halb acht bis halb neun, also nur eine Stunde. Die musikalische Artistik des Wunderkinds aber lässt das Publikum die Zeit vergessen. Seine Darbietung am Piano erinnert an das, was oben als ,übergeniale' Sphäre erläutert wurde, in der der Künstler und sein Instrument in einer Weise geradezu miteinander $\mathrm{zu}$ verschmelzen scheinen, die nicht mehr mit der traditionellen Genieästhetik zu erfassen ist:

Aber er selbst für sein Teil hat im stillen sein besonderes Vergnügen bei der Sache, ein Vergnügen, das er niemandem beschreiben könnte. Es ist dieses prickelnde Glück, dieser heimliche Wonneschauer, der ihn jedesmal überrieselt, wenn er wieder an einem offenen Klavier sitzt - er wird das niemals verlieren. Wieder bietet sich ihm die Tastatur dar, diese sieben schwarz-weißen Oktaven, unter denen er sich so oft in Abenteuer und tief erregende Schicksale verloren, und die doch wieder so reinlich und unberührt erscheinen, wie eine geputzte Zeichentafel. Es ist die Musik, die ganze Musik, die vor ihm liegt! Sie liegt vor ihm ausgebreitet wie ein lockendes Meer, und er kann sich hineinstürzen und

\footnotetext{
${ }^{235}$ Mann 2004, S. 397.

${ }^{236}$ Ebd., S. 400.
} 
selig schwimmen, sich tragen und entführen lassen und im Sturme gänzlich untergehen, und dennoch dabei die Herrschaft in den Händen halten, regieren und verfügen... Er hält seine rechte Hand in der Luft. ${ }^{237}$

Die ganz individuelle, entschlossene und bewusste Bereitschaft zur Produktion ist als Vereinigung des Künstler-Ich mit seinem Instrument zu begreifen. Sie erinnert darum an jene übergeniale Ich-Sphäre der Kunst, in welcher der Künstler (hier: das Wunder-Kind) seine Seele ganz in seinen Körper hineinfließen lässt, der seinerseits mit dem Instrument eins wird, in welcher er also seine Leidenschaft und Wonne, seine inneren „Abenteuer“ so ausleben kann, dass er sich zugleich als entindividualisiert und als göttlich inspiriert erlebt.

Es ist, als drücke er in seiner Melodie eine empfangene Botschaft aus, die vermittels seines Werkzeugs, des Klaviers, in seine Seele eindringt und in der sein menschliches Geschick mitsamt allen Schmerzen sich in ein Unendliches auflöst, das jenseits von Gut und Böse ist. Es sind diese Klänge, die am Übergang in die Trance die menschlichen Sorgen, Leiden und Schulden ins „Meer“ der Musik hinein forttragen. In ihnen erlangt er Reinigung und wird wieder rein und unberührt. Die Gefahr liegt darin, dass er sich auf diesem Kampfplatz der Seele verlieren könnte. Jedoch gelingt es ihm immer wieder, sich rechtzeitig wieder in den Griff zu bekommen und so gefasst weitere Klänge zu produzieren. Es ist der Augenblick vor dem ersten Ton, der die Seele erstarren und dann erbeben lässt, als ob sie ins dionysische Totenreich geriete; erst danach führt die Introduktion $\mathrm{zu}$ einer Entspannung - des Künstlers und des Publikums.

Diese Musikauffassung erinnert stark an diejenige Richard Wagners, so wie Nietzsche ihn wahrgenommen hat. Das gilt vor allem für die spielerische Art, mit der dieser „Teufelskerl“, der schlaue Knirps, sein Publikum verführt, ${ }^{238}$ mit der er Applaus hervorlocken kann. Mit der ganzen Kraft und Leidenschaft seines bewussten Geistes führt er mit den „schwunghaften, enthusiastischen“ Klängen seines feierlichen Marsches die „Leutehirne“ in eine Entindividualisierung hinein, ins Unbewusste - und der Applaus bricht los, einmütig, gerührt, begeistert:

${ }^{237}$ Ebd., S. 398.
${ }^{238}$ Ebd., S. 400. 
Seht doch, was für zierliche Hüften das Kind hat, indes es seinen kleinen Damengruß exekutiert! Klatscht, klatscht! Wartet, nun ziehe ich meine Handschuhe aus. Bravo, kleiner Saccophylax oder wie du heißt -! Aber das ist ja ein Teufelskerl! - - ${ }^{239}$

Diese Reaktionen sind der eigentliche Effekt, auf den seine begeisternde Artistik mit dem Instrument, seine scheinbar am Rande der Verrücktheit balancierende Beherrschung der Töne zielt. Das vermeintliche Jesuskind ist ein wahrer „Teufelskerl“".

Nach der Pause geht sein musikalisches Spiel von neuem los, das sein Publikum wieder in den Traum versetzt. Nun spielt Bibi weiter mit der kollektiven Seele; und auch die „Nachzügler, verspäteten Ankömmlinge“, die in den Konzertsaal hereindrängen, lockt er an. ${ }^{240}$ Anschließend spielt er ein ,richtiges' Kinderstück“, Le hibou et les moineaux, „Die Eule und die Spatzen“: Vögel, die durch den Kontrast der melodiösen Klänge, tiefe Bass-Töne und Höhenlagen, wunderlich plastisch in ihrem harmonischen Einklang dargestellt werden. Es ist sein Lieblingsstück, das er seinem begeisterten Publikum anbietet. Immer noch schwankend zwischen Mädchen und Knabe, Mann und Kind, als zutiefst ambivalente und zweideutige Gestalt, lässt er im künstlerischen Übergang zwischen spielerisch-genialer und ,übergenialer' Sphäre das Bild eines erwählten „Narren“ durchschimmern, der distanziert von der „verschwommenen Menschenmasse“, den im Sinne Tonio Krögers ,Gewöhnlichen', glänzend und auserkoren auf dem Podium spielt, sitzt und „Lorbeerkränze“ erwartet:

Im $\mathrm{Ba}$ sieht man den Uhu sitzen und grämlich mit seinen Schleieraugen klappen, indes im Diskant zugleich frech und ängstlich die Spatzen schwirren, die ihn necken wollen. ${ }^{241}$

Nun hat er durch seine Uhu-Piéce den gewünschten Erfolg erreicht; die lauschende Prinzessin ist bereits in die Fänge seiner Spielerei geraten: 
Sogar die Prinzessin beteiligt sich an dem Applaus, indem sie ganz zart ihre flachen Hände gegeneinander bewegt, ohne daß es irgendeinen Laut ergibt... ${ }^{242}$

Die latent kritische Stimme des Erzählers, die plötzlich ganz aus der Perspektive des Wunderkindes spricht, schildert diesen Erfolg, den der kleine Klavierspieler vor den plumpen Gehirnen erringt. Sie zeigt uns, wie hinter ihm sein Manager planend am Werk ist, der genau weiß, wie der „Uhu“-Reißer zum Garant des Massenerfolgs werden kann, und der die Kunst-Gestalt des schönen, geschlechtlich ambivalenten Griechenknaben mit seiner publikumswirksamen Artistik um des Geld willen benutzt und ihm beigebracht hat, wie er sein Publikum bewusst betören kann.

Die Stimme des Wunderkindes lässt diese ironische Distanz des Erzähler bemerken; durch seine Gedankenwiedergabe hindurch lässt er die Kritik am kunstreich-listigen Spiel des Wunderkindes spüren:

Aber ihr habt ja an diesem hibou einen Narren gefressen, ihr Publikum, obgleich er das Erste und Dümmste ist, was ich gemacht habe. Und er dankt lieblich. ${ }^{243}$

Das Meditations-Stück dient dann der Beruhigung, abwechselnd mit seinem spielerisch-artistisch vorgeführten Ego in der Etüde; abermals ist ihm die Bewunderung der Zuhörer sicher, und seine körperliche Beherrschung triumphiert. Dann werden die Hörer wieder in Trance versetzt, gerät ihre Seele in den Übergang von Moll-Klängen über den Halbton Cis in eine Phantasie, die Bibi mit neuen Einfällen und Wendungen auszugestalten weiß. Scheinbar voller Leidenschaft, verloren in die unendliche Phantasie, ist er seines Werkes doch ganz bewusst und „,bei der Sache“, um die „dumpfen, schwer beweglichen Seelen“ zu unterhalten. ${ }^{244}$

Es ist eine abenteuerliche künstlerische Betätigung, die der Pianist mit seinem durchtrainierten, das Musikinstrument einschließenden Leib, mit seinen durchaus „starkknochigen, trainierten Handgelenken“ ausführt. Es geht ihm einfach um das Spiel mit dem Publikum zu dessen Unterhaltung, um die Begeisterung der Leute und den kontrollierten Erfolg. Manchmal verbindet sich seine musikalische Einfühlungsgabe mit einer heimlichen Verachtung seines Publikums, der „Leute“:

\footnotetext{
${ }^{242}$ Ebd.

${ }^{243}$ Ebd., S. 401.

${ }^{244}$ Ebd., S. 401.
} 
Klage und Jubel, Aufschwung und tiefer Sturz - „meine Phantasie!“, denkt Bibi ganz liebevoll. „Hört doch, nun kommt die Stelle, wo es nach Cis geht!“ Und er läßt die Verschiebung spielen, indes es nach Cis geht. „Ob sie es merken?“ Ach nein, bewahre, sie merken es nicht! Und darum vollführt er wenigstens einen hübschen Augenaufschlag zum Plafond, damit sie noch etwas zu sehen haben. ${ }^{245}$

Nun hat dieser „Dreikäsehoch““ ${ }^{246}$ der nur für das artistische Spiel da ist und der inszeniert wirdwie ein erlösendes Jesuskind, das freilich kein Leiden kennt und seinem Publikum keinen wirklichen Übergang in einen Heilszustand anbietet, die „Leutehirne“ erschöpft. Er hat das Spiel bis auf die Spitze getrieben.

Und so werden nun auch kritische Meinungen laut, in denen die Zuhörer über die Funktionen der Tonkunst und über das Wesen des Wunderkindes nachdenken. Das mit Schmerz und Verzweiflung hantierende Talent, das Bibi aus der Genieästhetik herbeizitiert, bewundert der alte „Herr mit einem weißen Bart“, der offenbar viel musikalische Erfahrung besitzt; beschämt bemerkt er die musikalische Gekonntheit von Bibis „Wunderdingen“247 und vermag sich im Hinblick auf Bibis Gabe und seine musikalischen Fähigkeiten nicht zu entscheiden: Liegt hier wirklich eine göttliche Begabung vor, oder handelt es sich doch nur um den Bluff einer Spielerei? Gewiss ist Bibi keine Erlösergestalt, aber die vermeintliche spielerische Naivität dieses Wunderkindes erinnert ihn an deren Größe, als könne er doch die kollektive menschliche Seele hinüberführen in eine göttliche Einheit. „Wohltuend“, „süß“, unterhaltsam und unschuldig ist in seinen Augen dieses Kinderspiel, vor dessen Artistik man demütig wird:

Aber man muß bedenken, daß es von oben kommt. Gott verteilt seine Gaben, da ist nichts zu tun, und es ist keine Schande, ein gewöhnlicher Mensch zu sein. Es ist etwas wie mit dem Jesuskind. Man darf sich vor einem Kinde beugen, ohne sich schämen zu müssen. Wie seltsam wohltuend das ist. ${ }^{248}$

${ }^{245}$ Ebd., S. 402.

${ }^{246}$ Ebd.

${ }^{247}$ Ebd.

${ }^{248}$ Ebd., S. 402. 
Erscheint dieses Talent unbelastet von Qual und Gram und erst recht vom Wahnsinn, wie sie in der geistesgeschichtlichen Tradition zu Inspirationsvorstellungen und Geniekult gehören, so bleibt doch eine spekulative Erinnerung an diese kunstreligiöse Tradition bestehen - eben, „man muss bedenken, daß es von oben kommt.“

Im Grunde nicht anders ergeht es dem erfolgreichen Geschäftsmann „,mit der Papageiennase“, der ebenfalls nicht den geringsten Schimmer vom Teufelskerl, seinem vermeintlich kindlichen „Klingklang“ und den raffiniert geänderten Akkorden hat. ${ }^{249}$ Er durchschaut nicht die berechnenden Tricks seiner Pièces; und ausgerechnet er erkennt nicht, dass es im Grunde auf das Geschäft ankommt.

Auch die Klavierlehrerin mit ihrem altertümlich-konservativen Verständnis von Chopins Fantasie, in die Bibi nun von ihm selbst ausgedachte und auf den Effekt zielende, ganz neue Einfälle und Wendungen hineingebracht hat, findet sein Spiel nur musikalisch unerzogen und würde ihn am liebsten nur auf die richtige Bahn der Musik bringen.

Nicht einmal den heiklen Gedanken und dem sensiblen Erleben des jungen Mädchens mit dem bleichen Gesicht, das eine neue Generation vertritt, wird Bibis Artistik so recht erklärbar, ebenso wenig wie dem Offizier, der Bibis artistische Eigenart beobachtet. Bibis Leidenschaft für sein „,inbrünstiges Kinderspiel“ schwebt außerhalb ihres Verstandes, seine Gabe ist für sie nicht zu definieren.

Unklar bleibt, ob es um eine Täuschung des Publikums geht und um dessen Ausnutzung um des Geldes willen - oder doch, auf neue und andere Weise als in der Tradition, um die Kunst. Der Kritiker, der als Figur am deutlichsten die konventionelle Begrifflichkeit der bürgerlichen Musikauffassung repräsentiert und Bibis Spiel mit Chopins Musikstücken als bloßes „Fratzenspiel“ ansieht, das ihn aus der genialen Bahn des Genies herausführt und ihn nicht mehr als Träger eines romantischen Kunstverständnisses erscheinen lässt, hält Bibi für ein sich emanzipierendes Individuum, das sich selbst und seine Spielweise mit vitaler Frische von anderen Musikern absetzt. Bibi wird von ihm als ein „Einzelwesen“ verstanden, das mit der Kunst, einschließlich ihrer Leiden und Verzweiflung, im Übergang in die Vitalität berechnend spielt: 
„Als Einzelwesen hat er noch ein Ende zu wachsen, aber als Typus ist er ganz fertig, als Typus des Künstlers. Er hat in sich des Künstlers Hoheit und seine Würdelosigkeit $[\ldots]$. “250

Der kindliche Pianist repräsentiert demnach eine in sich abgeschlossene Lebenskunst, er ist ein Kunstwesen, das gegensätzliche Eigenschaften zusammenfasst: seine künstlerische „Hoheit [das Überlegenheitsgefühl], seine Würdelosigkeit [ein verbrecherisches Merkmal], seine Scharlatanerie [also ein betrügerischer Charakter] und seinen heiligen Funken [im Sinne heilig-göttlicher Begabung], seine Verachtung [der ,Leutehirne'] und seinen heimlichen Rausch [die genial-übersinnliche Empfänglichkeit]“. Dieses moderne ,Fratzenwesen’ ist sozusagen die fertige Fassung eines zeitgenössischen Kunstbegriffs überhaupt. Er erscheint damit als die Synthese der Begriffe Kunst und Leben, die einander nun nicht mehr konträr gegenüberstehen, sondern in ihm, im momentanen Jetzt seines Spiels verschmolzen sind - in einer nicht mehr ,genialen', sondern ,übergenialen' Weise.

So kann man sagen, dass die Figur Bibis in Thomas Manns Erzählung exemplarisch am Ende einer Entwicklungslinie geistesgeschichtlicher KünstlerKonzepte steht. Über dem Fassungsvermögen der „Leutehirne“ schwebt er nicht mehr als Genie, aber doch sehr wohl als genialisch und bezugslos. Ist nicht dieses artistisch-spielerische Moment Bibis, der kein leidender Erlöser mehr ist, die Veranschaulichung jener anzustrebenden übergenialen und vitalen Sphäre eines im modernen Sinne genialen Geistes, die alle Künstlergestalten der Geschichte zu erlangen suchten, und damit das Gegenteil des Dilettantismus?

Vielleicht ist gerade dies das Wesentliche dieser Kunst, dass sie außerhalb der Kritik und des Verstandes ist, dass sie im Übergang bleibt und immer das Werdende zeigt, wie „die griechische Hymne“ ${ }^{251}$ die die unabgeschlossene Interpretation des Künstlerischen bezeugt. So wird die Kritik in eine Starre versetzt wird und erweist sich als sekundär, auch wenn sie vom Kritiker selbst als „das Höchste“ des menschlichen Verstandes gedeutet wird, ${ }^{252}$ nicht anders als das Wesen Bibis, bei dem schwerlich zu unterscheiden ist, ob es ,eigentlich' weiblich oder männlich ist

\footnotetext{
${ }^{250}$ Ebd., S. 403 f.

${ }^{251}$ Ebd., S. 404.

${ }^{252}$ Ebd., S. 405; dieser Gedanke erinnert an einige Notizen Thomas Manns zum unvollendeten Essay „Geist und Kunst"“.
} 
und bei dem es als skandalös empfunden wird, wenn es vom Impresario geküsst wird - was auf die Mittler-Funktion dieser künstlerischen Figur weist, die beide Geschlechter anzieht:

Er hängt einen Lorbeerkranz um Bibis Hals [...] Und plötzlich, wie übermannt, beugt er sich nieder und gibt dem Wunderkinde einen $\mathrm{Ku}$, einen schallenden $\mathrm{Ku}$, gerade auf den Mund. Da aber schwillt der Sturm zum Orkan. Dieser Kuß fährt wie ein elektrischer Stoß in den Saal, durchläuft die Menge wie ein nervöser Schauer. ${ }^{253}$

Und die jüngere Frau stellt sich sogar einen Kuss Bibis vor - aber nicht als eines erotischen Wesens, sondern als eines Kindes:

„Wenn er mich küsste, so wär’ es, als küßte mein kleiner Bruder mich - es wäre kein Kuß.“254

Das übergängliche Wesen der Kunst und des Künstlers, die eine so große assoziative Breite eröffnen, werden in der Erzählung ausgespielt. Am Ende des Konzerts wendet sich der griechische Artist seiner Rhapsodie grecque zu,

welche schließlich in die griechische Hymne übergeht, und seine anwesenden Landsleute hätten nicht übel Lust, mitzusingen, wenn es nicht ein vornehmes Konzert wäre. $^{255}$

Im vornehmen und assoziativ-reflexiven Kopf des ältlichen Kritikers wird sie als unmittelbare politisch-kritische Anspielung auf die im Jenseits des genießenden Sinns existierende praktische Funktion der Musik und deren Macher verstanden, als ein Übergang in die Politik.

Aber ist dieser Bezug noch ein vitaler, oder bedeutet er schon den Tod für diesen Lebensbegriff überhaupt? Die künstlerische Vitalität soll ja als ein wichtiger Bestandteil des Lebens verstanden werden, von dem das künstlerische Wesen seine

\footnotetext{
${ }^{253}$ Ebd., S. 404.

${ }^{254}$ Ebd., S. 403.

${ }^{255}$ Ebd., S. 404 f.
} 
Belebung empfängt - was aber (vom Kritiker) wiederum als eine effektvolle Manipulation des Publikums markiert wird:

„Freilich, die Hymne mußte kommen. Man spielt die Sache auf ein anderes Gebiet hinüber, man läßt kein Begeisterungsmittel unversucht. [...]“256

Und diese Pièce, die in ihrer formal und motivisch lockeren Form das griechische Gedicht aufnimmt, verweist auf das künstlerische Bild des artistisch-modernen Musikers insgesamt, mit seiner scheinbar untreuen, eigenartig genialen, aber in sich abgeschlossenen Natur, der als (hier erneut angespielter) heroischer Herkules der mythologischen und geistesgeschichtlichen Tradition seinen Gegnern, seiner Hydra, eins auswischen würde. Als dieser Gegner ist hier mehr oder weniger Bibis Publikum zu verstehen, das raffiniert besiegt werden muss. ${ }^{257}$ Er versetzt es in einen leidenschaftlichen Zustand der Seele, verführt es zweckmäßig und pragmatisch mit den unendlichen Möglichkeiten seiner musikalischen Macht, der sie sich wie Masochisten ausliefern, Narren einer Leidenschaft, die nicht kritisch und verstandesmäßig fassbar ist.

All ihre Versuche, diesen ,kleinen versierten Wicht ${ }^{6258}$ assoziativ auf den Begriff zu bringen, schließen sich mehr oder weniger an die Persönlichkeit Richard Wagners an, wie Thomas Mann sie im Gefolge Nietzsches verstand, die fragwürdig und faszinierend bleibt. Der in ihr triumphierende Primat des Geistes über die Natur gibt sogar den nicht erkennenden Kritikern für einen Moment Anteil an einem übergenialen Geist. Aus der intern fokalisierten Stimme des in die Figur des Kritikers mit den vornehmen, aber leider „bespritzten Beinkleidern“259 verwandelten Erzählers, der sich rechtzeitig zu seiner Rettung vor Bibis Verführungskraft in die Position distanzierter Kritik hinein flüchtet, ergibt sich ein ambivalent-kritischer Gedankengang über diesen Mangel, der unter der Vorspiegelung eines gesunden Verstandes, einer Kenntnis des Guten und Schönen doch zur Fixierung der künstlerisch vielleicht toten Form nicht fähig ist.

Der Autor des Wunderkindes will dieses objektiv undefinierbare „Zwitterwesen“ der Kunst und ihres Trägers nicht in einer eindeutig konkretisierten Gestalt

\footnotetext{
${ }^{256}$ Ebd., S. 405.

${ }^{257} \mathrm{Vgl}$. http://de.wikipedia.org/wiki/Rhapsodie.

${ }^{258}$ Mann 2004, S. 400.

${ }^{259}$ Ebd., S. 403.
} 
bestimmen, sondern im Gegenteil - und folgerichtig - die Charakterzüge des kleinen Pianisten, mitsamt seiner begeisternden Gabe wie seiner seidenen Kostümierung, in ihrem Übergang zwischen weiblichem oder männlichem Knaben darstellen.

Auf jeden Fall ist dieser Knabe mit seiner raffinierten Artistik nicht zufällig griechischen Blutes: Ein klassizistischer Begriff des Künstlertums erreicht in der durch ihn verkörperten Jugendwelt der Moderne sein Ende, seinen Abschluss. Er spielt sie nur, aber er bleibt ihr nicht mehr treu. Die alten Leitbilder des „Genies“ von „Homer unter den Alten und Shakespeare unter den Neuern“260 - sind zwar noch immer ein wertvoller Schatz, wie lang gebrauchtes Gold und wie zu Eis erstarrte Geistigkeit. Die Natur gilt noch immer als die Quelle des genialen Geistes, aber dieser ist nun in die unempfindliche, spielerisch armselige Kälte, ins Eis versetzt worden, eben in die übergeniale Sphäre der Moderne. Sie nimmt in sich die absolute Kunst wie die Unendlichkeit des Kunsttons auf, die dieser kleine Grieche neu zu reflektieren vermag.

Diese neue Bandbreite seiner frei verfügbaren Ausdrucksmöglichkeiten führt zur Reflexion eines genuin weiblichen Wesens der Kunst - wie Thomas Mann sie ja selbst unter anderem 1903 in seinem Essay Das Ewig-Weibliche formuliert hatte ${ }^{261}$ -, das im knabenhaft-weiblichen Pianisten als Wesen des Künstlers überhaupt sichtbar wird. Dieser virtuose Künstler ist zugleich eben auch ein magerer „Hanswurst“; 262 er ist ein weiblicher und ein männlicher Künstler und beides in einem, er trägt sogar die Züge des (liebenswerten) Verbrechers, die dann in Thomas Manns Hochstaplerfigur Felix Krull gestaltet werden, und eines Verrückten, der aus der bürgerlichen Ordnung fällt und nicht mehr klassizistisch das „Meisterwerk, das in sich ruhende Gebilde“ vorführt. Der Drang, sich aus dem musikalischen „Kanon“ heraus zu bewegen und sich so auf neue Weise selbst als Artist und Virtuose hervorzutun, erzeugt in einer Explosion des Unechten das verbrecherische „Artefakt" eines die „Totalität“ der bereits auf die Spitze entwickelten Tonkunst gleichsam in sich zusammenraffenden Musikers, der nun als ein Moderner den eigentlich schon toten schönen Schein der Kunst in der Sphäre seines übergenialen Spiels belebt. In Thomas Manns um dieselbe Zeit zuerst entworfenem Doktor Faustus wird das wieder aufgenommen.

\footnotetext{
${ }^{260}$ Mann 1960.

${ }^{261}$ Vgl. dazu das Toni-Schwabe-Kapitel in Detering 2007.

${ }^{262}$ So denkt der Kritiker; Mann 2004, S. 405.
} 
Die „Gefahr des Unschöpferischen“263 muss diese in gewisser Weise altersstarre Jugend in Kauf nehmen, die vielleicht dieses „Artefakt" als das immer „schon fix und fertige Faktum“ inszeniert und so in der verfeinerten Moderne sein an die „Urfrühe“ des Menschengeistes auf eine Weise erinnert, ${ }^{264}$ die einen MusikalischEchten wie Beethoven ohnmächtig machen würde - wenn er in dieser modernen Welt überhaupt noch leben könnte. Bibi verkörpert dieses Faktum. 


\subsubsection{Der Künstler und sein Mäzen}

So, mit seiner gut trainierten Gabe und Könnerschaft, in seinem künstlerischen Überlegenheitsgefühl, verachtet Bibi sogar das von einer Hofdame angespielte Angebot der Prinzessin, in Zukunft an ihrem Hof zu wirken. Das Motiv weist sicher in die Geschichte der großen Künstler mit ihren Mäzenen zurück. Bibis Popularität schafft eine neue Art von Unterschied zwischen ihm selbst und der Prinzessin. Anstatt sich um sie zu gruppieren, kreist das Publikum um Bibi, als sei er der eigentliche Machthaber. Das wird in der Erzählung zwar nicht explizit gesagt, aber gezeigt: Bibis Spiel, und damit diese kleine Künstlerfigur selbst, zieht die Menschen exklusiv an, und gerade das wird in Thomas Manns Frühwerk bei aller Ironie gänzlich positiv dargestellt:

Die Leute [...] applaudieren und drängen vorwärts, um Bibi aus der Nähe zu sehen. Einige wollen auch die Prinzessin sehen; es bilden sich vor dem Podium zwei dichte Kreise um das Wunderkind und um die Prinzessin, und man weiß nicht recht, wer von beiden eigentlich Cercle hält. ${ }^{265}$

Dies eben deutet Bibis künstlerische gegenüber der Macht der Prinzessin an. Ist er nicht - wie in Thomas Manns ebenfalls in dieser Zeit entworfenen zweitem Roman - einer Königlichen Hoheit gleich, die es nicht mehr mit einem ,wahren Wesen' zu tun hat, sondern ausschließlich mit dem spielerischen Schein des Lebendigen, mit reiner Repräsentation? Genau dieses Letztere würde das Erstere erst „hoffähig“ machen. ${ }^{266}$

Und wenn Bibi das angedeutete Angebot annähme, was dann der alternde Kritiker vielleicht wiederum durchschauen könnte, dann müsste er seine besondere Würde hüten, die Würde seiner künstlerischen Scharlatanerie. Zugleich müsste er seine Verachtung der Prinzessin gegenüber zurückhalten. Verhielte er sich $\mathrm{zu}$ ihrer Gönnerschaft, wie Goethe und Schiller sich zu ihren Mäzenen verhalten haben, dann wäre er kein moderner Artist an der Spitze des verfeinerten Geistes der Moderne mehr.

\footnotetext{
${ }^{265}$ Mann 2004, S. 405.

${ }^{266} \mathrm{Ebd}$.
} 
Das musikalische Ergebnis von Bibis Kunst ist seine Popularität. Das Geheimnis seiner Wirkung beruht direkt auf seiner Berechnung des Erfolgs beim Publikum, weshalb ja auch die Klavierlehrerin ihn für „,wenig unmittelbar“ hält. ${ }^{267}$ Die Wirkung seiner nur scheinbar naiven Art des Spiels entspringt seinen sentimentalischen Hintergedanken.

Wenn in einem Nebenmotiv auf das „Pythia“-Wesen des Künstlers angespielt wird, das auf diese Weise unauffällig mit mythologischer und religiöser Bedeutung assoziiert wird, ${ }^{268}$ dann zeigt sich Bibi Saccellaphylaccas eben nicht mehr als „eine Hüterin“ der Kunst im Sinne des Mythos. ${ }^{269}$ Er spielt mit seinem Publikum unter Ausnutzung seines rein artistischen Talents, er unterhält es, indem er scheinbar ganz unschuldig bei der Sache ist; und er wirkt doch nur in der übergenialen Sphäre der modernen Artistik, die jeden modernen Künstler ausmacht, auch den Autor von Künstlernovellen.

Die ironische Charakterisierung des „Wunderkindes“ als eines neuen „Jesuskindes“ der Kunst bringt damit Thomas Manns ironische Kritik auch an sich selbst, an seinem eigenen Künstlertum zum Ausdruck. Diese Kritik schließt aber auch den kommerziellen Kauf eines Künstlers ein, der in der Gestalt des geschäftstüchtigen Impresario zur Erscheinung kommt. Schon der seinen Erfolg berechende Bibi selbst ist so zu verstehen. In diesem Konzertsaal wird nicht mehr die Musik als reine Kunst gehört, sondern hier vollzieht sich vielmehr die Show eines künstlerisch eigentlich ,kleinen’ Musikers.

Während die „Leutehirne“ in der Erzählung betört sind durch Bibis artistische Spielerei mit Musikstücken Chopins, bewundert der Autor selbst Bibis Gefasstheit im Umgang mit seinem musikalischen Können, seine gespielte Naivität dem Publikum gegenüber. Gerade das Artistische erscheint ihm als das Vitale in Bibi, als ein in den wieder kindlich gewordenen, übergenialen Geisteszustand umgekippten höchst verfeinerten Geist, als verkehrte Wiederkehr jener leidenden und verzweifelnden Genies - und insofern doch eines wahren Jesuskindes der künstlerischen Moderne mit einer besonderen musikalischen Gabe.

So erscheint Bibis artistische Sphäre als der anzustrebende Zustand eines künstlerischen Produktionsprozesses, der die anderen Künstlerfiguren, eine ironisch gezeichnete Bohème-Künstlerin und einen ebenso karikaturhaft dargestellten

\footnotetext{
${ }^{267}$ Ebd., S. 403.

${ }^{268}$ Vgl. Mann 2004, S. 406.

${ }^{269}$ Reed 2004, S. 277.
} 
künstlerischen Jüngling begeistert; deshalb denken sie, dass Bibi „liebenswürdig“ und „verehrungswürdig“ ist, ${ }^{270}$ so dass er ihnen als Maßstab, als vitale Synthese vorkommt.

Als Konsequenz kann diese Künstlerin schließlich nur gestehen, was sie aus dem ,Wesen' Bibis heraus gelernt hat - und was meinen Begriff einer ,übergenialen' Sphäre bestätigt:

„Ein Kind!“ denkt das unfrisierte Mädchen [...]. Und mit lauter, eintöniger Stimme sagt sie: „Wir sind alle Wunderkinder, wir Schaffenden.“

„Nun!“ denkt der alte Herr [...], „was ist denn das! Eine Art Pythia, wie mir scheint.

Aber der düstere Jüngling, der sie aufs Wort versteht, nickt langsam. ${ }^{271}$

Dieses künstlerische Spiel ist eine mögliche Lösung des auf die Spitze getriebenen Genialen in einer komplexen modernen Kultur. Diese ,übergeniale’ Geistessphäre artikuliert Thomas Manns ambivalente, immer mit Gewissensbissen verbundene Verehrung für Richard Wagners ,abgefeimte“ Artistik und seine Größe, die Nietzsche als ein die Popularität berechnendes, maskiertes und vom psychologisch versierten Kritiker entlarvtes, aber eben auf seine neue Weise wieder ganz vitales Spiel eines sentimentalischen Musikers beschrieben hat, einer Künstlernatur mit einer - wenn man es pointiert sagen will - neuen Naivität.

Dies alles ist eingeschlossen in die Antwort des Wunderkindes, in sein „Oui, Madame“. Dabei stellt er selbst nicht mehr das eigentliche, künstlerische Genie dar, sondern vielmehr ein modernes Scheingenie, das als das ,Übergeniale' in einer plastischen Gestalt erscheint. Von diesem modernen Künstler wird jener alternde Kritiker unterschieden, der das Vitale dieses Spiels nicht erkennt und somit ausweglos gefangen bleibt in der sentimentalischen Sphäre eines Ideals, dessen Zeit doch längst vergangen ist.

\footnotetext{
${ }^{270}$ Mann 2004, 406.

${ }^{271}$ Ebd., S. 406.
} 


\section{Literaturverzeichnis}

\section{Primärliteratur}

\subsection{Schriften von Thomas Mann}

Mann, Thomas: Betrachtungen eines Unpolitischen. Frankfurt am Main: S. Fischer 1974. (Gesammelte Werke, Bd. XII: Reden und Aufsätze 4.)

Mann, Thomas: Frühe Erzählungen, 1893-1912. Hrsg. von Terence J. Reed unter Mitarbeit von Malte Herwig. Frankfurt am Main: S. Fischer, 1997. (Sämtliche Werke, Große kommentierte Frankfurter Ausgabe, Werke - Briefe - Tagebücher. Bd. 2:1: Text, Bd. 2.2: Kommentar.)

Mann, Thomas: Die Bekenntnisse des Hochstaplers Felix Krull. Gesammelte Werke, Bd. 7. Frankfurt am Main: S. Fischer 1974.

Mann, Thomas: Sämtliche Erzählungen. Thailändische Übersetzung von Pornsan Watanagura und anderen. Bangkok: Chulalongkorn University Press 2007.

Mann, Thomas: Essays I (1893-1914). Hrsg. von Heinrich Detering. Frankfurt am Main: Fischer, 2002. (Sämtliche Werke, Große kommentierte Frankfurter Ausgabe, Werke - Briefe - Tagebücher. Band 14.1: Text, Bd. 14.2: Kommentar.)

Mann, Thomas: Doktor Faustus. Das Leben des deutschen Tonsetzers Adrian Leverkühn, erzählt von einem Freunde. Hrsg. von Ruprecht Wimmer und Stephan Stachorski. Frankfurt am Main: Fischer 1997. (Sämtliche Werke, Große kommentierte Frankfurter Ausgabe, Bd. 10.1: Text, Bd. 10.2: Kommentar.)

Mann, Thomas: Königliche Hoheit. Roman. Hrsg. von Heinrich Detering. Frankfurt am Main: S. Fischer 2004. (Thomas Mann: Sämtliche Werke, Große kommentierte Frankfurter Ausgabe, Bd. 4.1: Text, Bd. 4.2: Kommentar)

Mann, Thomas: Notizbücher 1-6 und 7-14. Hrsg. von Hans Wysling und Yvonne Schmidlin. Frankfurt am Main: S. Fischer 1991/92.

Mann, Thomas: Schwere Stunde. Faksimile der Handschrift. Hrsg. von Bernhard Zeller. Marbacher Zeitschrift 9. Stuttgart: Klett, 1975. 


\subsection{Schriften anderer Autoren}

Benn, Gottfried: Probleme der Lyrik. Sämtliche Werke, Bd. VI: Prosa 4. Hrsg. von Gerhard Schuster. Stuttgart: Klett-Cotta 2001, S. 9-44.

Nietzsche, Friedrich: Der Fall Wagner. Ein Musikanten-Problem. In: Werke. Kritische Gesamtausgabe. 3. Band, 6. Abteilung. Hrsg. Giorgio Colli und Mazzino Montinari. Berlin: 1969. S. 7-39.

Schiller, Friedrich: Sämtliche Werke Bd. 5. München: Carl Hanser Verlag 1959.

Schiller, Friedrich: Über naive und sentimentalische Dichtung. In: Friedrich Schiller: Sämtliche Werke. Philosophische Schriften (10 Bände). Hrsg. von Hans-Günther Thalheim. Berliner Ausgabe. 8. Band. Barthold Pelzer. Berlin: Aufbau-Verlag, 2005, S. 433-522.

Schopenhauer, Arthur: Sämtliche Werke. Erster Band. Hrsg. von Paul Deussen. München: R. Piper \& Co., 1911.

\section{Sekundärliteratur}

Arnold, Heinz Ludwig / Detering, Heinrich: Grundzüge der Literaturwissenschaft. 8. Auflage München: dtv 2008

Brües, Otto: Thomas Mann. Reden und gesammelte Aufsätze. Krefeld: Otto Brües Freundeskreis - Gesellschaft für Literatur, 1996.

Detering, Heinrich (Hrsg.): Thomas Mann Essays I 1893-1914. Teilband 14.2: Kommentar. Frankfurt am Main: Fischer, 2002.

Detering, Heinrich: Das offene Geheimnis. Zur literarischen Produktivität eines Tabus von Winckelmann bis zu Thomas Mann. Göttingen: Wallstein 1994.

Detering, Heinrich: Juden, Frauen und Literaten. Zu einer Denkfigur beim jungen Thomas Mann. Frankfurt am Main: Fischer, 2005.

Detering, Heinrich: Kunstreligion und Künstlerkult. In: Georgia Augusta. Wissenschaftsmagazin der Georg-August-Universität Göttingen. Kulturen und Konflikte. Ausgabe 5. Göttingen: Mai 2007, S. 124-133. 
Grimm, Gunter E.: Metamorphosen des Dichters. Das Selbstverständnis deutscher Schriftsteller von der Aufklärung bis zur Gegenwart. Frankfurt am Main: S. Fischer, 1992.

Grössmann, Wilhelm: Deutsche Kulturgeschichte im Grundriss. Neubearbeitung. Ismaning: Hueber-Verlag, 1960.

Heine, Gerd / Schommer, Paul: Thomas Mann Chronik. Frankfurt am Main: Klostermann 2004.

Huch, Ricarda: Blütezeit der Romantik. 12. Auflage. Leipzig: H. Haessel, 1922.

Kommerell, Max: „Schiller als Gestalter des handelnden Menschen“. In: Schillers Schriften. Band 8. Frankfurt am Main: Vittorio Klostermann Verlag, 1934.

Koopmann, Helmut (Hrsg.): Thomas Mann Handbuch. 3. Auflage. Stuttgart:

Kröner, 2001.

Kurwinkel, Tobias: Positiver Außenseitertum: Thomas Manns Wunderkind als Geliebter Apolls. In: http://www.thomasmann.de

Kurzke, Hermann: Thomas Mann. Epoche - Werk - Wirkung. 3. Auflage. München: C.H. Beck, 1997.

Kurzke, Hermann: Thomas Mann. Das Leben als Kunstwerk. Eine Biographie. München: C. H. Beck 1999.

Martinez, Matias / Scheffel, Michael: Einführung in die Erzähltheorie. 6. Auflage. München: C.H. Beck, 2005.

Muncker, Franz: Zu Schillers Dichtung. München: Verlag der K.B. Akademie der Wissenschaften, 1906. [=Separat-Abdruck aus den Sitzungsberichten der philosophisch-philologischen und der historischen Klasse der Königlich Bayerischen Akademie der Wissenschaften 1906, Heft 2]

Nündel, Ernst: Die Kunsttheorie Thomas Manns. Bonn: Bouvier-Verlag, 1972.

Ohl, Hubert: Ethos und Spiel: Thomas Manns Frühwerk und die Wiener Moderne. Eine Revision. 1. Auflage. Freiburg im Breisgau: Rombach-Verlag 1995.

Reed, Terence J.: Thomas Mann. Frühe Erzählungen 1893-1912. Kommentar. Frankfurt am Main: S. Fischer, 2004.

Renner, Rolf Günter: Das Ich als ästhetische Konstruktion. „Der Tod in Venedig“ und seine Beziehung zum Gesamtwerk Thomas Manns. Freiburg im Breisgau: Rombach-Verlag, 1987.

Scherrer, Paul / Hans Wysling: Quellenkritische Studien zum Werk Thomas Manns. Bern / München: Vittorio Klostermann Verlag 1967 (Thomas-Mann-Studien, Bd. I). 
Schmidt, Jochen: Die Geschichte des Genie-Gedankens in der deutschen Literatur, Philosophie und Politik 1750-1945. Bd. 1-2. Darmstadt: Wissenschaftliche Buchgesellschaft 1985.

Srichai, Sunthorn: Die Darstellung des Künstlers in Thomas Manns Tonio Kröger und Seini Saovaphongs Kw Amram Khong Wanlaya. Eine komparatistische Studie. Magisterarbeit an der Ramkhamhaeng University Thailand 2005.

Sudheimer, Hellmuth: Der Geniebegriff des jungen Goethes. Inaugural-Dissertation. Berlin: 1932.

Vaget, Hans Rudolf: Thomas Mann-Kommentar zu sämtlichen Erzählungen. München: Hanser 1984.

Wild, Inge: Thomas Mann: Tonio Kröger. Grundlagen und Gedanken zum Verständnis erzählender Literatur. Frankfurt am Main: Diesterweg-Verlag 1994.

Walzel, Oskar. Schiller und die bildende Kunst. In: Separat-Abdruck aus dem Marbacher Schillerbuch, o J.

Wysling, Hans: Narzissmus und illusionäre Existenzform. $\mathrm{Zu}$ den Bekenntnissen des Hochstaplers Felix Krull. Bern / München 1982. (Thomas-Mann-Studien, Bd. V)

Wysling, Hans / Marianne Fischer (Hrsg.): Dichter über ihre Dichtungen: Thomas Mann. Band 14/I. Teil I: 1889-1917. Passau: Heimeran-Verlag, 1975.

Wysling, Hans: Thomas Mann heute. Sieben Vorträge. München u.a.: Francke, 1976.

Wysling, Hans: „Geist und Kunst“. Thomas Manns Notizen zu einem „Litteratur“Essay. Ediert und kommentiert. In: Scherrer / Wysling 1967, S. 123-233.

Wysling, Hans / Schmidlin, Yvonne: Thomas Mann. Ein Leben in Bildern. 2. Auflage Zürich: Artemis 1994.

http://www.de.wikipedia.org

Für Betreuung und Hilfe bei der sprachlichen Überarbeitung danke ich Herrn Professor Detering und Herrn Dr. Torsten Hofmann. 


\section{Versicherung}

Hiermit versichere ich an Eides statt, dass ich die eingereichte Dissertation „Zur Darstellung künstlerischer Existenz in Thomas Manns frühen Erzählungen Das Wunderkind, Schwere Stunde und Der kleine Herr Friedemann. Eine vergleichende Untersuchung“" selbständig und ohne unerlaubte Hilfe verfasst habe. Anderer als der von mir angegebenen Hilfsmittel und Schriften habe ich mich nicht bedient. Alle wörtlich oder sinngemäß den Schriften anderer Autorinnen oder Autoren entnommenen Stellen habe ich kenntlich gemacht. Die Abhandlung ist noch nicht veröffentlicht worden und noch nicht Gegenstand eines Promotionsverfahrens gewesen. 